\title{
Land Subsidence Along the Texas Gulf Coast Due to Oil and Gas Withdrawal
}

\author{
by
}

Kaveh Khorzad, (B.S. Geo Sci)

\author{
Thesis \\ Presented to the Faculty of the Graduate School of \\ The University of Texas at Austin \\ in Partial Fulfillment \\ of the Requirements \\ for the Degree of \\ Master of Science in Geological Sciences
}

The University of Texas at Austin

May, 2000 


\section{Copyright}

by

Kaveh Khorzad

2000 


\section{Land Subsidence Along the Texas Gulf Coast Due to Oil and Gas Withdrawal}

Approved by Supervising Committee:

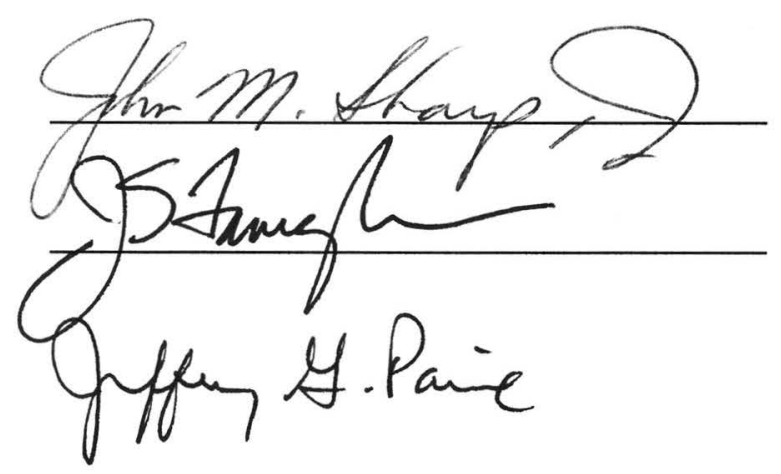




\section{Dedication}

To Dad and Mom: Thankyou for making so many sacrifices in your lives so that I am able to be here. I Love You.

To Davoud and Roxanna: A guy couldn't have asked for a better pair of siblings, I am lucky to be called your brother. 


\section{Acknowledgements}

It is amazing as through the course of time how many people touch you. There have been many people that have helped me both directly and indirectly that I wish to thank. Thankyou Jack for giving me the opportunity to go to graduate school, without your help I would never be here. Thankyou to my Dad and Mom, I take for granted how lucky I am to have such great parents. Thankyou for making sacrifices in your lives so that I can have a better life. Thankyou for pushing me to strive for more when I accepted mediocrity. Thankyou to my brother and sister. Thankyou Roxanna for putting up with me and being my friend when I needed one. Thankyou Davoud for being a great role model for which I can follow. Thanks Angelo for being more than just my best friend. Thankyou to my research group for stretching my mind and allowing me to be the best I can. Thankyou Karen for your advice as well as editing skills. Finally I would like to thank God for the many gifts that He has given to me. 
May, 2000 


\begin{abstract}
Land Subsidence Along the Texas Gulf Coast Due to Oil and Gas Withdrawal
\end{abstract}

\author{
Kaveh Khorzad, (M.S. Geo Sci) \\ The University of Texas at Austin, 2000
}

Supervisor: John M. Sharp Jr.

Land subsidence caused by groundwater withdrawal in the HoustonGalveston region is a well-documented phenomenon. Subsidence of up to $3 \mathrm{~m}$ (10ft) has been calculated in the region since 1905. Hydrocarbon withdrawal is a plausible cause of subsidence where groundwater withdrawal has diminished and significant petroleum production has occurred for over 70 years.

Sixteen fields were investigated by acquiring reservoir bottom hole pressure data (BHP) near bore-hole extensometers set up by the Harris-Galveston Coastal Subsidence District (HGCSD). All reservoirs were found to be well below 
hydrostatic pressure; a few of them were underpressured even before production began showing a possible hydraulic connection between fields. BHP data was used in a reservoir model and a boundary clay reservoir model to calculate subsidence. Subsidence under these fields is predicted to be as high as $0.30 \mathrm{~m}$ $(\sim 1.00 \mathrm{ft})$ in a nine-year period or $33.33 \mathrm{~mm} \mathrm{yr}^{-1}\left(1.3 \mathrm{in} \mathrm{yr}^{-1}\right)$ at the Goose Creek field and as low as $0.007 \mathrm{~m}(0.023 \mathrm{ft})$ in a twenty-year period or $0.33 \mathrm{~mm} \mathrm{yr}^{-1}$

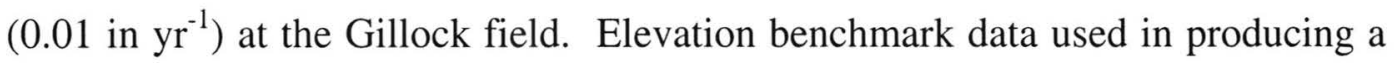
cross section of a line of oil fields show connection of subsidence bowls above fields on two scales: A smaller local scale subsidence bowl on the order of $5 \mathrm{~km}$ (3.1 mi) and a more regional subsidence bowl on the order of $40 \mathrm{~km}(24.9 \mathrm{mi})$.

Point estimation of the contribution to total subsidence from petroleum production and groundwater withdrawal show that the majority of the subsidence occurring presently in Harris and Galveston counties is from oil and gas withdrawal. Effects from clay equilibration caused by previous groundwater pumping were interpreted to be minimal.

Implications of this study are: 1) hydrocarbon production, although not the major contributor to most land surface subsidence in this area, is significant and 2) depressurization and subsequently subsidence from oil and gas fields may be regional, connecting neighboring fields. This is inferred from the fact that some fields were already underpressured before production began in addition to benchmark data showing connection of subsidence bowls. 


\section{Table of Contents}

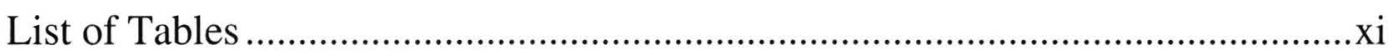

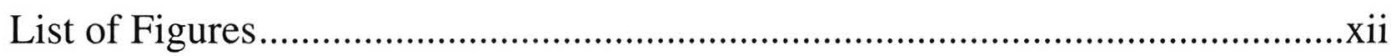

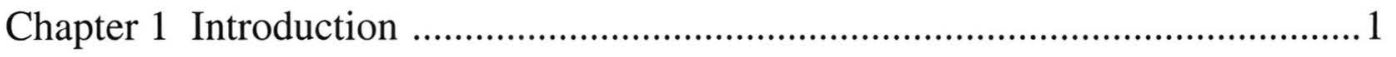

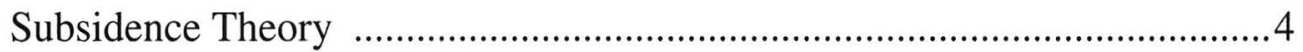

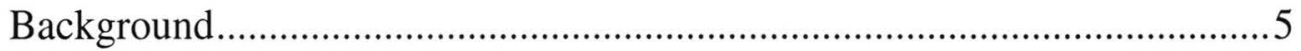

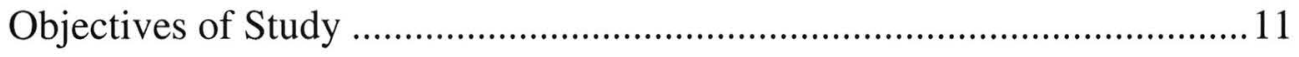

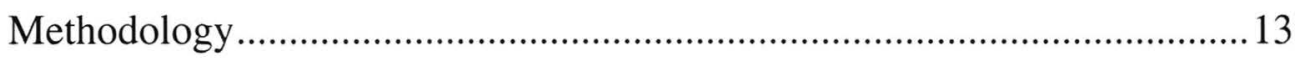

Chapter 2 Geology/Hydrogeology of study area ...............................................16

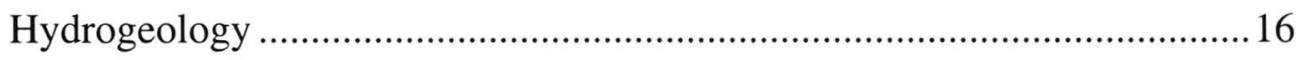

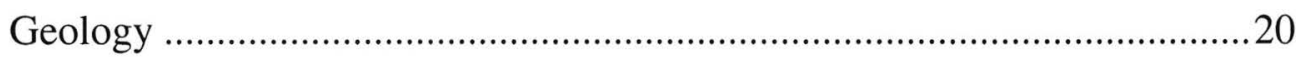

Chapter 3 Bottom hole pressure data..................................................................2

Methodology and Results of BHP Data ...................................................28

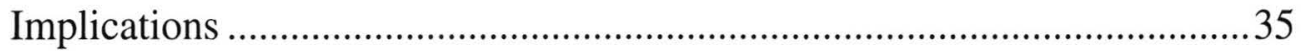

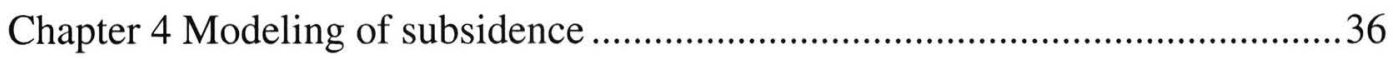

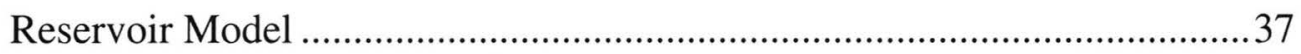

Semi-Infinite Boundary Clay Model .........................................................42

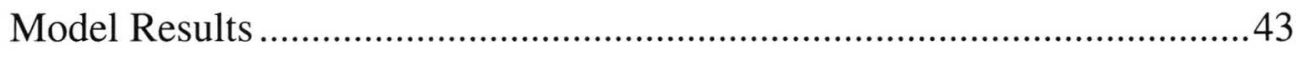

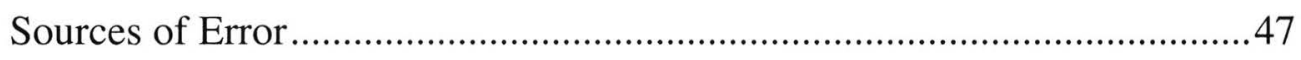

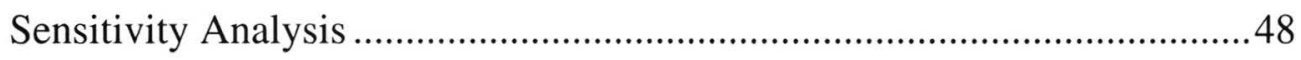

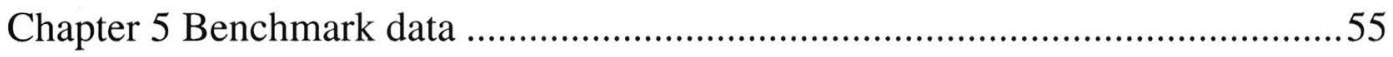

Methodology and Background .................................................................5

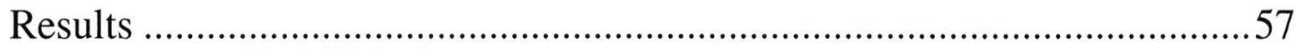

Chapter 6 Point estimation of subsidence from groundwater and petroleum.........70

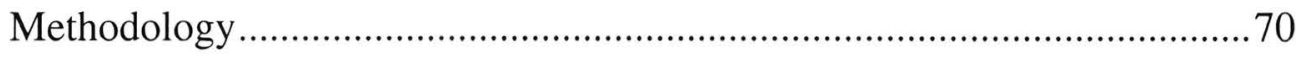

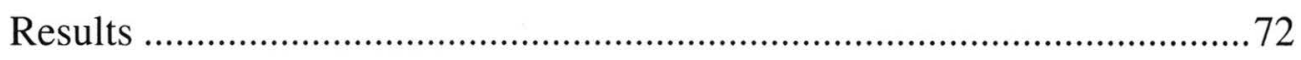




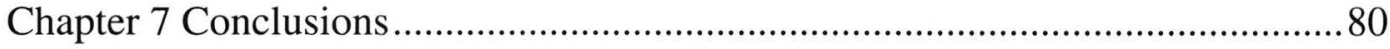

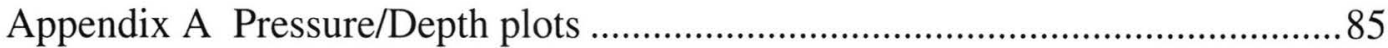

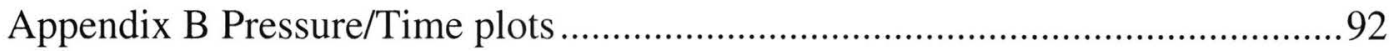

Appendix C Key to symbols used in FORTRAN code ..................................99

Appendix D Code to reservoir and semi-infinite boundary clay models ............. 100

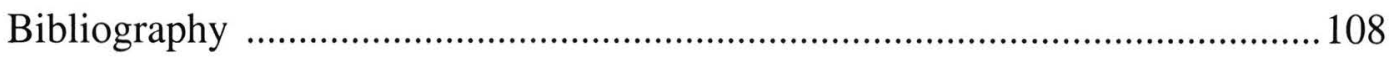

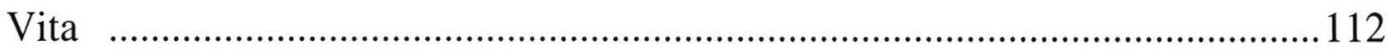




\section{List of Tables}

Table 1.1: $\quad$ Production data for thirteen fields within the study area................. 10

Table 4.1: $\quad$ Model inputs and results........................................................ 44

Table 6.1 Point estimation of subsidence for groundwater and petroleum ......73 


\section{List of Figures}

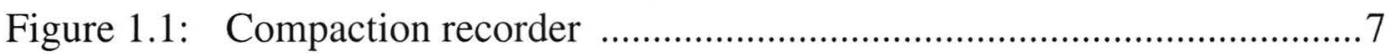

Figure 1.2: Map of oil and gas fields within study area: Harris and Galveston

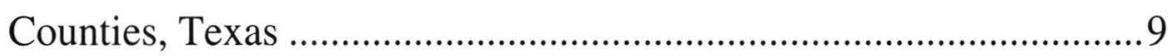

Figure 1.3 Active surface faults located within the Houston Area .....................12

Figure 2.1 Geologic time scale showing location of geologic and hydrologic

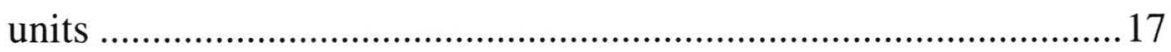

Figure 2.2 Cross-section showing hydrologic units............................................ 18

Figure 2.3 Gulf Coast depositional sequence......................................................2

Figure 2.4 Frio depositional systems of the Texas Gulf Coast ...........................22

Figure 2.5 Location of Yegua Formation............................................................24

Figure 2.6 Lower Miocene depositional framework ..........................................26

Figure 3.1 Pressure/Depth plots for the South Gillock and Clinton Fields........29

Figure 3.2 Pressure/Time plots for the South Gillock and Clinton Fields ..........32

Figure 3.3 Graphs showing hydraulic connection between neighboring

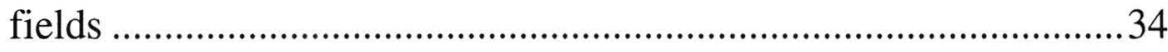

Figure 4.1 Sensitivity analysis of reservoir depth................................................50

Figure 4.2 Sensitivity analysis of vertical hydraulic conductivity ......................51

Figure 4.3 Sensitivity analysis of pressure decline ……………………...........52

Figure 4.4 Sensitivity analysis of cumulative clay thickness...............................54

Figure 5.1 Map showing placement of leveling lines L-17497 and L-24406 ....58

Figure 5.2 Relative rates of vertical movement relative to benchmark C1138..59

Figure 5.3 Map showing placement of leveling lines L-13947 and L-22990 ...61 
Figure 5.4 Relative rates of vertical movement relative to benchmark R8.......62

Figure 5.5 Map showing placement of leveling lines L-17494 and L$24742 / 1$ .63

Figure 5.6 Relative rates of vertical movement relative to benchmark P54 ......64

Figure 5.7 Map showing placement of leveling lines L-17497 and L-19672 ....66

Figure 5.8 Relative rates of vertical movement relative to benchmark H168 ...67

Figure 6.1 Head gradient versus subsidence estimated above petroleum fields .76

Figure 6.2 Head gradient versus subsidence calculated for points above petroleum fields within the Chicot and Evangeline Aquifers 77 


\section{Chapter 1: Introduction}

Land subsidence is the result of pore-fluid extraction from compressible sediments. This phenomenon is found in many places throughout the world, including California, Arizona, Nevada, Italy, Mexico, Bangladesh, Guatemala, China, and the Texas Gulf Coast. In the Sacramento Valley, California, $27.5 \mathrm{ft}$ (8.4 m) of subsidence has occurred since the early 1900s (Borchers, 1998). Land subsidence causes structural damage to buildings, bridges, and roads, and increases the chances of flooding in coastal areas. Along the Texas Gulf Coast average annual costs related to subsidence were estimated at $\$ 14.6$ million (Warren et al., 1974).

A substantial portion of the Texas coast submerged at high rates during the 1900s. Average rates of submergence near the Texas Gulf Coast have been

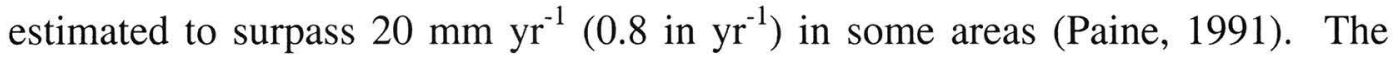
causes of this submergence or inundation of the sea can be attributed to two causes, a rise in sea level (eustatic sea level rise) and a lowering of the land surface (subsidence). Rates of eustatic sea level rise near the Texas Gulf Coast are between 1.5 and $2.5 \mathrm{~mm} \mathrm{yr}^{-1}\left(0.06\right.$ and 0.10 in $\left.\mathrm{yr}^{-1}\right)$ using tidal gauge data (Sharp and Germiat, 1990). Rates of eustatic sea level rise are much lower than rates of submergence in some areas, consequently it is likely that subsidence is responsible for much of the submergence.

Because of the high costs and high risk of land loss in coastal regions worldwide, improving our understanding and predicting of subsidence is critically 
important. Subsidence has been a particular problem in the Texas Gulf Coast region since the growth in population has resulted in an increase in subsurface fluid withdrawal. Since 1930 the U.S. Geological Survey (USGS) and the city of Houston have studied the effects of groundwater withdrawal on subsidence. Within the Houston area approximately 4,700 $\mathrm{mi}^{2}\left(12,200 \mathrm{~km}^{2}\right)$ of land has subsided more than $0.5 \mathrm{ft}(0.15 \mathrm{~m})$. Historically, up to $10 \mathrm{ft}(3 \mathrm{~m})$ of subsidence has been measured within the Harris-Galveston region (HGCSD, 1998). Gabrysch and Coplin (1990), and Williams and Ranzau (1987) attribute most of the subsidence in the region to water-level declines within aquifers.

Some researchers (Sharp and Hill, 1995; Kreitler, 1976; Holzer and Bluntzer, 1984) have suggested that hydrocarbon withdrawal has played a role in subsidence in the Harris-Galveston region. They cite evidence from the Goose Creek Field showing $1 \mathrm{~m}(3.28 \mathrm{ft}$ ) of subsidence from 1917 to 1925 (Pratt and Johnson, 1926). In addition, the Po Delta Field in Italy (Poland and Davis, 1969), more than twenty-one fields in California (Yerkes and Castle, 1969), the Dosso degli Angeli field in the Northern Adriatic Sea (Bau et al., 1999), and the Groningen Gas Field in the Netherlands (Schoonbeek, 1977) have been studied as to the effect of petroleum production on subsidence.

Many more studies have been done on subsidence caused by groundwater withdrawal than on the effects of petroleum extraction. There are two principle reasons why studies on hydrocarbon production are rare. The first reason is that hydrocarbon production is thought to be minimal, and thus overlooked, in areas where groundwater withdrawal rates are high. Secondly, acquisition of data, such 
as bottom hole pressures involved in petroleum production, is difficult. Previous studies within the Harris-Galveston region have focused on the Chocolate Bayou, Mykawa, South Houston, and the Goose Creek Fields (Gabrysch and Coplin, 1990; Holzer and Bluntzer, 1984; Kreitler, 1976; Yerkes and Castle, 1969). Holzer and Bluntzer (1984) show that the majority of the subsidence historically in the Houston area can be attributed to groundwater withdrawal with the exception of the Barbers Hill, Cedar Bayou, Humble and Pierce Junction Fields. Most of the studies within the Harris-Galveston region concentrate on local fields, ignoring regional subsidence caused by the combination of many fields within a region.

The purpose of this study is to characterize and estimate subsidence caused by petroleum production within Harris and Galveston counties in southeast Texas. This paper has five sections, with the first being a background on the hydrogeology and geology of the area. Chapters Three and Four discuss bottom hole pressures (BHP) from depressurization of oil and gas fields and modeling of subsidence above these oil and gas fields. Chapter Five discusses the acquisition of $1^{\text {st }}$ order releveling data and the regional extent of subsidence from oil and gas depressurization within the Harris-Galveston region. In Chapter Six subsidence estimates from modeling and groundwater data are used to quantify the contribution to total subsidence at a single point from petroleum production and groundwater withdrawal. Harris and Galveston counties contain many oil and gas fields that have been in production for over seventy years. This study considers whether there is a detectable signal from this on-going withdrawal. 


\section{Subsidence Theory}

Fluids such as water, oil, and gas exert pressure (pore-fluid pressure) on the surrounding sediment at depth beneath the ground surface. When these fluids are withdrawn, the pore-fluid is reduced and causes an increase in effective stress or the grain to grain stress. The increase in effective stress increases the total stress as shown by Terzaghi's law:

$$
\sigma=\sigma^{\prime}+p
$$

Where: $\sigma=$ total stress $\left[\mathrm{N} / \mathrm{m}^{2}\right]$

$\sigma^{\prime}=$ effective stress $\left[\mathrm{N} / \mathrm{m}^{2}\right]$

$\mathrm{p}=$ pore-fluid pressure $\left[\mathrm{N} / \mathrm{m}^{2}\right]$

When this increase occurs in highly compressible sediments, such as shales found within the Gulf Coast Basin, compaction occurs at depth. The surface expression of this compaction is subsidence.

A simplified equation for calculation of subsidence is stated as (Domenico and Schwartz, 1990):

$$
\mathrm{db}=\alpha \mathrm{b} \rho_{\mathrm{w}} \mathrm{g} d \mathrm{dh}
$$

Where: $\mathrm{db}=$ change in thickness [m]

$\alpha=$ aquifer compressibility $\left[\mathrm{m}^{2} / \mathrm{N}\right]$

$\mathrm{b}=$ thickness of aquifer [m]

$\rho_{\mathrm{w}}=$ fluid density $\left[\mathrm{kg} / \mathrm{m}^{3}\right]$

$\mathrm{g}=$ acceleration of gravity $\left[9.8 \mathrm{~m} / \mathrm{s}^{2}\right]$

$\mathrm{dh}=$ change in head $[\mathrm{m}]$ 
Equation 1.2 is a simplified model of subsidence. Many key parameters are omitted from Equation 1.2 and must be taken into account to characterize more completely the subsidence in an area. Parameters such as porosity, hydraulic conductivity, depth of reservoir beneath the land surface, and clay thickness should be taken into consideration. The last parameter, clay thickness, is of special importance because shales and clays are much more compressible than sands. Knowledge of the aquifer thickness in Equation 1.2 accounts for the sand and clay layers and generally a compressibility of a sand is used as an average of the entire aquifer, but the compressibility of these layers are much different. Equation 1.2, therefore, underestimates the amount of compaction actually occurring. The model used in this paper accounts for many of the key parameters more completely characterizing subsidence occurring from fluid withdrawal.

\section{Background}

Historically, measurement of subsidence in the Harris-Galveston region has been done using releveling methods. Stable benchmarks are set into concrete in the ground at locations throughout the two counties. Elevation measurements are taken periodically and the difference in elevation measurements at a point equates to the amount of vertical movement of the ground. Beginning in the early 1970s, borehole extensometers have been placed at eleven sites throughout Harris and Galveston counties. An extensometer is a deep well that directly measures compaction. At the surface of the extensometer lies a slab of concrete with a steel table and recorder on top. When compaction occurs, the land surface subsides 
along with the table and recorder, allowing a needle to record the amount of compaction (Fig. 1.1).

In the Harris-Galveston region subsidence rates reached their maximum during the years 1943-1978 where more than $8 \mathrm{ft}(2.4 \mathrm{~m})$ of subsidence or $2.7 \mathrm{in}$ $\mathrm{yr}^{-1}\left(6.9 \mathrm{~cm} \mathrm{yr}^{-1}\right)$ occurred near the Baytown region just east of Houston (HGCSD, 1998). A majority of the subsidence during this time period has been attributed to high rates of groundwater withdrawal (Gabrysch and Coplin, 1990). The decline in water levels caused damage to many areas within the two counties. For example, the San Jacinto Monument, which was built to commemorate the Battle of San Jacinto, has experienced subsidence up to $7 \mathrm{ft}$ (2.1 m) (HGCSD, 1998).

In 1970, 525 million gallons of groundwater $\left(1.98 \mathrm{E} 06 \mathrm{~m}^{3}\right)$ were pumped per day, causing groundwater levels to drop as much as $200 \mathrm{ft}(61 \mathrm{~m})$ in some areas. To combat the problem, the Harris-Galveston Coastal Subsidence District (HGCSD) was formed in 1975. The main purposes of the district were to regulate groundwater use and to change the dependence of water use from groundwater to surface water. Surface water for the two counties now comes from Lakes Livingston, Houston, and Conroe. With the conversion to surface water, groundwater use has been reduced dramatically from $525 \mathrm{mgd}\left(1.98 \times 10^{6} \mathrm{~m}^{3}\right)$ in 1970 to $275 \mathrm{mgd}\left(1.04 \times 10^{6} \mathrm{~m}^{3}\right)$ in 1997 , with groundwater levels rising as much as $160.0 \mathrm{ft}(48.8 \mathrm{~m})$. The reduction in groundwater use has also decreased the rate of subsidence. During 1978-1995, the Baytown region, which was experiencing the highest rates of subsidence, subsided less than $0.5 \mathrm{ft}$ 


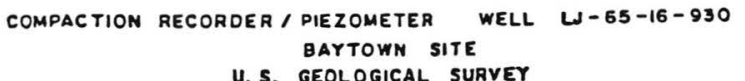

U. S. GEOL OGICAL SURVEY

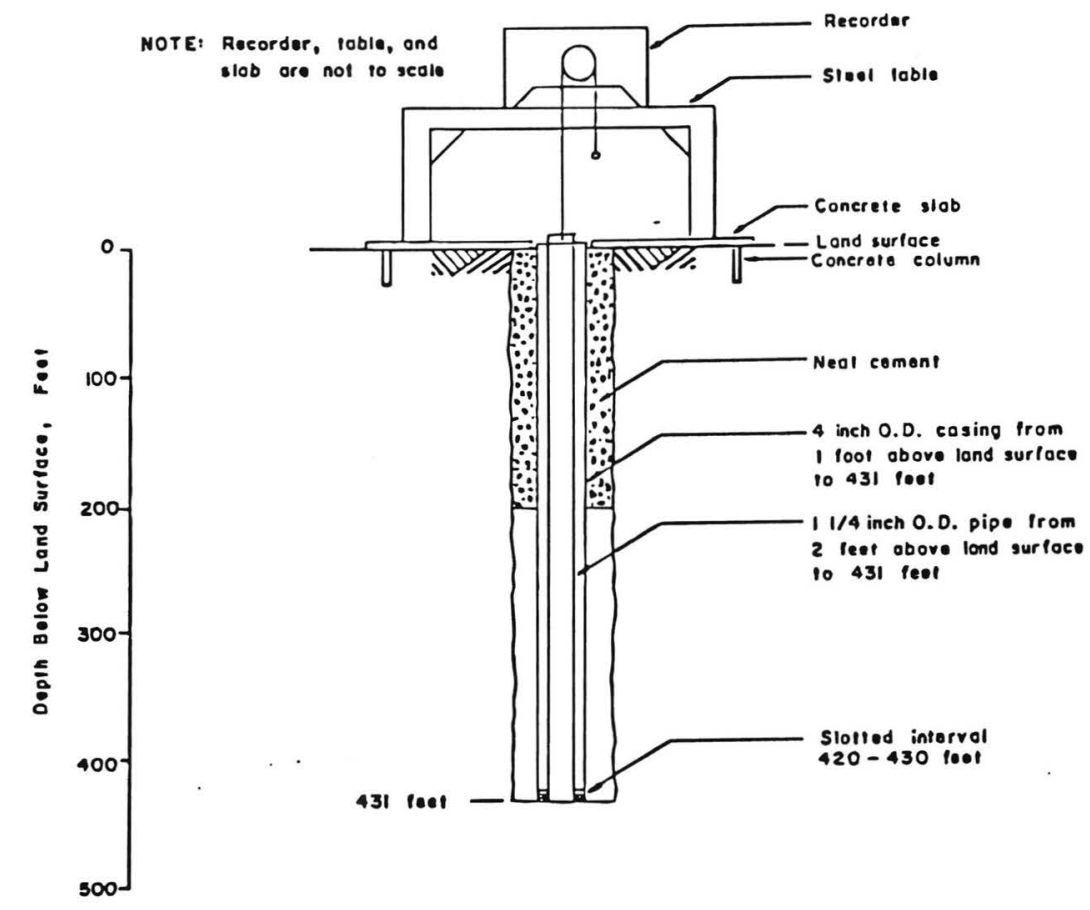

NOTE, All depthe shown ore relerenesd to land surfoce

Figure 1.1 Extensometer (From The Harris-Galveston Coastal Subsidence District) 


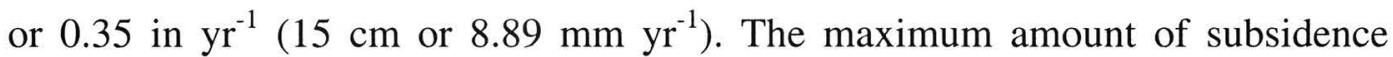
during this time period was in the Jersey Village region located northwest of

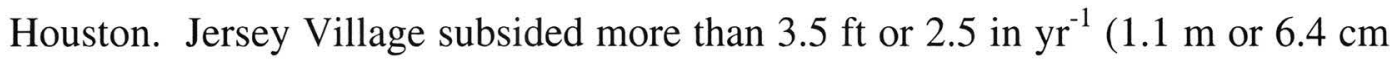
$\left.\mathrm{yr}^{-1}\right)$ (HGCSD, 1998). High rates of subsidence are still found in Jersey Village because the region has not yet been converted to surface water. This is one of the fastest growing areas of Houston.

Petroleum production began in the Harris-Galveston region in 1908 with the discovery of the Goose Creek Field near Baytown. Pratt and Johnson (1926) discovered the effects of oil and gas production on subsidence with the Goose Creek Field. Many other fields have since been discovered and have been producing hydrocarbons in the region for well over seventy years. This study's area of interest has an extensive coverage of oil and gas fields (Fig. 1.2) which reached a production peak during the 1970s. Table 1.1 shows production data for thirteen fields within the study area. The South Gillock Field and the Webster Field, for example, have produced 1.2 million cubic feet (MCF) of gas and 5.9 billion barrels (BBLS) of oil, respectively, up to 1996 (Railroad-Commission, 1995). Although subsidence has decreased dramatically in much of Harris and Galveston counties, measurable amounts of subsidence still exist. Because of the vast coverage of fields that have been producing large amounts of oil and gas for as much as seventy years, petroleum production might be responsible for subsidence in areas where groundwater production has ceased in the past 30 years. 


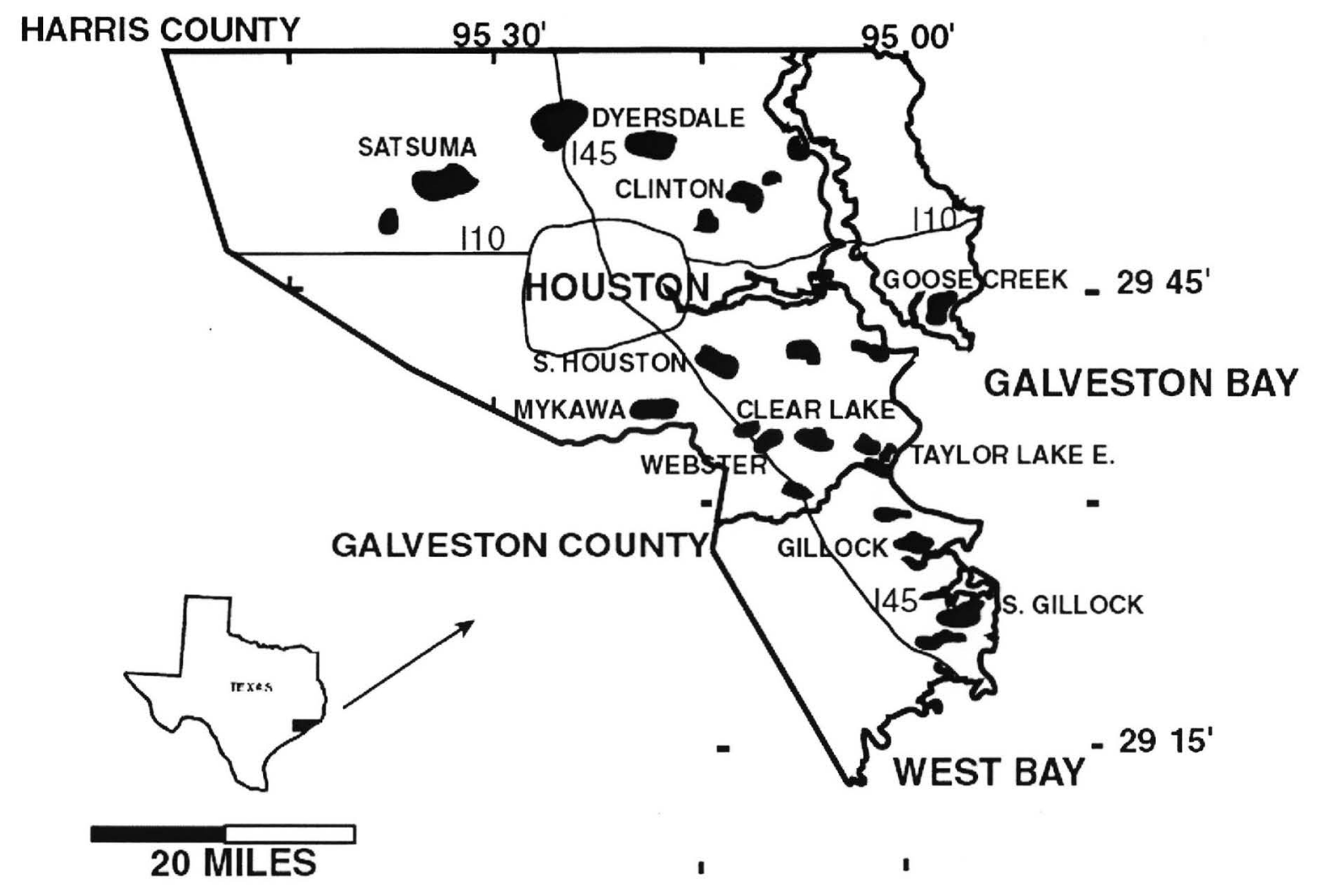

Figure 1.2 Map of oil and gas fields within Harris and Galveston Counties, Texas 


\begin{tabular}{|l|l|l|l|}
\hline FIELD & $\begin{array}{l}\text { DISCOVERY } \\
\text { DATE }\end{array}$ & $\begin{array}{l}\text { Total Gas Produced to } \\
\mathbf{1 9 9 6} \text { (MCF) }\end{array}$ & $\begin{array}{l}\text { Total Crude Oil Produced } \\
\text { to 1996 (BBLS) }\end{array}$ \\
\hline Addicks & 1987 & 67,219 & N/A \\
\hline Clear Lake & 1938 & $11,137,304$ & $24,211,825$ \\
\hline Clinton & 1937 & $17,616,316$, & $1,691,997$ \\
\hline Durkee & 1950 & 367,016 & $13,685,264$ \\
\hline Dyersdale & 1940 & $1,685,512$ & $19,198,381$ \\
\hline Goose Creek & 1908 & $1,469,951$ & $141,540,539$ \\
\hline Mykawa & 1929 & 369,570 & $4,160,596$ \\
\hline Rankin & 1946 & $4,591,095$ & $7,429,557$ \\
\hline Satsuma & 1936 & 515,952 & $4,619,892$ \\
\hline So. Gillock & 1948 & $116,230,546$ & $45,490,401$ \\
\hline So. Houston & 1935 & $2,118,047$ & $36,225,130$ \\
\hline Taylor Lake & 1965 & 620,918 & 386,917 \\
\hline Webster & 1936 & $3,708,464$ & \\
\hline
\end{tabular}

Table 1.1 Production data for thirteen fields within the study area 
Surface fault movement around oil and gas fields may also indicate subsidence caused by petroleum production. Figure 1.3 shows some of the surface faults located around oil and gas fields in the Houston area. Note the location of the faults around the edges of the fields. Subsidence does not appear to cause the faulting directly in many cases. Verbeek and Clanton (1981), and Sheets (1979) suggest that the latest episode of surface fault movement was triggered by the effects of petroleum production. According to Yerkes and Castle (1969), the changes in horizontal stress induced by differential compaction from subsidence causes faulting.

There are several examples in the study area of surface fault movement. The Clinton Field Fault is an active fault encircling the Clinton Oil Field and is the surface expression of a larger and older subsurface fault. The Clinton Field Fault was discovered in 1937 shortly after production began and has had vertical displacement up to $4.0 \mathrm{ft}(1.2 \mathrm{~m})$ (Sheets, 1979). The Wooster Fault located on the north end of the Goose Creek Field along with the Hogg Island Fault on the south end of the Goose Creek Field form an east-west graben in which the oil field is located (Sheets, 1979). Faulting may be associated with subsidence caused by production of the Goose Creek Field during 1917-25 (Holzer and Bluntzer, 1984).

\section{Objectives of Study}

Many studies have documented the effects of groundwater withdrawal on subsidence (Borchers, 1998; Gabrysch and Coplin, 1990; HGCSD, 1998; Holzer and Gabrysch, 1987; Kasmarek et al., 1997), but fail to document petroleum 


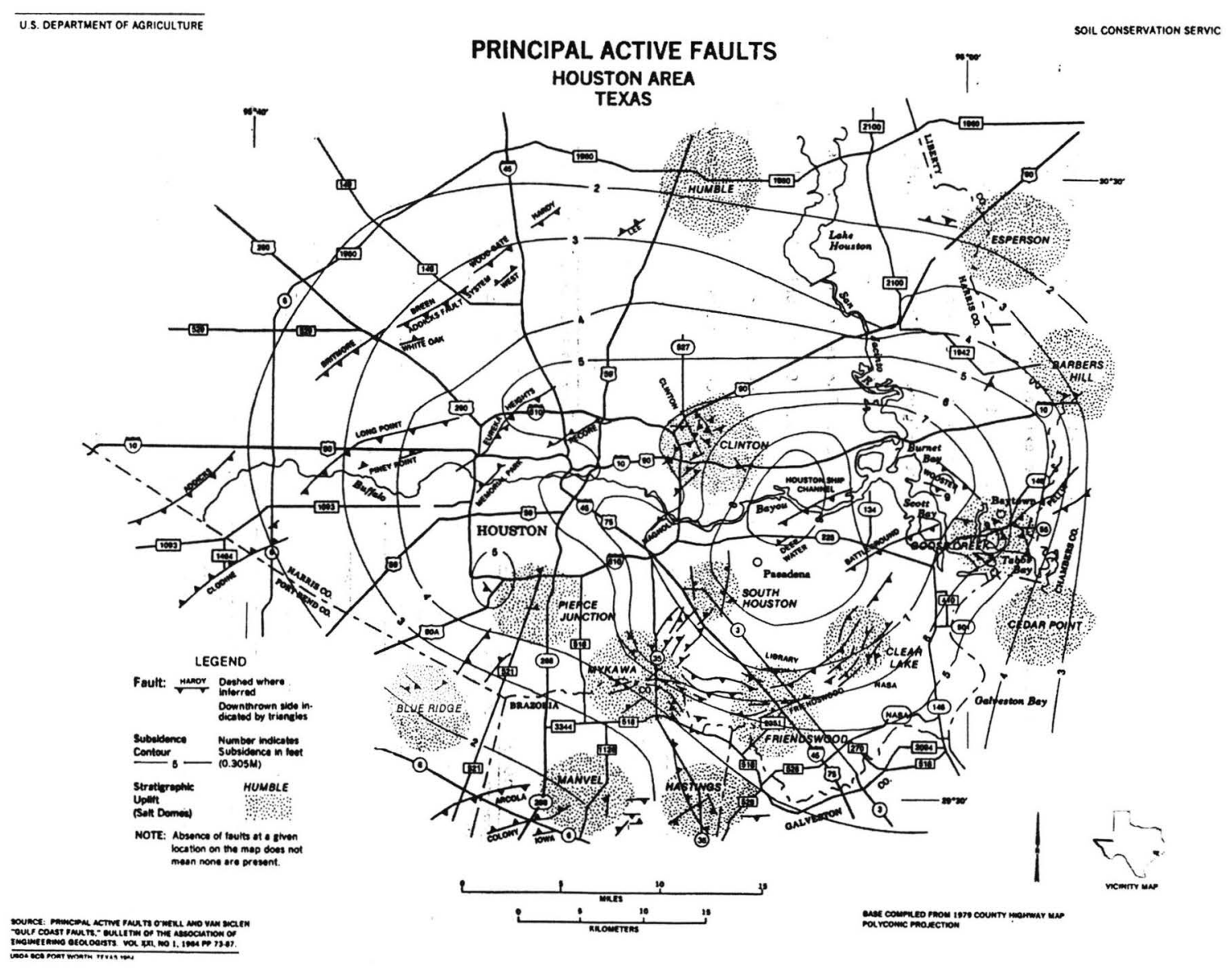

Figure 1.3 Active surface faults located within the Houston area (From Van Siclen et al., 1984) 
production as a viable cause of subsidence in the Harris-Galveston region. While some have studied the effects of oil and gas production on subsidence (Erickson, 1976; Hejmanowski, 1995; Murria, 1991; Pratt and Johnson, 1926; Schoonbeek, 1977; Sharp and Hill, 1995), these have been localized around a small number of fields and may have overlooked the regional aspect of oil and gas field depressurization. Regional studies of this magnitude (many small fields over 1400 $\mathrm{mi}^{2}$ ) are rare because data (BHP) are hard to acquire. The objective of this study is to quantify the effects of petroleum production on subsidence and to consider regional as well as local effects.

The hypotheses tested in this study include:

- Subsidence caused by petroleum production is a significant contributing factor to total subsidence that should not be ignored.

- Depressurization and subsequent subsidence over local oil or gas fields may have a regional effect.

- Compaction within and in the vicinity of the reservoir should be considered when characterizing an oil or gas reservoir.

- Currently, in places where groundwater withdrawal has ceased, petroleum production and equilibration of clays account for the majority of subsidence in Harris and Galveston counties.

\section{Methodology}

Originally BHP data were to be acquired for thirty oil and gas fields within Harris and Galveston counties to estimate subsidence. This number was reduced to sixteen because of the lack of BHP data at the Texas Railroad 
Commission and electric logs for some fields (See Fig. 1.2). Over 8000 BHP measurements were acquired from oil and gas wells within fields in the two counties. BHP data are important for estimation of subsidence because it represents the change in head (dh) shown in Equation 1.2. BHP is measured in pounds per square inch (psi) and is analogous to a head level in a water well. It can be converted to an equivalent head level in meters by:

$$
\mathrm{dh}=\mathrm{psi} * 0.704
$$

Pressure decline within oil and gas wells was analyzed to understand depressurization of the area temporally and spatially. A computer code was then written for two models to quantify subsidence above oil and gas fields. The two models used, which will be discussed in detail later, include Geertsma's Nucleus of Strain Model (Geertsma, 1973) and Sharp and Hill's Semi-Infinite Boundary Clay Model (Sharp and Hill, 1995).

It has been shown that removal of fluids in compressible sediments will cause some subsidence, but to understand whether subsidence above petroleum fields is localized or regional, connecting neighboring fields over the study area is of greater importance. For this reason $1^{\text {st }}$ order releveling lines were obtained from the National Geodetic Survey (NGS). The purpose for obtaining benchmark data was to construct cross-sections through a line of oil and gas fields within the study area. Cross-sections were constructed by taking elevation differences over a set time from a series of benchmarks across oil and gas fields. From the crosssections it is possible to determine whether subsidence bowls above these fields are local or regional by connecting neighboring fields. Additional fields not 
chosen for BHP analysis were used in Chapter Five to better understand the regional extent of subsidence. 


\section{Chapter 2: Geology/Hydrogeology of study area}

The Harris-Galveston region located within the Gulf Coast Basin of Texas, formed over 70 million years ago. Sedimentary deltaic deposits form a broad plain consisting of clays, silts, sands, and gravels dipping gently to the southeast. The stratigraphic units found within the Harris-Galveston region from oldest to youngest are the Oakville Sandstone, Fleming Formation, Goliad Sand, Willis Sand, Bentley Formation, Montgomery Formation, Beaumont Formation and, at the surface, undifferentiated Quaternary alluvial deposits (Fig 2.1). The Harris-Galveston region is characterized by a flat gentle topography consisting of numerous barrier islands, estuaries, and lagoons. Average rainfall is

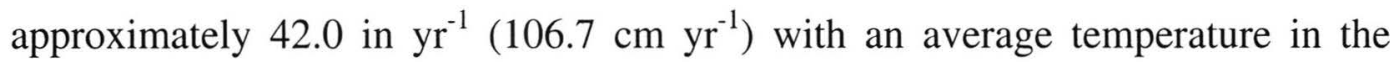
winter of $43^{\circ} \mathrm{F}\left(6^{\circ} \mathrm{C}\right)$ and $94^{\circ} \mathrm{F}\left(34^{\circ} \mathrm{C}\right)$ in the summer.

\section{Hydrogeology}

The groundwater system in the Harris-Galveston region consists of sand and clay lenses. The sands are connected laterally with interbedded clay lenses forming a sinuous connection within the sands. The Jasper, Evangeline, and Chicot aquifers (Fig. 2.1) are found in the area. Figure 2.2 is a hydrogeologic section showing the delineating the aquifers. The Chicot and Evangeline aquifers are the source of the majority of groundwater used in the Harris-Galveston region. These aquifers are underlain by the Burkeville confining layer and are considered to be separate aquifers because of a distinct difference in hydraulic conductivity 


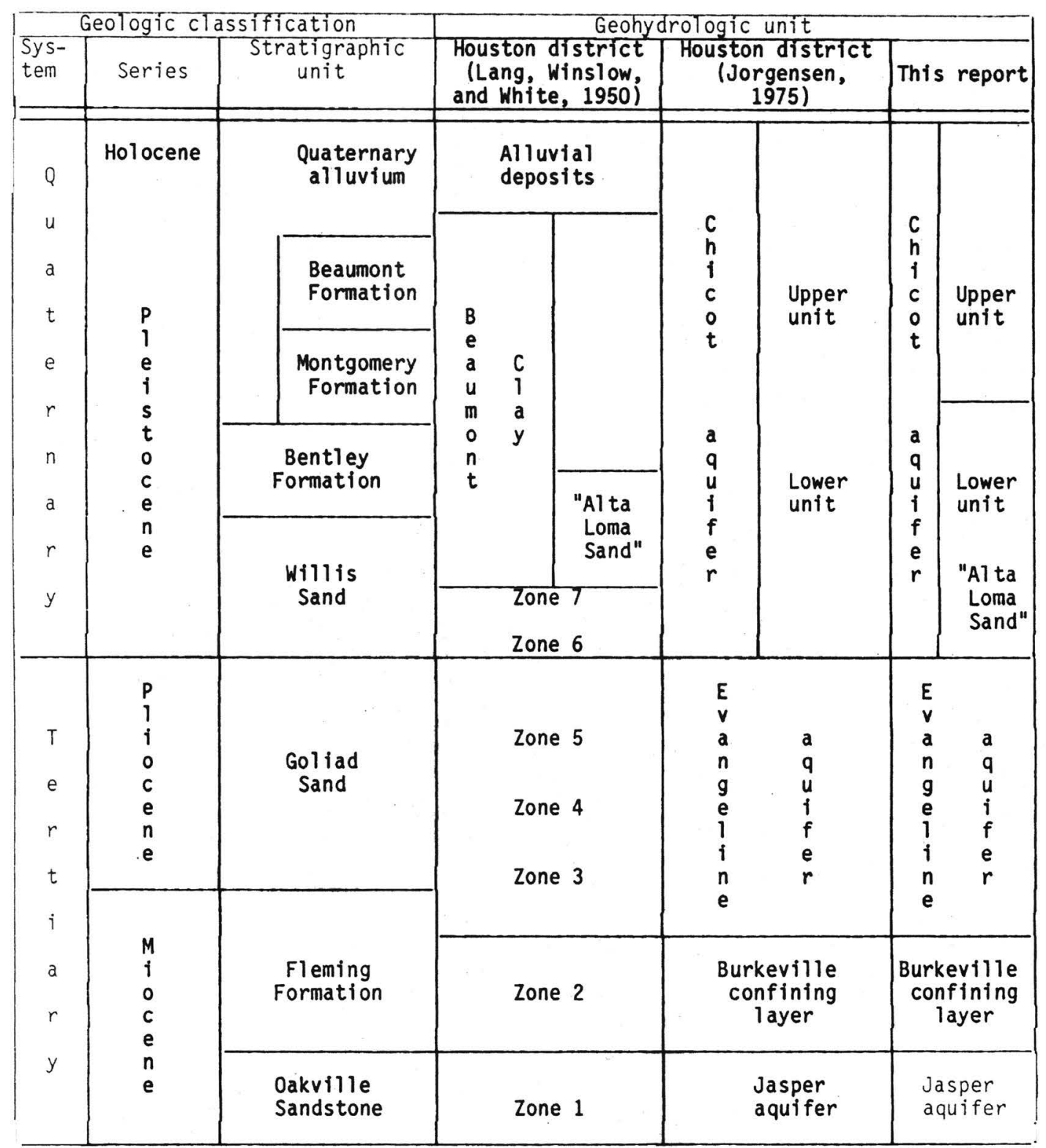

Figure 2.1 Geologic time scale showing location of geologic and hydrologic units (from Williams et. al., 1987, labeled "This report” on figure) 


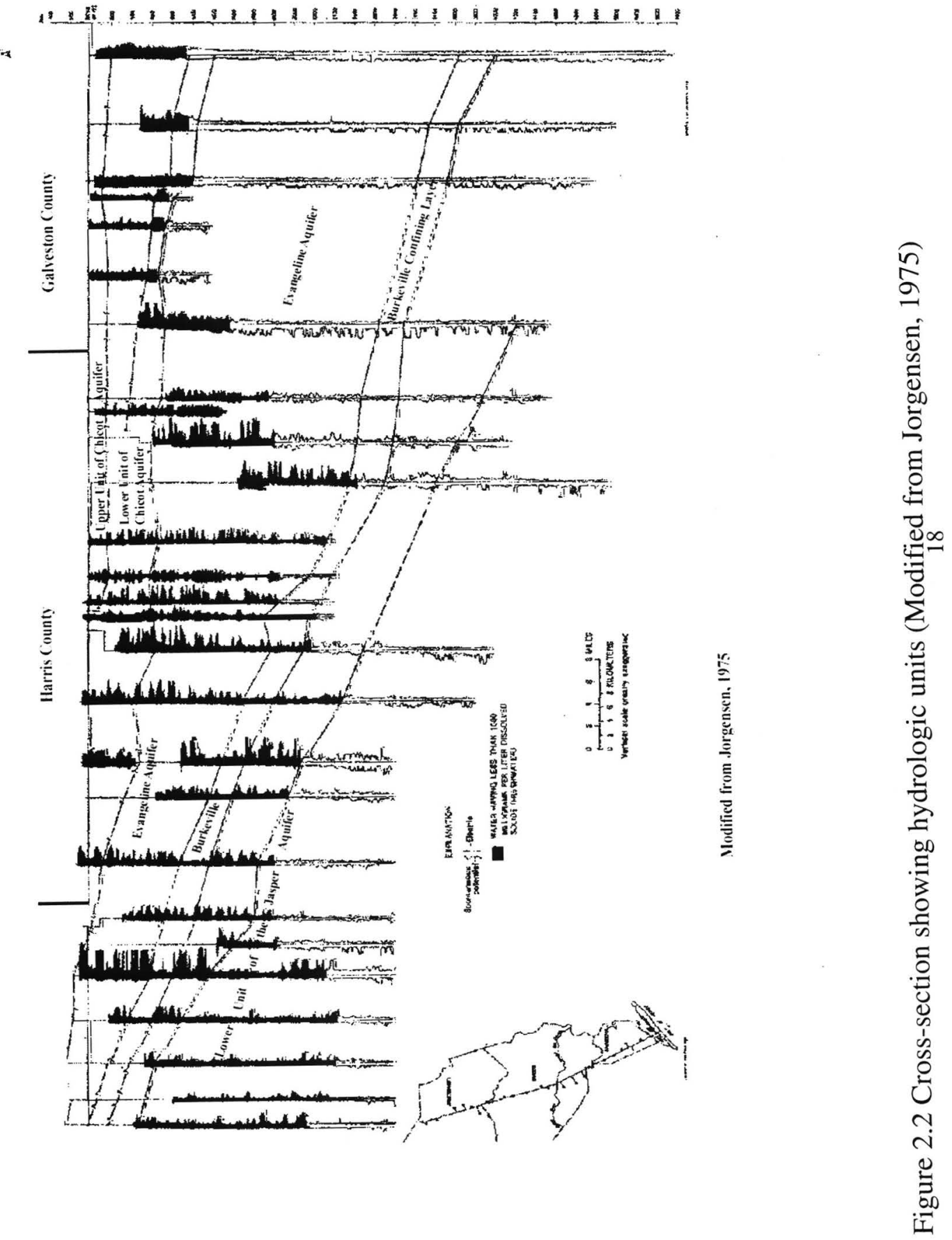


(Gabrysch and Coplin, 1990). The system is leaky and artesian because of the high pressures found in the Gulf Coast Basin.

The Jasper aquifer, composed predominately of terrigenous clastic sediments, underlies the Burkeville confining unit. The Jasper aquifer contains only two wells in northern Harris county which yield suitable quality water (Williams and Ranzau, 1987) and is unusable in the Harris-Galveston region.

The Chicot aquifer is composed of the Willis Sand, Bentley Formation, Montgomery Formation, Beaumont Formation, and Quaternary alluvium (Fig. 2.1). The Chicot consists of sands with interbedded clay lenses, and is confined except for the northern portion of Harris county (Williams and Ranzau, 1987). The difference in hydraulic conductivity and elevation of potentiometric surfaces are the criteria for separation of the system into two aquifers. In southeastern Harris County and Galveston County the Chicot contains a thick sand layer known as the Alta Loma Sand which provides the source for the majority of groundwater used in this area.

Underneath the Chicot is the Evangeline aquifer. The Chicot contains the more permeable sand layers as well as the more compressible clay layers. The Evangeline aquifer is composed of the Goliad Sand and the upper portion of the Fleming Formation. It underlies the Chicot and is similar lithologically (Fig. 2.2). The Evangeline is the major source of groundwater in the Houston area as well as northern Harris County. In southern Harris County and Galveston County, the Evangeline aquifer contains brackish waters and is unusable. 


\section{Geology}

The majority of the oil and gas fields in the study area produce from three different zones or formations, which include the Frio and Yegua Formations, and the Miocene fluvial, deltaic, and delta-flank sandstones (Fig. 2.3). All are characterized by deltaic sequences, prograding to the southeast.

The Frio Formation of Oligocene age overlays the Vicksburg Formation and is capped by the Anahuac Shale confining layer. It was divided into distinct depositional systems by Galloway et al. (1982). A majority of the petroleum fields producing from the Frio lie in the Houston Delta System, consisting of several minor, laterally coalescent, vertically repetitive deltaic cycles (Galloway et al., 1982). Ancient rivers similar in size to the current Brazos and Trinity rivers, formed the Houston Delta System with deltas extending into open Gulf waters. Deltaic sands were deposited along strike through marine processes, with constant migration of delta lobes and associated reworking and inundation by the sea. Coastal progradation was slow, causing a broad transition boundary with the Greta/Carancahua barrier/strandplain system (Fig. 2.4). In the Anahuac transgression, marine domination was evident with retreat of the Houston Delta System. The Frio interval associated with the Houston Delta System is between 1800 and $7500 \mathrm{ft}$ (550 and $2300 \mathrm{~m}$ ) thick, with sand content decreasing distally from 60 percent to 10 percent (Galloway et al., 1982). Structurally, the Frio includes deep salt anticlines, shallower salt diapers with associated faults, salt- 


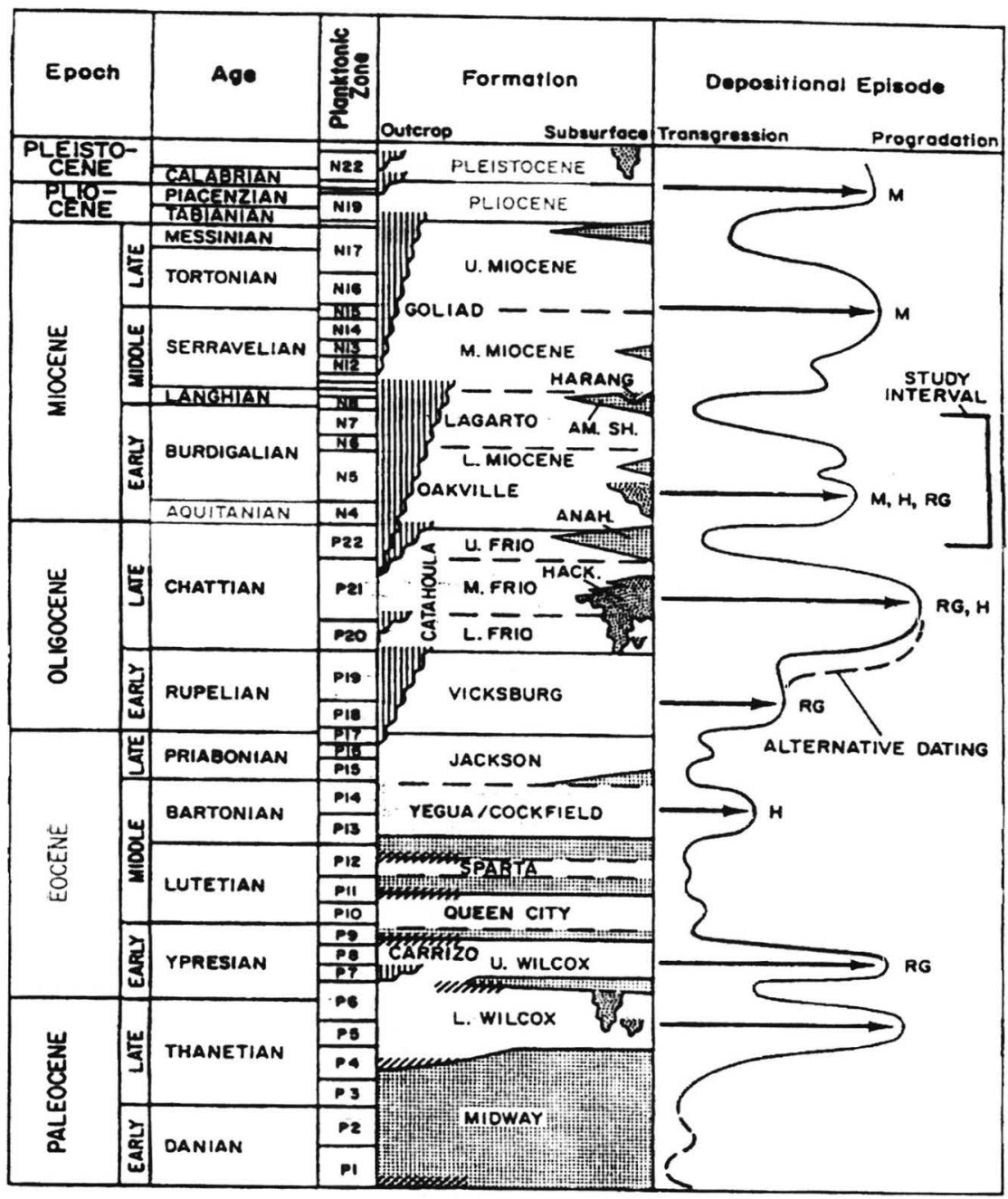

Figure 2.3 Gulf Coast depositional sequence (from Galloway et. al., 1986) 


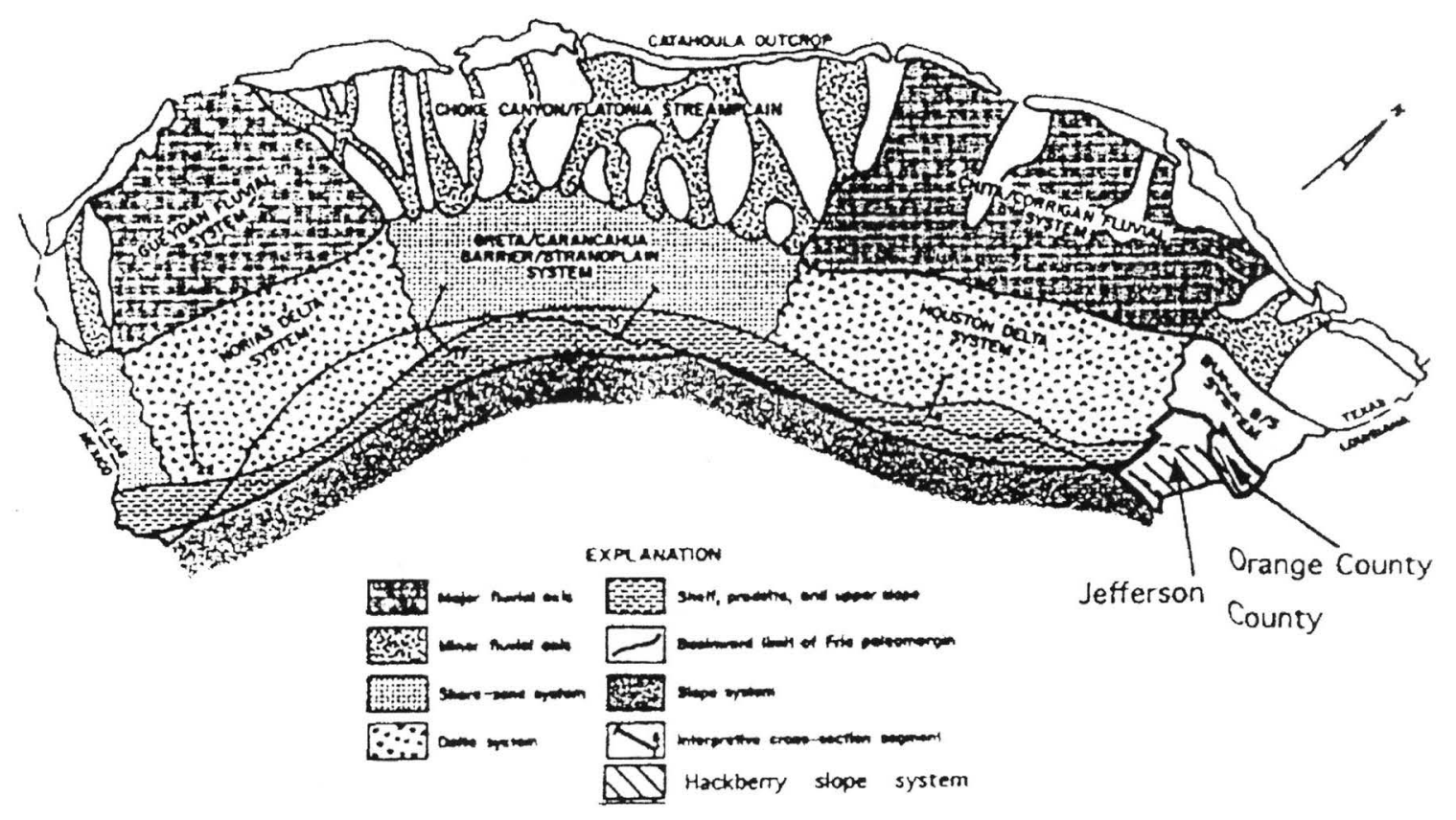

Figure 2.4 Frio depositional systems of the Texas Gulf Coast (from Galloway et. al., 1986) 
withdrawal basins, and regional growth faults. Growth faulting into continually higher strata has caused a close pattern of strike-parallel fractures, which makes it very distinctive. From a reservoir viewpoint, the delta-front and delta-plain sands merge along strike to form moderately continuous reservoirs (Galloway et al., 1982). Salt diapers caused abrupt changes in sandstone thickness. Most of the traps in this area are from faulted anticlines above deep salt ridges or from growth-faults, which are sealed against the upthrown or downthrown block (Galloway et al., 1982).

The Yegua Formation (Fig. 2.5), of upper middle Eocene age overlies the Sparta Formation, and underlies the Jackson Formation. Fields producing from this formation are found mainly in Harris County. It is a fine-grained marine shale and sandstone unit with a gentle dip to the southeast. During deposition of the Yegua there was an overall eustatic sea level drop, with minor sea level fluctuations. The Yegua is characterized by progradational, aggradational and retrogradational phases (Meckel, 1993). Uplift and erosion of the southern Rocky Mountains and regional rhyolitic volcanism in west Texas and northern Mexico increased clastic deposition into the Gulf basin. Structural features affecting the Yegua include structural lows of the Houston Salt Basin in east Texas. Depocenters are concentrated along the down-dip edge of the Wilcox fault zone. The paleo-shelf edge contains significant Yegua-age growth faults, and the up-dip edge of overpressured sediment (Winker and Edwards, 1983). Down dip of the shelf edge are sand bodies are located which are used for hydrocarbon extraction. 


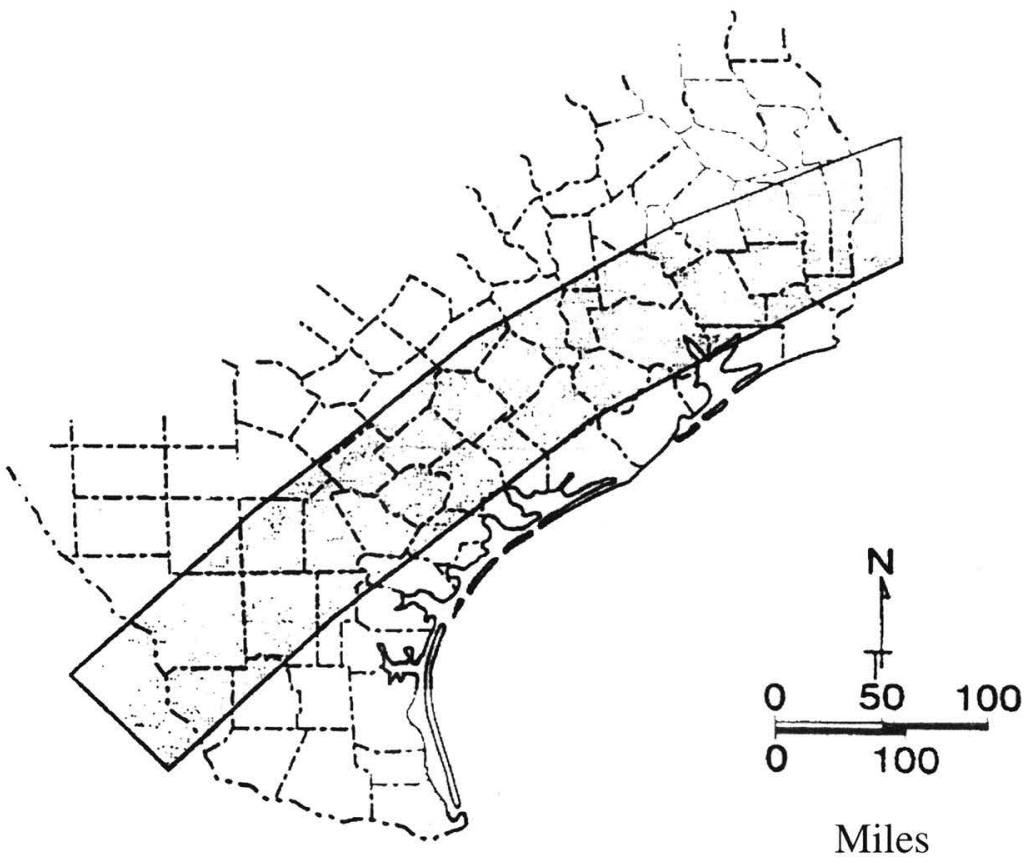

Figure 2.5 Location of Yegua Formation (From Meckel, 1993) 
Miocene fluvial, deltaic, and delta flank sandstones form reservoirs for petroleum fields located in southern Harris County and much of Galveston County. They are of lower Miocene age, with gently dipping sands and mudstones thickening coastward. Deposition took place on a shallow-water shelf platform above the Frio shelf margin (Fig. 2.6). As in other formations of the Gulf Coast Basin, dominant structural features include deep and shallow salt diapers, growth faults and sediment extrusion and uplift. Reservoirs within the lower Miocene have produced more than $2.7 \mathrm{bbl}$ (billion barrels of oil), making it a major producing unit in the Gulf Coast Basin (Galloway et al., 1986). Galloway et al. (1986) have grouped Lower Miocene production into nine plays. The Mykawa and Dyersdale fields are examples of fields found in and around salt domes of the Houston salt diapir province. Structural traps include deep and shallow salt domes and fault systems. There is a close connection between Lower Miocene and Frio zones, with Lower Miocene zones being collections of leakage from richer Frio plays (Galloway et al., 1986). 


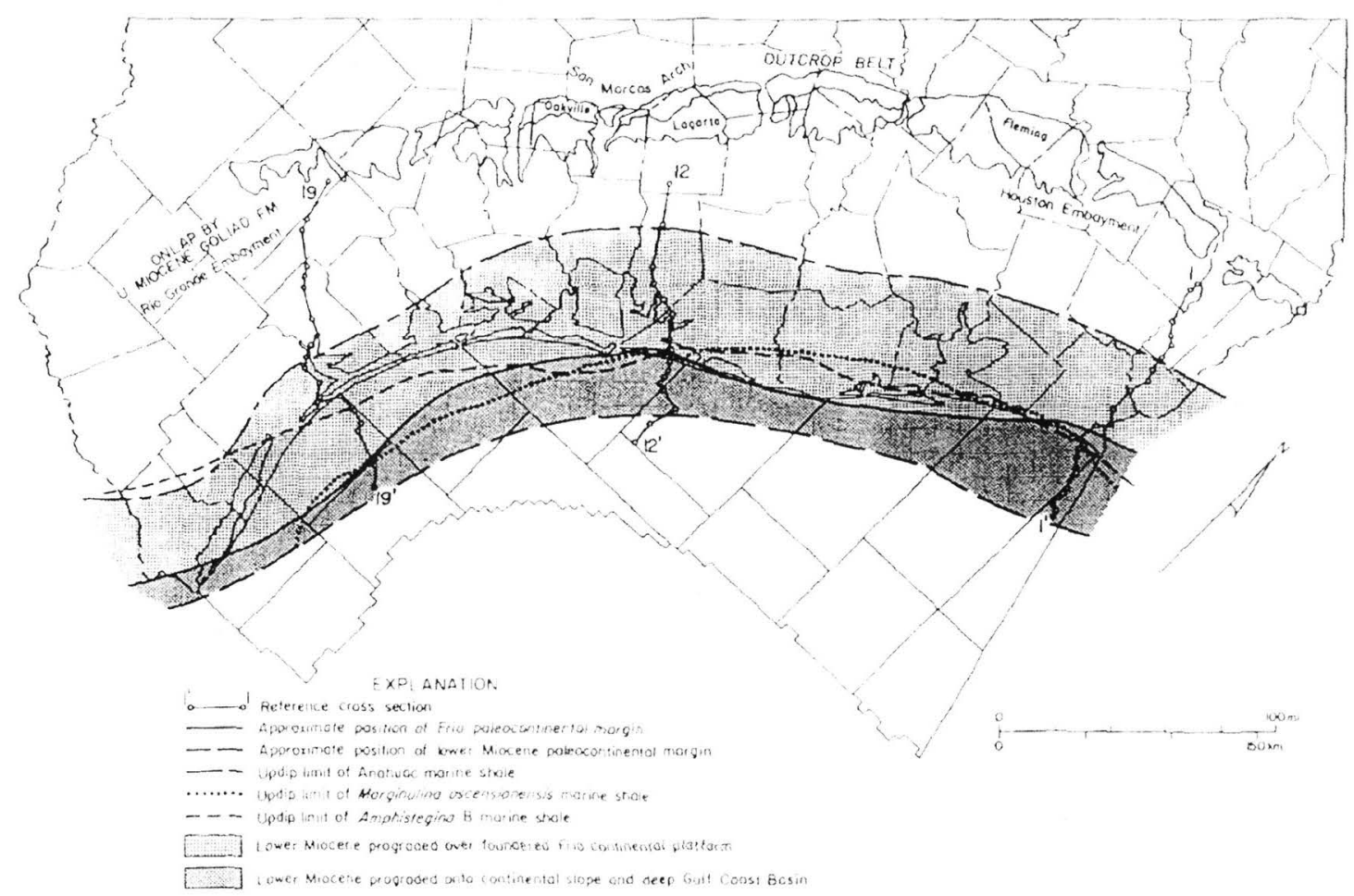

Figure 2.6 Lower Miocene depositional framework (from Galloway, 1986) 


\section{Chapter 3: Bottom hole pressure data}

Originally, in the Gulf Coast Basin, pore-pressure increases with depth as a result of sediment loading. At shallow depths pressures are at or near hydrostatic pressure ${ }^{1}$. When an additional load is placed on a system in which water can not escape, the system can not compress and release water so that the additional load must be borne by the water. This additional load causes an increase in pressure at depth in excess of hydrostatic. In the Gulf Coast Basin loading exceeds water release at depth and in turn causes an increases in pressure in excess of hydrostatic. Such a pressure regime is termed "overpressured" or "geopressured".

As mentioned in Chapter One, BHP data are measurements of the pressure at the base or "bottom" of the oil or gas well and are directly analogous to a head level in a water well. From the generalized subsidence model (Equation 1.2), a reduction in head, or BHP, increases compaction which in turn increases the amount of subsidence. The changes in pressure of these fields indicates how much depressurization has occurred since pumping began and provides an input to the model for calculation of subsidence above these fields.

\footnotetext{
${ }^{1}$ Hydrostatic pressure is the pressure exerted by a column of water under its own weight.
} 


\section{Methodology and Results of BHP Data}

From open files at the Texas Railroad Commission, BHP data were acquired for sixteen petroleum fields within the study area for analysis of depressurization of these fields over time. Information in these files includes a BHP measurement, date of measurement, well number within the field, and the field name of the well. Acquisition of BHP data proved difficult. Typically, wells within petroleum fields are not usually measured for BHP. Bottom hole pressures are taken in most cases because an oil or gas well is under investigation. A majority of the BHP data for the study area dates to the late 1960s to early 1970s, and the latest measurements are up to 1997. In most cases the temporal coverage of BHP data lacks the initial BHP when a well first began production.

Once the data were collected, graphs were plotted showing the relationship between pressure and depth. Each data point within the graphs represents a pressure measurement at one well within the field. To better understand depressurization through time a second type of graph was constructed showing the pressure gradient through time.

As stated above, before production began, many of the wells within petroleum fields in the study area were overpressured or geopressured. Figure 3.1 shows a pressure/depth graph for the South Gillock and Clinton Fields. Wells were plotted within each field with respect to lithostatic and hydrostatic pressures. Lithostatic pressure is the stress exerted by the porous medium with its pore fluids; this is generally estimated at 1.0 psi $\left(6.9 \times 10^{3} \mathrm{~Pa}\right)$ per foot of depth. Hydrostatic pressure generally increases by $0.465 \mathrm{psi} \mathrm{ft}^{-1}\left(3.2 \times 10^{3} \mathrm{~Pa} \mathrm{ft}^{-1}\right)$. An 


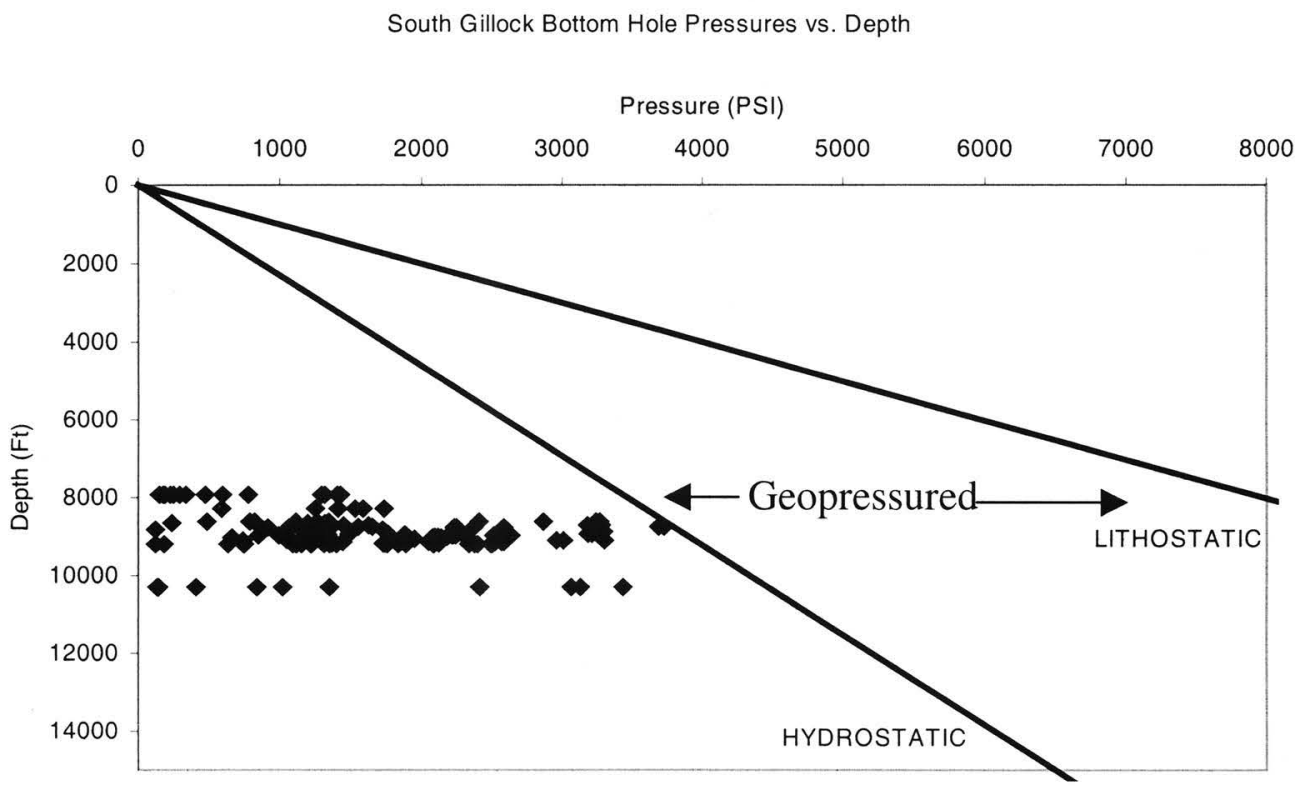

Clinton Bottom Hole Pressures VS Depth

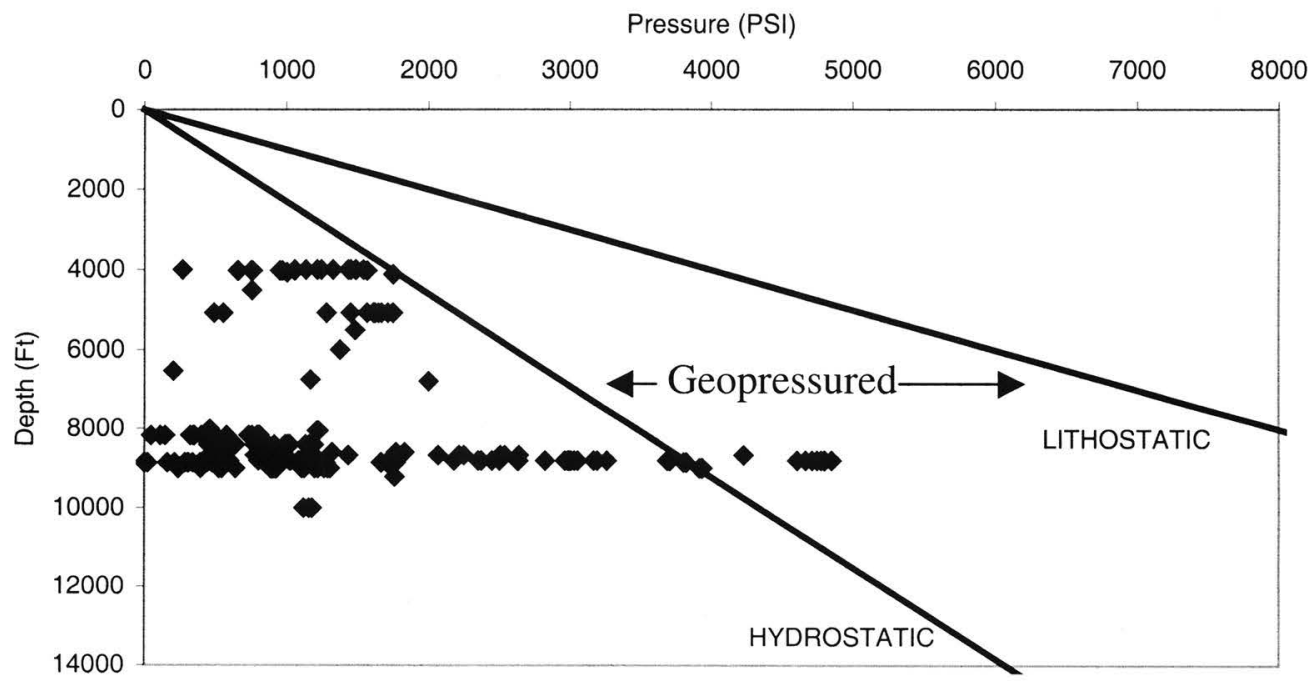

Figure 3.1 Pressure/Depth plots for the South Gillock and Clinton Fields 
important feature of Figure 3.1 is the locations of the data points. Nearly all of the wells plot below the hydrostatic pressure line and are clearly underpressured. For example, at the South Gillock Field, the Frio Reservoir had shut-in pressures of $3297 \mathrm{psi}(21 \mathrm{MPa}$ ) in 1976, and in 1996 the pressures were reduced to $224 \mathrm{psi}$ (1.5 MPa). This is a pressure decline of $3073 \mathrm{psi}$ in twenty years or an equivalent head decline of $7096 \mathrm{ft}(2163 \mathrm{~m})$. Initial BHPs, are assumed to be near $90 \%$ of lithostatic pressure before any petroleum production occurred in the region, this assumption was also used in Sharp and Hill's work (1995). This assumption is considered valid because at production depths sediments within the Gulf Coast Basin have been under high stress and pressure for long periods of time, and thus are able to produce pressures near lithostatic (Sharp and Hill, 1995). Above 90\% of lithostatic, rocks will fracture to release pore fluids until pressures are reduced (Domenico and Schwartz, 1990). Given this assumption, at the South Gillock Field in the Frio Reservoir, pressure declines were 7876 psi (51 MPa) since 1948, when the South Gillock Field first began production. This is an equivalent head decline of 18,193 ft (5545 m). The South Gillock and Clinton Fields were not the only underpressured fields in the study area. All of the fields show this same trend of depressurization. Appendix A1-A14 contains the pressure/depth plots for the remaining fields in the study area.

Causes of depressurization include hydrocarbon or groundwater extraction, downward flow through low-permeability strata, and expansion of low permeability rocks upon erosion (Neuzil, 1986). Although the Gulf Coast Basin contains many low permeability rocks, depressurization by the latter two 
processes would not have produced pressures as low as was found within these fields. It is likely then that petroleum extraction produced these under pressures; defined as pressures below hydrostatic.

It is clear from the pressure/depth plots that all of the fields in the study area are depressurized. To understand the temporal variation in depressurization, time series graphs (Figure 3.2) are plotted with a pressure gradient (pressure depth $^{-1}$ ) for the South Gillock and Clinton Fields. The two fields began production before the data shown in plots (1948 and 1937 respectively), but it is clear in the South Gillock Field plot that there is a pressure decline starting from 1975 through 1996. The Clinton Field plot has more scatter in the data but still shows this linear trend of pressure decline through time. Note that almost all of the wells within the two fields remain below hydrostatic pressure. Appendix B1B14 contains the pressure/time graphs for the remaining fields in the study area. As with the pressure/depth plots for the South Gillock and Clinton fields, all of the fields in the study area show the same depressurization with time.

The scatter in the data for Figs. 3.2 and B1-B14 can be attributed to two factors, multiple reservoir production and fluctuation in production. Most of the petroleum fields within the study area produce from one reservoir such as the Frio, although some fields produce from multiple reservoirs. From the pressure/depth plots, most of the fields have data points that cluster around a depth interval. This cluster signifies a single producing zone. Plots with significant scatter in the data where there may be several clusters around depth intervals indicate multiple reservoirs. Operators do not always agree on a standard 
South Gillock Pressure Gradient vs. Time

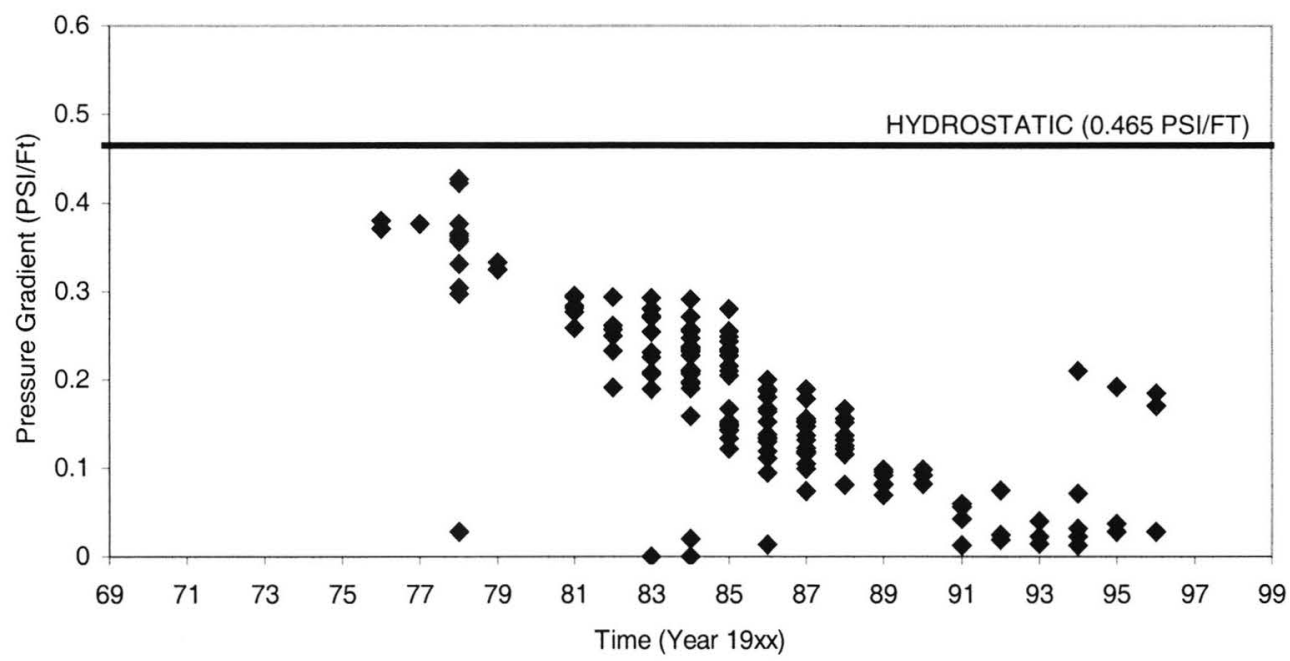

Clinton Pressure Gradient vs. Time

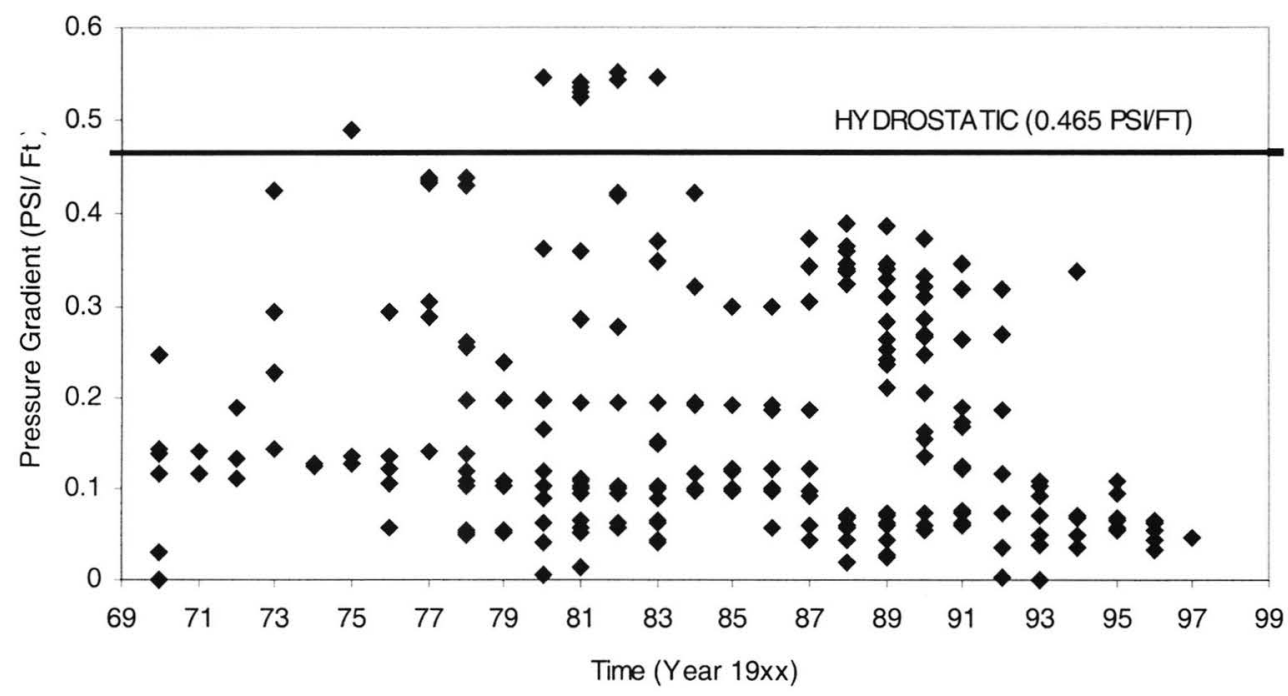

Figure 3.2 Pressure/Time Plots for the South Gillock and Clinton Fields 
for naming production zones. The same zone may be given two different names. For example, in some zones the Frio is called the lower Miocene zone. Also, electric logs were not readily available and made correlation of zones between wells extremely difficult. Despite the difficulty of differentiating reservoirs, the multiple reservoir Clinton Field in Fig. 3.1 still shows depressurization over time.

The second cause of scatter in the data can be attributed to fluctuations in production. In the 1970s production reached a peak and thus a greater amount of depressurization would have occurred. Production decreased in the 1980s, causing less depressurization of the reservoir, leading to fluctuations or scatter in the data over time. The Clinton Field (Fig. 3.2) shows such a trend. In the late 1970s production was high so there was a declining trend in pressure, as production decreased in the 1980s the pressure increased a little declining again in the 1990s with an increase in production.

From the BHP data, it is apparent that some of the petroleum fields in the study area were already underpressured before production began. This occurs in fields that began production within the last twenty years. This phenomenon may be from a hydraulic connection between neighboring fields. Many of the fields in the study area are close to each other such that pumping occurring in one field can depressurize a neighboring field. Figure 3.3 shows pressure/time plots for the Clear Lake Field which began production in 1938 and the Seabrook East Field which began production in 1980 . The two fields are within 2.0 miles $(3.2 \mathrm{~km})$ of each other and produce from the same reservoir. From Figure 3.3 it is clear that the Clear Lake Field has been underpressured since the early 1970s. Even before 
Clear Lake Pressure Gradient vs. Time

Production Began in 1938

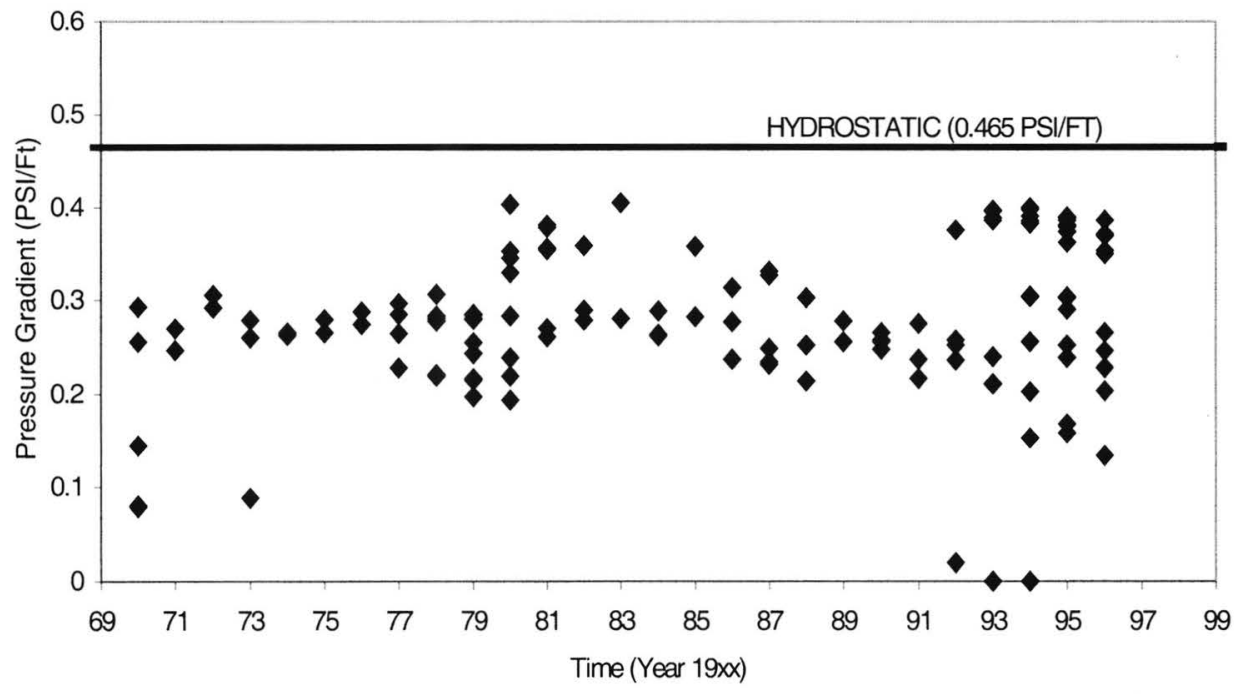

Seabrook East Pressure Gradient vs. Time Production Began in 1980

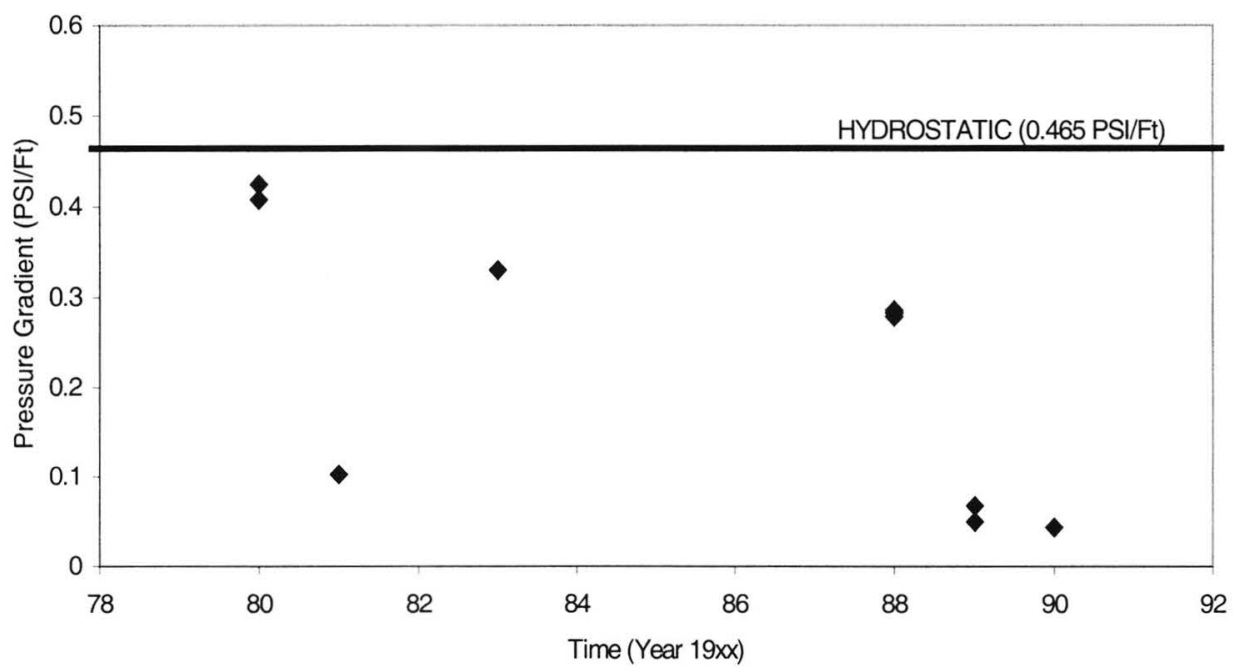

Figure 3.3 Graphs showing hydraulic connection between neighboring fields 
production began in 1980, the Seabrook East Field was underpressured. It appears a hydraulic connection between the closely located fields resulted in depressurization of the Seabrook East Field from production in the Clear Lake Field.

\section{Implications}

The main objective of acquiring BHP data was to identify depressurization of petroleum fields. From the pressure/depth plots (Fig. 3.1, A1-A14) it is clear that all of the fields in the Harris-Galveston region have been depressurized below hydrostatic pressure. The pressure/time plots (Fig 3.2, B1-B14) show that reservoir pressures have declined over time. A possible hydraulic connection in neighboring fields is inferred from data such as shown in Figure 3.3. This shows that depressurization of a petroleum field is not confined to an individual field but may affect the area around it as well.

Since significant depressurization has occurred in the Harris-Galveston region from petroleum production, subsidence above oil and gas fields may be detectable. In Equation 1.2 a reduction in pressure results in an increase in compaction and then subsidence. Later, we quantify the amount of subsidence actually occurring above these fields and test the observation noted in Figure 3.3 that depressurization and subsequent subsidence may be regional by connecting fields within the study area. The following chapter provides a model which uses BHP data from this chapter as well as many other field based and calculated parameters to fully model subsidence above oil and gas fields within the HarrisGalveston region. 


\section{Chapter 4: Modeling of subsidence}

Chapter 3 considered the extent of depressurization occurring from petroleum production. However, a model is needed to quantify the actual amount of subsidence occurring above petroleum fields. Modeling of subsidence can be as simple as Equation 1.2, but to characterize the system fully, other parameters must be taken into consideration. An understanding of the geology of a reservoir is key, because a model of subsidence is only as good our understanding of the lithology and hydrogeology of the area. The advantage of the models used in this study is that much of the data input into the model are field-based.

The main objective of modeling in this area is to discern whether subsidence caused by oil and gas withdrawal is measurable in the HarrisGalveston region. Two models are used in this study, a reservoir model and a semi-infinite boundary clay model (SIBCM). The reservoir model takes into account compaction of clay layers within the reservoir, and it is based upon Geertsma's nucleus of strain model (1973), modified by Helm (1984). The SIBCM takes into account compaction of clays bounding the reservoir and was developed by Sharp and Hill (1995). The total subsidence is simply the addition of subsidence calculated by the reservoir model and the SIBCM.

Input data for the total subsidence model comes from BHP measurements discussed in Chapter 3 as well as an extensive coverage of electric logs acquired from the Bureau of Economic Geology at The University of Texas at Austin. The electric logs were used to identify reservoirs within petroleum fields as well as clay thicknesses and lithology of the reservoir. 


\section{Reservoir Model}

Oil and gas reside in permeable sandstones predominantly found within traps in a reservoir. Within a sandstone reservoir are clay or shale layers that contain fluids such as petroleum or water. The clay layers are more compressible than sandstone by about two orders of magnitude (Domenico and Schwartz, 1990). When petroleum is extracted from the sandstone, fluids flow from the shales into the sandstone. This causes a loss of fluid typically referred to as "dewatering" within the compressible shales initiating compaction. Knowledge

of cumulative clay thickness (b) within a reservoir is an input into a model for estimating subsidence.

Because field data for petroleum wells within the Harris-Galveston region are sparse, many parameters used in the model have to be calculated. Dickinson (1953) found a logarithmic relation of porosity with depth:

$$
\begin{aligned}
& n=n_{\text {ref }}-a\left(\ln \frac{z}{z_{\text {ref }}}\right) \text { at } \mathrm{z}>0 \\
& \mathrm{n}=\text { porosity } \\
& \mathrm{n}_{\text {ref }} \text { and } \mathrm{z}_{\text {ref }} \text { are reference values for porosity and depth } \\
& \mathrm{z}=\text { depth } \\
& \mathrm{a}=\text { an empirical constant (within the Gulf Coast assumed to equal } 0.103 \text { ) }
\end{aligned}
$$

Storativity is another important variable measuring the amount of fluid per unit area stored or expelled from storage within a reservoir per unit change in head. Storativity has two components, a recoverable and non-recoverable portion. In modeling subsidence, the non-recoverable portion of storativity is important in 
estimating the inelastic component of a reservoir. Non-recoverable storativity $\left(\mathrm{S}_{\mathrm{skv}}\right)$ is calculated by the equation:

$$
\begin{aligned}
& S_{s k v}=\frac{a}{(G-1)(1-n)^{2} z} \\
& S_{\text {skv }}=\text { nonrecoverable portion of storativity } \\
& \mathrm{G}=\text { specific gravity of solids } \\
& \mathrm{z}=\text { depth }
\end{aligned}
$$

From equations (4.1 and 4.2) a maximum amount of subsidence can be calculated by:

$$
\begin{aligned}
& \Delta \mathrm{b}^{\prime}=\mathrm{S}_{\mathrm{skv}} \mathrm{b} \Delta \mathrm{h} \\
& \Delta \mathrm{b}^{\prime}=\text { maximum subsidence } \\
& \mathrm{b}=\text { cumulative thickness of clay layers within reservoir } \\
& \Delta \mathrm{h}=\text { decline in head }
\end{aligned}
$$

Equation 1.3 is used to convert pressure decline to an equivalent head decline.

From Equation 4.3 we can estimate subsidence for later calculations. Shales have lower permeabilities $\left(10^{-12} \mathrm{~m} \mathrm{~s}^{-1}\right)$ than sandstones, and when they dewater, the time required for fluids to leave the shale and compaction to occur is not instantaneous. The calculation of the time lag $(\tau)$, is a useful parameter in predicting how long the effects of subsidence will last. This can be solved by:

$$
\begin{aligned}
\tau & =\left(\frac{S_{s k v}\left(\frac{H}{2}\right)^{2}}{K}\right) \\
\mathrm{H} & =\text { thickness of the thickest clay layer within the reservoir }
\end{aligned}
$$


$\mathrm{K}=$ vertical hydraulic conductivity of the clays

Effective stress $\left(\sigma^{\prime}\right)$ or the grain to grain stress is calculated by:

$$
\begin{aligned}
& \sigma^{\prime}=\rho_{\mathrm{w}} \mathrm{g} \Delta \mathrm{h} \\
& \rho_{\mathrm{w}}=\text { density of water } \\
& \mathrm{g}=\text { gravitational acceleration }\left(9.8 \mathrm{~m} \mathrm{~s}^{-2}\right)
\end{aligned}
$$

Geertsma's (1973) equation for subsidence directly over a disk-shaped reservoir with uniform pressure drop is:

$$
U_{z}(0,0)=-2(1-v) c_{m} b \Delta p\left(1-\left(\frac{C}{\left(1+C^{2}\right)^{\frac{1}{2}}}\right)\right)
$$

$v=$ Poisson's ratio

$\mathrm{c}_{\mathrm{m}}=$ coefficient of uniaxial compression

$\mathrm{C}=\mathrm{DR}^{-1}(\mathrm{D}=$ depth to compressing beds and $\mathrm{R}=$ radius of the reservoir $)$

The coefficient of uniaxial compaction is calculated by:

$$
c_{m}=\frac{S_{s k v}}{\rho g}
$$

Equation 4.6 does not account for the depth at which a reservoir is located. Shallow reservoirs, assuming all other variables are equal, will cause greater amounts of subsidence than deeper reservoirs. Equation 4.8 accounts for the depth of a reservoir to calculate subsidence by: 


$$
U_{z}(0, z)=-c_{m} b \Delta p\left[\left(\frac{C(Z-1)}{2\left(1+C^{2}(Z-1)^{2}\right)^{\frac{1}{2}}}\right)-\left(\frac{(3-4 v) C(Z+1)}{\left(2\left(1+C^{2}(Z+1)^{2}\right)\right)^{\frac{1}{2}}}\right)+\right]
$$

where: $\mathrm{Z}=\mathrm{zD}^{-1}$

$\mathrm{z}=$ depth to reservoir

At the land surface $z=0$, and Equation 4.8 reduces to Equation 4.6.

The previous equations (4.6-4.8) for estimation of subsidence actually are calculating compaction at depth. For an accurate estimation of subsidence, the attenuation of compaction at depth to the land surface must be considered as well as the radius (r) of influence of a reservoir. Helm's equation (1984) for attenuation (A) of subsidence at the land surface is shown by:

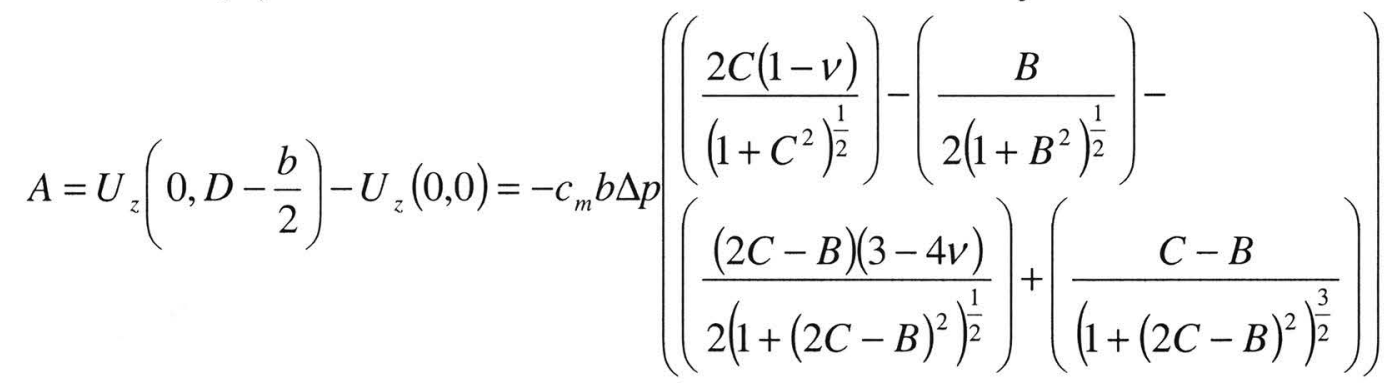

$$
\begin{aligned}
& B=b(2 R)^{-1} \\
& R=\text { radius of influence (reservoir radius) }
\end{aligned}
$$


Helm's modified estimate of subsidence, taking into account attenuation, is the difference between maximum subsidence and attenuation of subsidence to the land surface:

$$
\mathrm{U}_{\mathrm{z} \text { mod }}(0,0)=\Delta \mathrm{b}^{\prime}-\mathrm{A}
$$

A coning factor $(\mathrm{E})$ that is the ratio of land subsidence to reservoir compaction over the center of a reservoir is defined by Helm as:

$$
\begin{aligned}
& E=\frac{U_{z \bmod }(0,0)}{\Delta b^{\prime}}=\left(\frac{1-2 C(1-v)}{\left(1+C^{2}\right)^{\frac{1}{2}}}\right)+\left(\frac{B}{2\left(1+B^{2}\right)^{\frac{1}{2}}}\right)+\left(\frac{(2 C-B)(3-4 v)}{2\left(1+(2 C-B)^{2}\right)^{\frac{1}{2}}}\right) \\
& \left(\frac{C-B}{\left(1+(2 C-B)^{2}\right)^{\frac{3}{2}}}\right)
\end{aligned}
$$

For a deep reservoir which has a radius much larger than its thickness, as $\mathrm{C}$ approaches infinity and B approaches 0, the coning factor (E) approaches 0.5 despite the value of Poisson's ratio. Limits to Equation 4.11 specify that the depth to the compressible beds (D) cannot be less than the half-thickness of the reservoir, requiring that $B \leq C$. This requires that $0 \leq b \leq R$.

From these equations (4.9-4.11) we can now calculate total subsidence, taking coning into effect, by knowing the depth to compressible beds within a reservoir (D), reservoir radius (R), thickness of compressible beds (b), and changes in pressure $(\Delta \mathrm{p})$. Helm's modified estimate of total subsidence above a reservoir is:

$$
\mathrm{U}_{\text {mod }}(0,0)=\mathrm{ES}_{\mathrm{skv}} \mathrm{b} \Delta \mathrm{h}
$$


The key to variables can be found in Appendix C, and the code for the reservoir model can be found in Appendix D.

\section{Semi-Infinite Boundary Clay Model}

When withdrawing oil or gas from a reservoir or groundwater from an aquifer, dewatering of clays occurs not only within the reservoir but also at the bounding clay layers around a reservoir. The semi-infinite boundary clay model (SIBCM) developed by Sharp and Hill (1995) considers the compaction of clays bounding the reservoir. The model was developed with an analogy to heat flow based upon a solution from Carslaw and Jaeger (1959). Using an error function to describe the pressure decline within a reservoir, the pressure decline at a vertical distance from the reservoir can be obtained by:

$\Delta p=\Delta p_{r}\left[\operatorname{erf}\left(\frac{y}{2\left(\frac{K t}{S_{s k v}}\right)^{\frac{1}{2}}}\right)\right]$

$\Delta \mathrm{p}=$ attenuation of pressure to the bounding clay layer

$\Delta \mathrm{p}_{\mathrm{r}}=$ pressure decline in the reservoir

$\mathrm{y}=$ vertical distance above or below the reservoir

$\mathrm{K}$ = vertical hydraulic conductivity

$\mathrm{t}=$ time of calculation (time span of $\left.\Delta \mathrm{p}_{\mathrm{r}}\right)$

Two assumptions are used in this model, one that the reservoir contains a homogenous sandstone matrix and the second that an instantaneous pressure decline occurs in the reservoir with a time dependent pressure change in the bounding clay layer. The value obtained for $\Delta \mathrm{p}$ in Equation 4.13 is actually a 
portion of the pressure decline in the reservoir $\left(\Delta \mathrm{p}_{\mathrm{r}}\right)$. The actual decline in pressure within the bounding clay layer $\left(\Delta \mathrm{p}_{\mathrm{c}}\right)$ is:

$$
\Delta \mathrm{p}_{\mathrm{c}}=\Delta \mathrm{p}_{\mathrm{r}}-\Delta \mathrm{p}
$$

Once the pressure decline in the bounding clay layer is determined, it can be converted to an equivalent head decline. This head decline is input back into the previous equations (4.1-4.12) to calculate attenuation and an estimate of subsidence from the compaction of the bounding clay layers. Recall that the total subsidence is then the addition of subsidence calculated by the reservoir model and the SIBCM. The code for the SIBCM can be found in Appendix D.

\section{Model Results}

Twelve fields were modeled based upon availability of BHP data and adequate electric logs for estimation of subsidence. Reservoir thickness, cumulative clay thickness, and largest clay thickness within the reservoir were determined from electric logs while reservoir depth and pressure declines were obtained through the Texas Railroad Commission files. Table 4.1 shows model inputs and results for the twelve fields within the study area.

When running the model some values were held constant and estimated because of a lack of direct measurements. These include:

Sediment specific gravity

Vertical hydraulic conductivity

Reservoir radius

Young's modulus

Poisson's ratio
2.6

$10^{-14} \mathrm{~m} \mathrm{~s}^{-1}$

$1000 \mathrm{~m}$

$10^{8} \mathrm{~Pa}$

0.3 


\begin{tabular}{|c|c|c|c|c|c|c|c|c|c|c|}
\hline Field & $\begin{array}{l}\text { Reservoir } \\
\text { Depth (m) }\end{array}$ & $\begin{array}{l}\text { Time } \\
\text { Span } \\
\text { (Yrs) }\end{array}$ & $\begin{array}{c}\text { Reservoir } \\
\text { Thickness } \\
\text { (m) }\end{array}$ & $\begin{array}{c}\text { Total Clay } \\
\text { Thickness } \\
\text { (m) }\end{array}$ & $\begin{array}{c}\text { Largest } \\
\text { Clay } \\
\text { Thickness } \\
\text { (m) }\end{array}$ & $\begin{array}{l}\text { Head } \\
\text { Loss } \\
(\mathrm{m})\end{array}$ & $\begin{array}{c}\text { Subsidence } \\
\text { Reservoir } \\
\text { Model (m) }\end{array}$ & $\begin{array}{c}\text { Subsidence } \\
\text { SIBCM } \\
\text { (m) }\end{array}$ & $\begin{array}{c}\text { Total } \\
\text { Subsidence } \\
(\mathrm{cm})\end{array}$ & $\begin{array}{c}\text { Rate } \\
\left(\mathrm{mm} \mathrm{yr}^{-1}\right)\end{array}$ \\
\hline $\begin{array}{l}\text { Clear } \\
\text { Lake }\end{array}$ & 1840 & 14 & 18.29 & 6.71 & 2.13 & 94.17 & 0.03 & 0.0002 & 3.02 & 2.16 \\
\hline Clinton & 2700 & 26 & 24.38 & 9.14 & 3.66 & 587.84 & 0.11 & 0.01 & 12.00 & 4.62 \\
\hline Durkee N. & 2429 & 19 & 17.37 & 4.88 & 3.66 & 501.25 & 0.06 & 0.003 & 6.30 & 3.32 \\
\hline Dyersdale & 1079 & 22 & 5.18 & 1.22 & 0.61 & 109.12 & 0.01 & 0.01 & 2.00 & 0.91 \\
\hline Gillcok & 2576 & 20 & 5.49 & 1.83 & 0.91 & 156.29 & 0.006 & 0.0005 & 0.65 & 0.33 \\
\hline $\begin{array}{l}\text { Goose } \\
\text { Creek }\end{array}$ & 4175 & 9 & 18.29 & 7.01 & 3.05 & 3743.87 & 0.29 & 0.01 & 30.00 & 33.33 \\
\hline $\begin{array}{c}\text { Houston } \\
\text { So. }\end{array}$ & 1615 & 11 & 12.19 & 4.54 & 1.13 & 566.02 & 0.11 & 0.0001 & 11.01 & 10.00 \\
\hline Mykawa & 1179 & 12 & 8.23 & 2.13 & 0.91 & 1113.02 & 0.17 & 0.12 & 29.00 & 24.16 \\
\hline $\begin{array}{c}\text { New } \\
\text { Mykawa }\end{array}$ & 1483 & 20 & 16.76 & 3.66 & 1.23 & 1111.62 & 0.20 & 0.002 & 20.2 & 10.10 \\
\hline Satsuma & 2318 & 19 & 10.97 & 2.13 & 0.91 & 694.14 & 0.04 & 0.002 & 4.20 & 2.21 \\
\hline $\begin{array}{c}\text { So. } \\
\text { Gillock }\end{array}$ & 2664 & 20 & 15.85 & 5.79 & 3.05 & 1326.34 & 0.16 & 0.06 & 22.00 & 11.00 \\
\hline $\begin{array}{l}\text { Taylor } \\
\text { Lake E. }\end{array}$ & 3097 & 10 & 7.92 & 3.66 & 1.52 & 2268.28 & 0.14 & 0.003 & 14.30 & 14.30 \\
\hline
\end{tabular}

Table 4.1 Model inputs and results 
Thickness of clay layer above and below the reservoir $1 \mathrm{~m}$ Young's modulus, Poisson's ratio, and the sediment specific gravity are from the literature on studies in similar settings (Sharp and Hill, 1995; Tuma, 1983). The reservoir radius was set at $1000 \mathrm{~m}$ as an average reservoir radius for fields within the study area (Helm, 1984; Sharp and Hill, 1995).

Vertical hydraulic conductivity $(\mathrm{K})$ of the clays was set at $10^{-14} \mathrm{~m} \mathrm{~s}^{-1}$ for two reasons, the time frame of subsidence $(\tau)$ it produced and previous use in similar studies (Sharp and Hill, 1995). When larger values for $\mathrm{K}\left(10^{-10} \mathrm{~m} \mathrm{~s}^{-1}\right)$ taken from the literature (Freeze and Cherry, 1979) were used, the time frame of subsidence from the model was on the order of hours or days. Recalling from earlier discussions on subsidence theory and compaction of clays, clays do not compact instantaneously but rather equilibrate over long periods of time. The time spans produced from the larger $\mathrm{K}$ values were unrealistic considering the depths (over $2000 \mathrm{~m}$ ) from which petroleum fields produce. A K of $10^{-14} \mathrm{~m} \mathrm{~s}^{-1}$ produced subsidence time frames on the order of decades. It appears likely that the majority of clay equilibration and compaction would occur over decades or longer, as is found in groundwater studies on subsidence (Gabrysch and Coplin, 1990; Sharp and Hill, 1995). The use of this lower value of K can also be illustrated from the way hydraulic conductivity is measured. Values for hydraulic conductivity are given for in the horizontal direction and not in the vertical as is used in the model. Sharp and Hill (1995) discuss the mineral structure of clays as a plausible reason for this lower value of $\mathrm{K}$. They state that the platy, disc-like structure of clays enables fluids to flow easier in the horizontal rather than the 
vertical direction as would be shown by lower values for $\mathrm{K}$ in the vertical direction. It should be noted that the $\mathrm{K}$ does not affect the estimate of total subsidence but rather the time frame of subsidence.

From model simulations, total subsidence ranges from $0.65 \mathrm{~cm}(0.28$ in) or

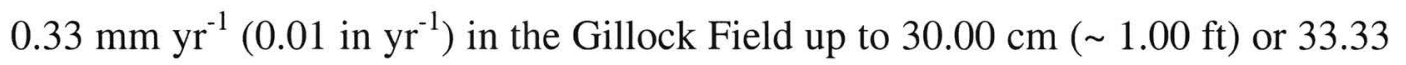

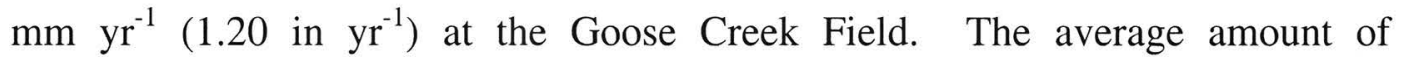
subsidence for petroleum fields within the Harris-Galveston region is $12.89 \mathrm{~cm}$

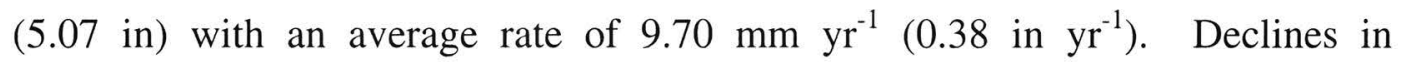
equivalent head ranged from $94.17 \mathrm{~m}(308.97 \mathrm{ft})$ at the Clear Lake Field to $3743.87 \mathrm{~m}(1.23 \mathrm{E} 04 \mathrm{ft})$ at the Goose Creek Field. These head losses are large when compared to head losses from water wells in studies of subsidence from groundwater extraction (Gabrysch and Coplin, 1990; HGCSD, 1998; Williams and Ranzau, 1987). These large head losses however do not amount to more subsidence because water wells are at much shallower depths (10-100 m; 33-328 ft) than oil and gas wells (1000-5000 m; 3281-16405 ft).

The time span when most of these calculations were done depends upon the BHP measurement dates. The petroleum fields within the study area have BHP measurements ranging from the mid 1970s to the late 1990s. Subsidence estimated through the simulations is calculated for production within the last twenty years. In Table 4.1 subsidence from petroleum production within the Harris-Galveston region in the last twenty years is measurable. These estimates are conservative in that the overlap of subsidence bowls between neighboring fields is not taken into account, which would produce larger values of subsidence. 
The subsidence caused by oil and gas production on these fields is not large compared to subsidence caused by groundwater withdrawal. However, they are detectable by traditional methods such as benchmark releveling and extensometers.

From Chapter 3 we have shown that all of the fields in the study area have been depressurized significantly, in some cases with a loss of equivalent head levels up to $2000 \mathrm{~m}$ (6562 ft). Simulation results of subsidence caused by compaction of clays within and bounding the reservoir produce estimates of subsidence up to $30.00 \mathrm{~cm}(0.98 \mathrm{ft})$, with average amounts of subsidence around $13.00 \mathrm{~cm}$ (5.12 in). It is clear from the data shown in Chapters 3 and 4 that depressurization and subsequent subsidence above oil and gas fields within the Harris-Galveston region is occurring at measurable rates due to petroleum production. The question now lies whether subsidence above these fields are localized or regional. The following chapter uses $1^{\text {st }}$ order releveling lines to determine whether there is a regional trend of subsidence in the study area due to petroleum production.

\section{Sources of Error}

Results from our simulations compare well with other studies in the Gulf Coast considering subsidence from oil and gas production (Germiat and Sharp, 1990; Helm, 1984; Sharp and Hill, 1995). Sharp and Hill (1995) found up to 40 $\mathrm{cm}$ of subsidence in the Big Hill and Fannett Fields of Jefferson County, Texas. Potential sources of error in our simulations include data uncertainties for vertical 
hydraulic conductivity $(K)$, nonrecoverable storativity $\left(S_{\text {skv }}\right)$, reservoir radius $(R)$, and clay thickness (b).

Now consider the calculation of $S_{\text {skv }}$. Helm (1984) states that estimates of $\mathrm{S}_{\text {skv }}$ within $2000 \mathrm{~m}(6562 \mathrm{ft})$ of the land surface are "high but reasonable." The values of $S_{\text {skv }}$ obtained from simulations compared favorably to similar studies in the literature (Freeze and Cherry, 1979; Sharp and Hill, 1995). Because our estimates of subsidence and storativity are comparable to values obtained in previous studies, we have confidence in our results for $S_{\text {skv }}$.

The estimation of cumulative clay thickness (b) is another source of error. Electric logs were used to determine a value for b. Logs for the fields were difficult to locate, and many were difficult to read because of the scale used in the $\log$. The scaling on these logs was large, and b was estimated as a lower value to obtain a lower limit for clay thickness. Values for $\mathrm{b}$ are conservative and may in fact be greater, increasing the amount of subsidence estimated due to scale effects. A final source of error is attributed to the time span of subsidence to occur $(\tau)$. The question that arises, is all of the compaction from pumping petroleum during the mid 1970 s to the late 1990 s complete? Values for $\tau$ were found to be on the order of decades up to centuries. It is plausible that the clays have not yet equilibrated and further compaction may still occur, and result in subsidence greater than predicted.

\section{Sensitivity Analysis}

Sensitivity analysis was conducted to understand the sensitivity of reservoir depth, vertical hydraulic conductivity, decline in pressure, and 
cumulative clay thickness. The first sensitivity analysis considered reservoir depth. Reservoir depth was increased from $1.00 \mathrm{~m}(3.28 \mathrm{ft})$ to $100000 \mathrm{~m}(3.28 \mathrm{E}$ $05 \mathrm{ft}$ ). Figure 4.1 uses the inputs into the model as well as varying values of reservoir depth versus porosity, time span of subsidence, and total subsidence. In Figure 4.1 an increasing depth to the reservoir produced a decrease in porosity with a log-normal trend. We would expect that increasing depths, higher pressures, and more compaction of sediment would cause a decrease in porosity. Although the decrease in porosity is greater at depth, attenuation of compaction decreases with depth, and clays equilibrate slower closer to the surface. Thus, compaction at depth will have less effect on subsidence than compaction at the surface.

Sensitivity analysis performed on vertical hydraulic conductivity ranging from $10^{-8} \mathrm{~m} \mathrm{~s}^{-1}\left(2.84 \mathrm{E}-03 \mathrm{ft} \mathrm{day}^{-1}\right)$ to $10^{-18} \mathrm{~m} \mathrm{~s}^{-1}\left(2.84 \mathrm{E}-13 \mathrm{ft} \mathrm{day}^{-1}\right)$ is shown in Figure 4.2. Figure 4.2 has a logarithmic trend of decreasing time of equilibration with an increase in conductivity. Because $\mathrm{K}=10^{-14} \mathrm{~m} \mathrm{~s}^{-1}$ produced a decadal time scale, $10^{-14} \mathrm{~m} \mathrm{~s}^{-1}$ was chosen for estimating subsidence.

Analysis of varying pressure declines versus effective stress and total subsidence is shown in Figure 4.3. Pressures were varied from 1 psi $(6.9 \mathrm{~Pa})$ to 100000 psi $(6.9 \mathrm{E} 08 \mathrm{~Pa})$. In Figure 4.3 there is a logarithmic trend in increasing effective stress from increasing pressure. Likewise there is a logarithmic increase in subsidence vs. pressure. This appears to be consistent with Terzaghi's law (Equation 1.1). An increase in effective stress causes an increase in compaction therefore increasing subsidence. 


\section{Constants}

Vert K $(\mathrm{m} / \mathrm{s})$

Rerservoir thickness $(\mathrm{m})$

Cum. clay thickness (m)

Largest clay thickness $(\mathrm{m})$

Specific gravity

Delta P (PSI)

Poisson's ratio

Young's modulus (Pa)

Reservoir radius $(\mathrm{m})$

Time of calculation (Years)

Thickness above/below res (m)
Variables

1.00E-14

20

Depth to reservoir $(\mathrm{m})$

1

10

100

1000

10000

100000

$1.00 \mathrm{E}+09$

1000

20

1

Effects On Porosity With Variable Reservoir Depth

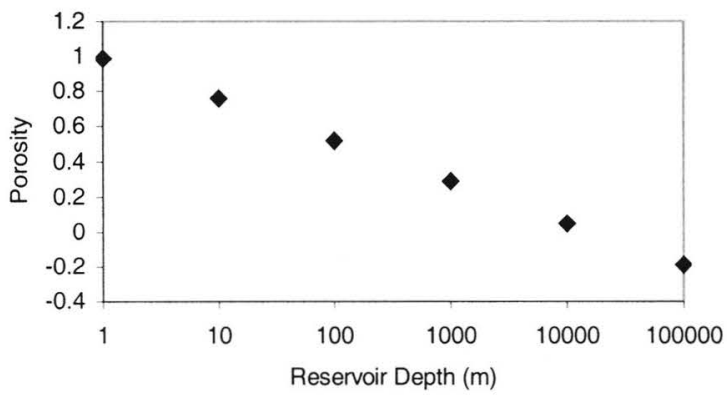

Effects on Equilibration of Clays With Variable Reservoir Depth

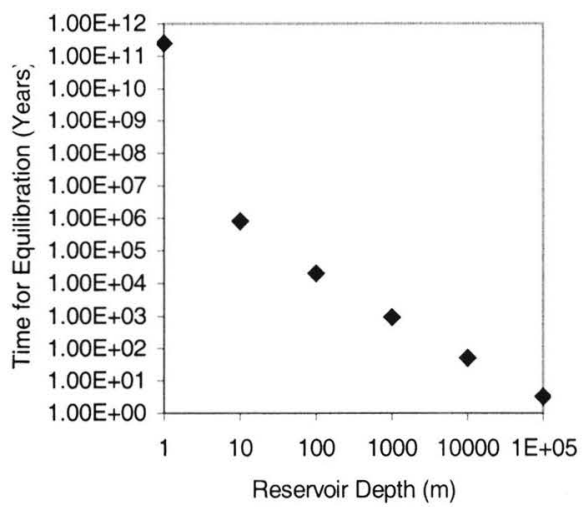

Effects On Total Subsidence With Variable Reservoir Depth

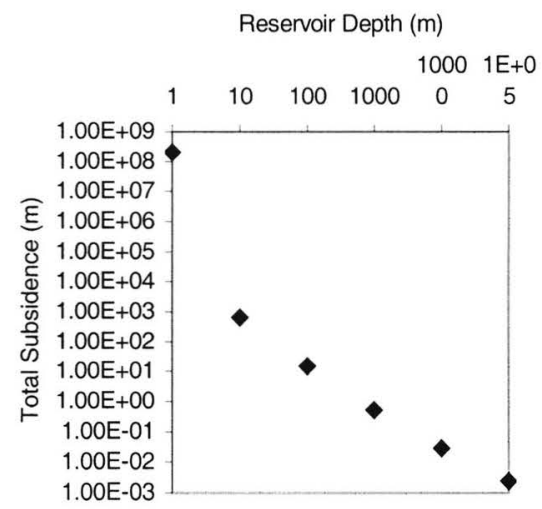

Figure 4.1 Sensitivity analysis of reservoir depth 
Constants

Reservoir thickness (m)

Depth to Reservoir (m)

Cum. clay thickness (m)

Largest clay thickness (m)

Specific gravity

Delta P (PSI)

Poisson's ratio

Young's modulus $(\mathrm{Pa})$

Reservoir radius $(\mathrm{m})$

Time of calculation (Years)

Thickness above/below res (m)
$2.00 \mathrm{E}+01$

2200

8

3

2.6

1000

0.3

$1.00 \mathrm{E}+09$

1000

200
Variables

Vert K $(\mathrm{m} / \mathrm{s})$

1.00E-08

$1.00 \mathrm{E}-10$

$1.00 \mathrm{E}-12$

$1.00 \mathrm{E}-14$

$1.00 \mathrm{E}-16$

$1.00 \mathrm{E}-18$

\section{Effects On Time for Clay Equilibration With Variable Vertical}

Hydraulic Conductivity

Vertical Hydraulic Conductivity $(\mathrm{m} / \mathrm{s})$

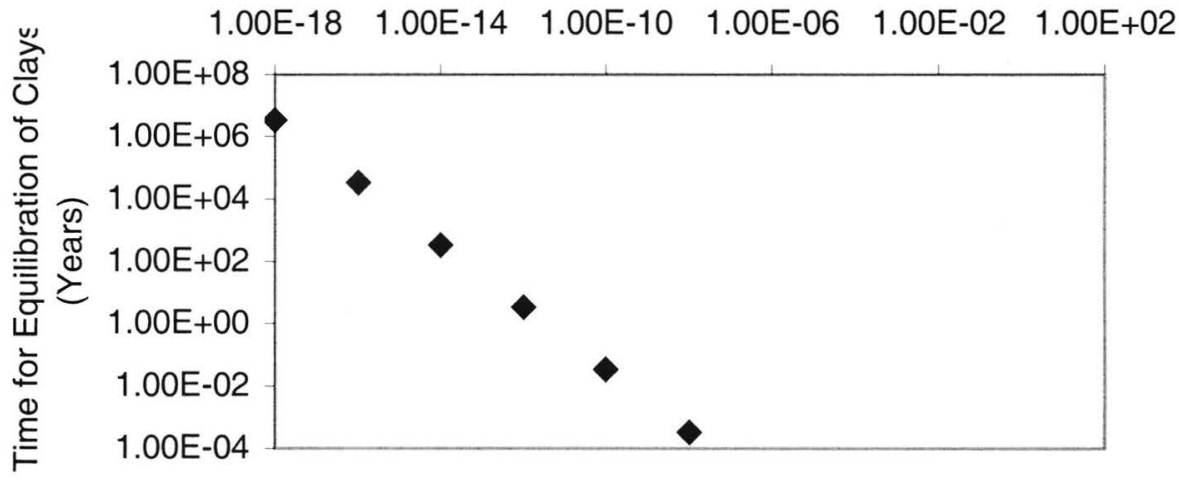

Figure 4.2 Sensitivity analysis of vertical hydraulic conductivity 
Constants

Vert K $(\mathrm{m} / \mathrm{s})$

Depth to Reservoir (m)

Cum. clay thickness $(\mathrm{m})$

Largest clay thickness (m)

Specific gravity

Reservoir thickness (m)

Poisson's ratio

Young's modulus $(\mathrm{Pa})$

Reservoir radius $(\mathrm{m})$

Time of calculation (Years)

Thickness above/below res (m)

\section{Variables}

1.00E-14

2200

Delta P (PSI)

8

3

2.6

20

0.3

$1.00 \mathrm{E}+09$

1000

20

1

Effects On Effective Stress $W$ ith Variable Delta

Pressure

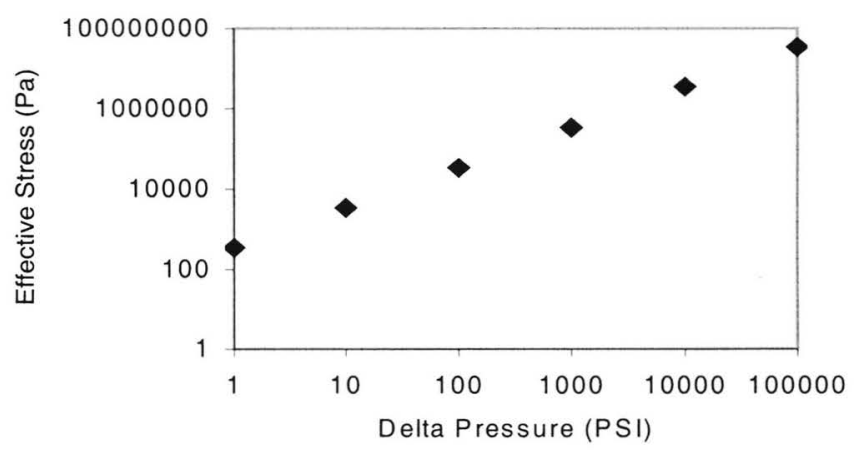

Effects On Total Subsidence With Variable Delta

Pressure

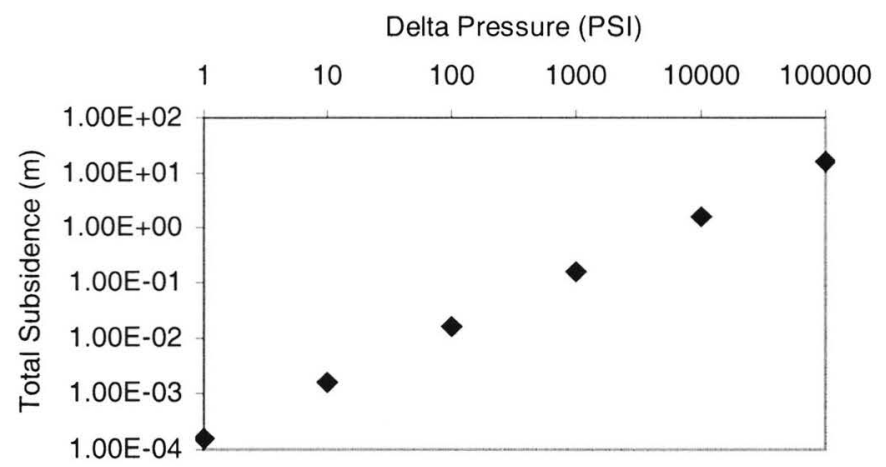

Figure 4.3 Sensitivity analysis of pressure decline 
Analysis of varying cumulative clay thickness from $0.5 \mathrm{~m}(1.6 \mathrm{ft})$ to $9.0 \mathrm{~m}$ $(29.5 \mathrm{ft})$ is shown in Figure 4.4. The largest clay layer (LARC) was set at half the thickness of the total clay thickness (CUMC). On a linear scale an exponential trend is found with time equilibration of clays. As clay thickness increases, the time for clay equilibration increases. Total subsidence increases linearly with an increase in clay thickness as well. As stated before, more compaction will occur in thicker clays.

From the sensitivity analyses, we conclude that the key variables in estimating subsidence are clay thicknesses within the reservoirs, pressure decline, and reservoir depth. Data acquired for estimation of subsidence above petroleum fields in the Harris-Galveston region for reservoir depth and pressure were acquired from field measurements. The values for depth and pressure up to an error of $5 \%$ would not dramatically alter the estimate of subsidence. Clay thickness obtained through electric $\operatorname{logs}$ is a more sensitive parameter than reservoir depth and pressure. Subsidence varies greatly with a small difference in clay thickness. Clay thickness estimates were low (thin) because of scaling effects on logs. When modeling subsidence, it is important to have accurate estimates of clay thickness and to acquire as many electric logs as possible. 
Constants

Vert $\mathrm{K}(\mathrm{m} / \mathrm{s})$

Depth to Reservoir (m)

Reservoir thickness (m)

Specific gravity

Delta P (PSI)

Poisson's ratio

Young's modulus $(\mathrm{Pa})$

Reservoir radius $(\mathrm{m})$

Time of calculation (Years)

Thickness above/below res $(\mathrm{m})$

\section{Variables}

1.00E-14

2200

20

3

2.6

1000

0.3

$1.00 \mathrm{E}+09$

1000

20

1
Cum. clay thickness $(\mathrm{m})$

0.5

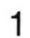

3

5

7

9

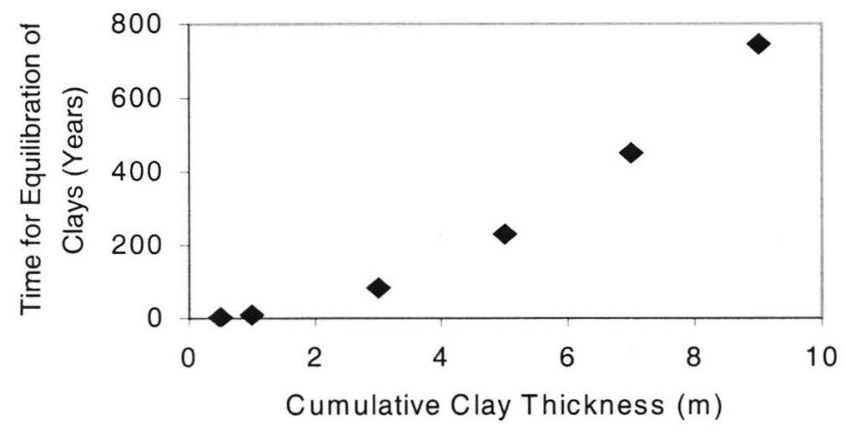

Effects On Total Subsidence W ith Variable Cum.

Clay Thickness (LARC $=.5 \mathrm{CUMC}$ )

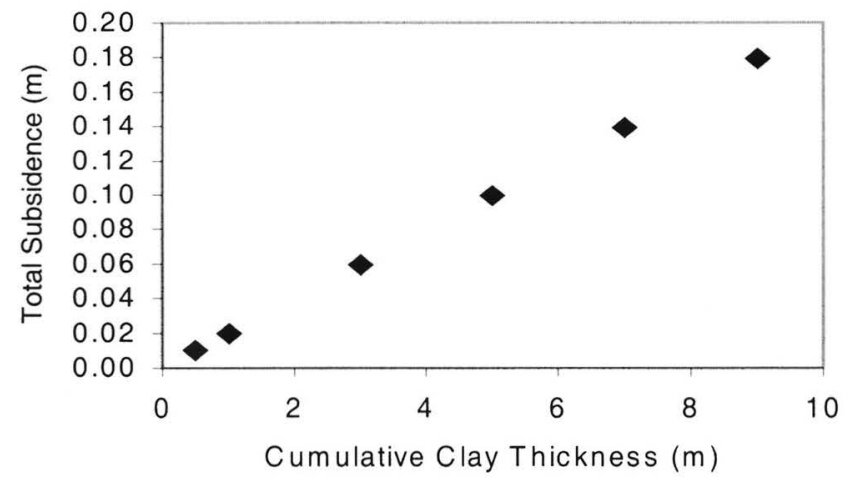

Figure 4.4 Sensitivity analysis of cumulative clay thickness 


\section{Chapter 5: Benchmark data}

The model results and BHP data discussed in the previous chapters indicate that subsidence should be occurring above oil and gas fields in the Harris-Galveston region. The subsidence is measurable and detectable in most cases. To quantify regional subsidence, it is important to determine the regional extent of subsidence from petroleum production. This is also important for urban planning and management. Presently, in Harris and Galveston Counties, groundwater withdrawal is minimal because surface water is used as the major source of water. Thus, subsidence from groundwater withdrawal is not a major factor for planning future infrastructure such as roads and bridges. In contrast, understanding whether subsidence from oil and gas production is localized or regional then becomes important in municipal planning. The radius of influence of oil and gas fields, therefore, should be mapped and quantified. This chapter discusses the use of $1^{\text {st }}$ order releveling data acquired from the National Geodetic Survey (NGS) in determining whether subsidence above petroleum fields in the Harris-Galveston region is local or regional.

\section{Methodology and Background}

First-order releveling data were acquired from the NGS and used to construct cross-sections along a line of oil and gas fields in the study area to determine the extent of subsidence bowls above these fields. Releveling lines are composed of point benchmarks located along the line. Benchmarks have been installed and used to calculate subsidence in the Harris-Galveston region since the 
early 1900s. Today, subsidence is mapped with the use of the global positioning system (GPS), making subsidence maps of a region quicker and easier to produce.

Benchmarks are metal discs that are set into concrete in stable ground. The elevation of a benchmark is taken at a point in time and measured again at a later time. The difference in elevation between the two time periods is the change in elevation over that time period. Benchmarks do not measure an absolute difference in elevation, but rather reflect relative change in elevation. This is because elevation measurements of a line of benchmarks are taken with respect to a common benchmark. So, the actual difference in elevation is with respect to the common benchmark and not sea level. The common benchmark is chosen at a point where the ground is thought to be stable.

Four cross-sections were constructed along a line of oil and gas fields spread across Harris and Galveston Counties. Leveling lines were chosen based on two criteria. The first is that at least one benchmark along a leveling line must be within an oil and gas field, and the second is that the comparative measurements must have occurred in the time period mid 1970 s to present. The second criterion allows correlation of subsidence from model runs and benchmark data. These criteria made it difficult to construct more than four cross-sections for characterizing the extent of subsidence throughout the entire Harris-Galveston region. More lines of benchmarks would have fit these criteria if the same leveling lines were measured at two different time periods. This problem arises when benchmarks measured along one leveling line are not measured at a later point in time along the same leveling line. Benchmarks must be cross-referenced 
in a database to find leveling lines measured at different times and containing many of the same benchmarks. Then, a third line of benchmarks must be created containing common benchmarks to the previous leveling lines. From this final leveling line, a cross-section is created that includes the horizontal distance from a common benchmark in the $\mathrm{x}$-axis versus a relative rate of elevation change in the $\mathrm{z}$-direction (elevation $*$ time $^{-1}$ ) in the $y$-axis.

\section{Results}

Figure 5.1 shows the line of benchmarks for leveling lines L-17497 and L24406. The line starts near Galveston Bay in eastern Galveston County and runs through southeast Harris County. Benchmarks contained within the line run through six oil and gas fields, which include the Galveston, South Gillock, Gillock, Taylor Lake East, Taylor Lake, and Goose Creek Fields. Figure 5.2 depicts the cross-section of the leveling line across these fields with the location of the oil and gas fields and the model estimates of subsidence rates in parentheses along the cross-section. The common benchmark in this line is C1138 with the time period of measurement from 1959 to 1978. On a small scale, subsidence bowls can be found above fields around the Galveston and South Gillock Fields, the Gillock Field, the Taylor Lake East Field (T.L.E.), the Taylor Lake Field and the Goose Creek Field. Benchmarks were inspected in the field as to their stability and history. Most of the benchmarks were found to be stable except for the few indicated by dashed lines in Figure 5.2. The benchmarks connected by dashed lines were unstable because they were located on bridges or 


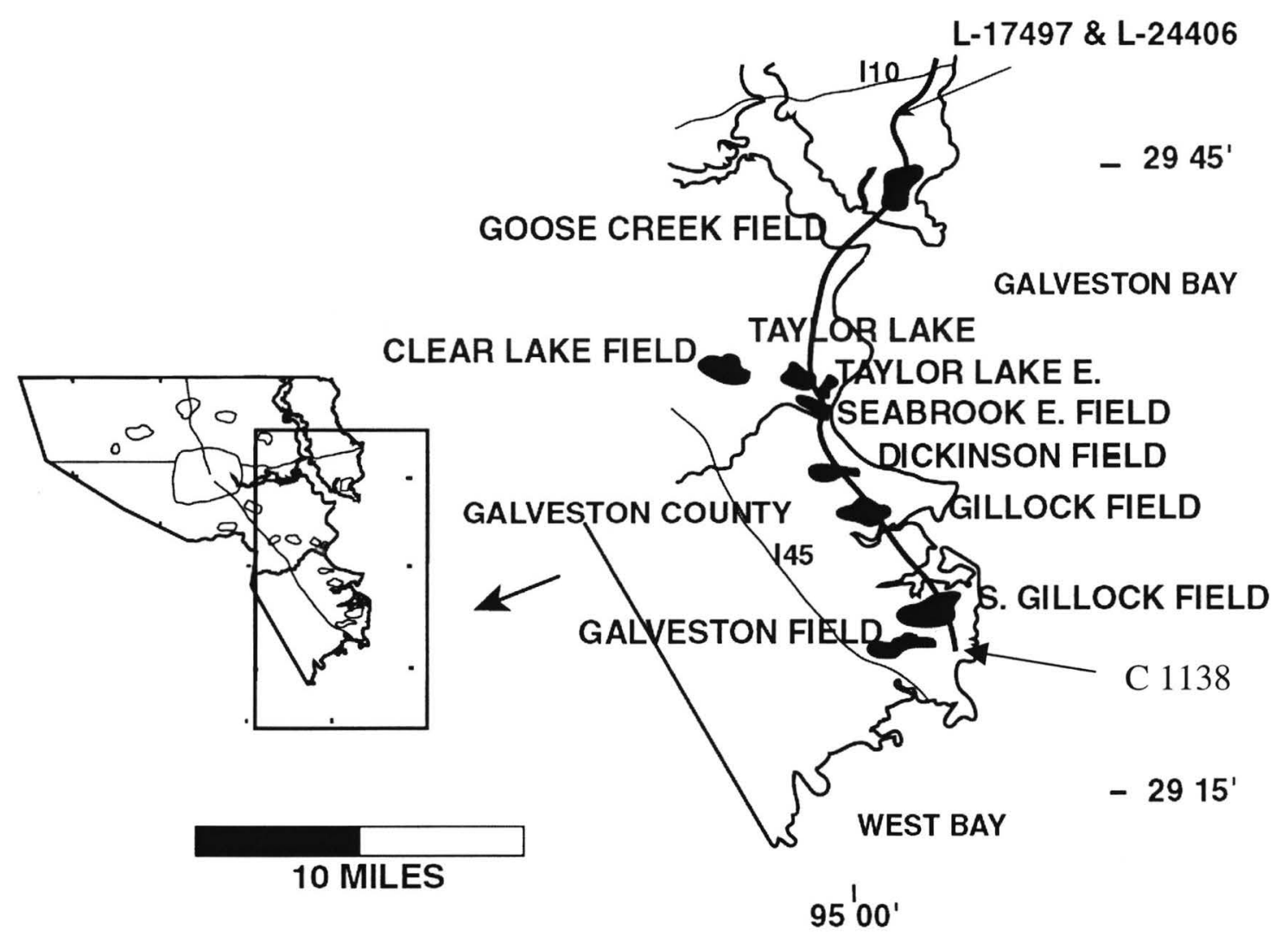

Figure 5.1 Map showing placement of leveling lines L-17497 and L-24406 


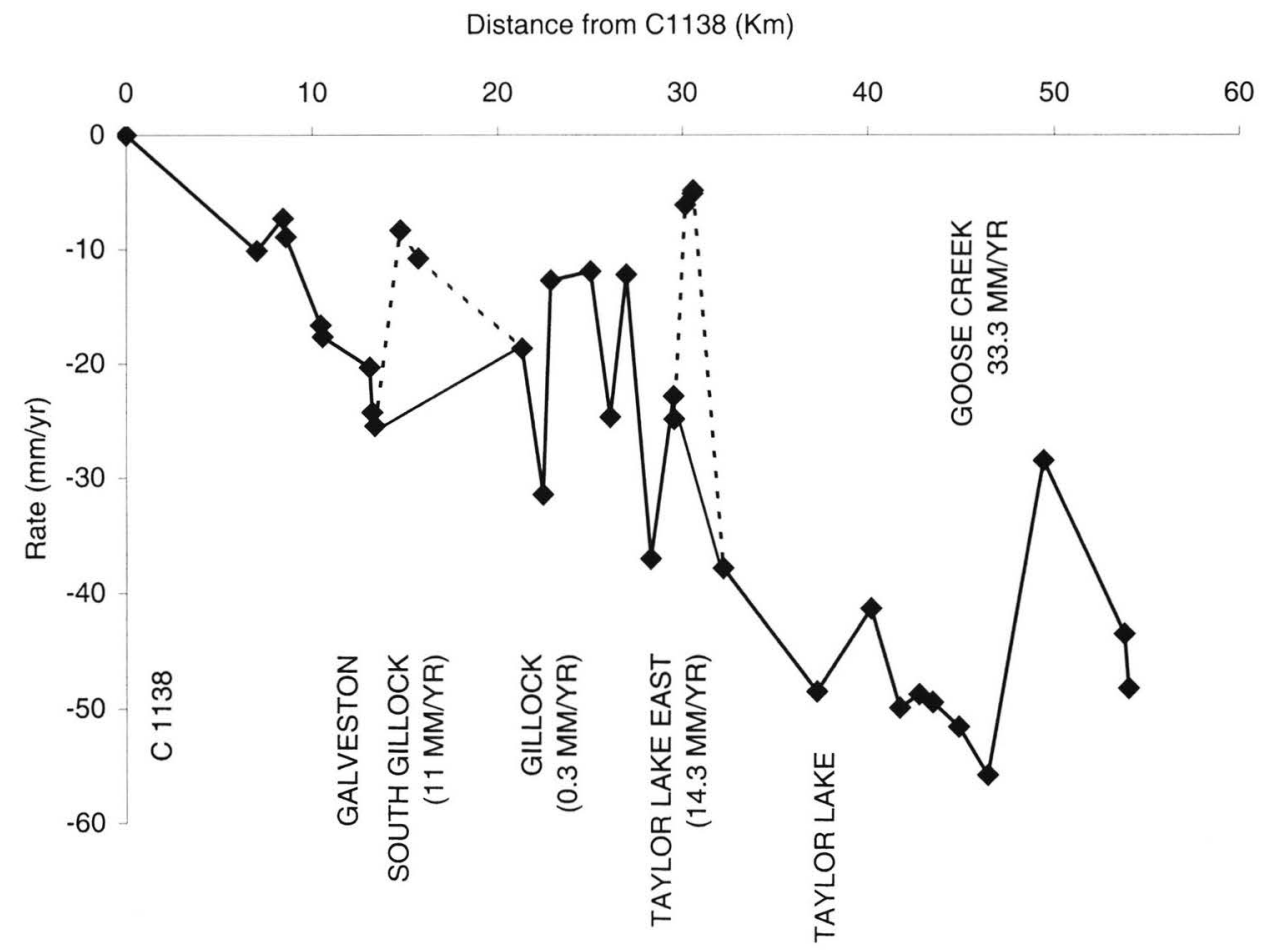

Figure 5.2 Relative rates of vertical movement relative to benchmark C1138. Subsidence estimates from the model are shown in parentheses. The dashed line indicates "unstable" benchmarks. 
had construction above them. A benchmark located on a bridge is unstable because maintenance of the bridge including construction disrupts the original setting and elevation of the benchmark. In some cases these benchmarks were moved. Ignoring these unstable benchmarks, a larger regional scale subsidence bowl can be traced as indicated by the solid line. One possible cause for this regional bowl of subsidence is from the combination of all the petroleum fields along the line as well as neighboring fields located next to the line. From Figure 5.2 , two scales of subsidence are visible, a local scale on the order of about 5.0 $\mathrm{km}$ (3.1 miles) and a larger regional scale on the order of 40.0-60.0 km (24.9-37.3 miles). Figure 5.2 shows a trend of increasing subsidence along the coast moving northeast.

In Figure 5.3 is the line of benchmarks for leveling lines L-13947 and L22990. The cross-section shown in Figure 5.4 runs through central Galveston County to southern Harris County. The Webster Northeast, Webster, Pearce Lake, and South Gillock Fields are located along this cross-section. The time period of this cross-section is 1951-1973. From Figure 5.4 small-scale subsidence bowls are present on the order of 2.0-5.0 km (1.2-3.1 miles) as well as a regional trend (on the order of $35.0-40.0 \mathrm{~km} ; 21.7-24.9$ miles) from the combination of neighboring fields. Figure 5.4 shows a trend of increasing subsidence towards the coast.

The line of benchmarks for leveling lines L-17494 and L-24742/1 are in Figure 5.5. The cross-section runs through northern Harris County through the West Clinton, Clinton, and Sword Fields. Figure 5.6 is the cross-section of this 


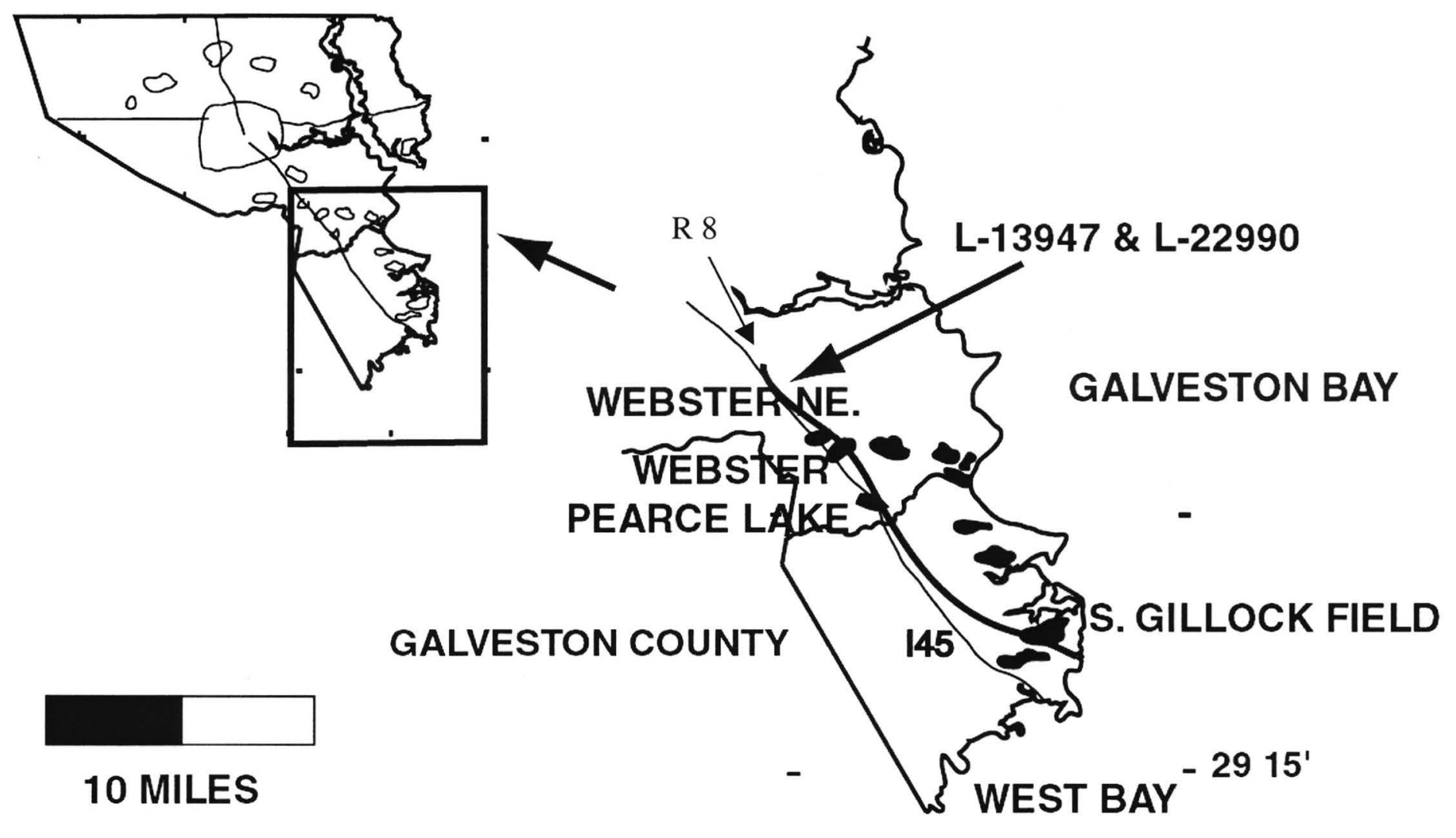

Figure 5.3 Map showing placement of leveling lines L-13947 and L-22990 


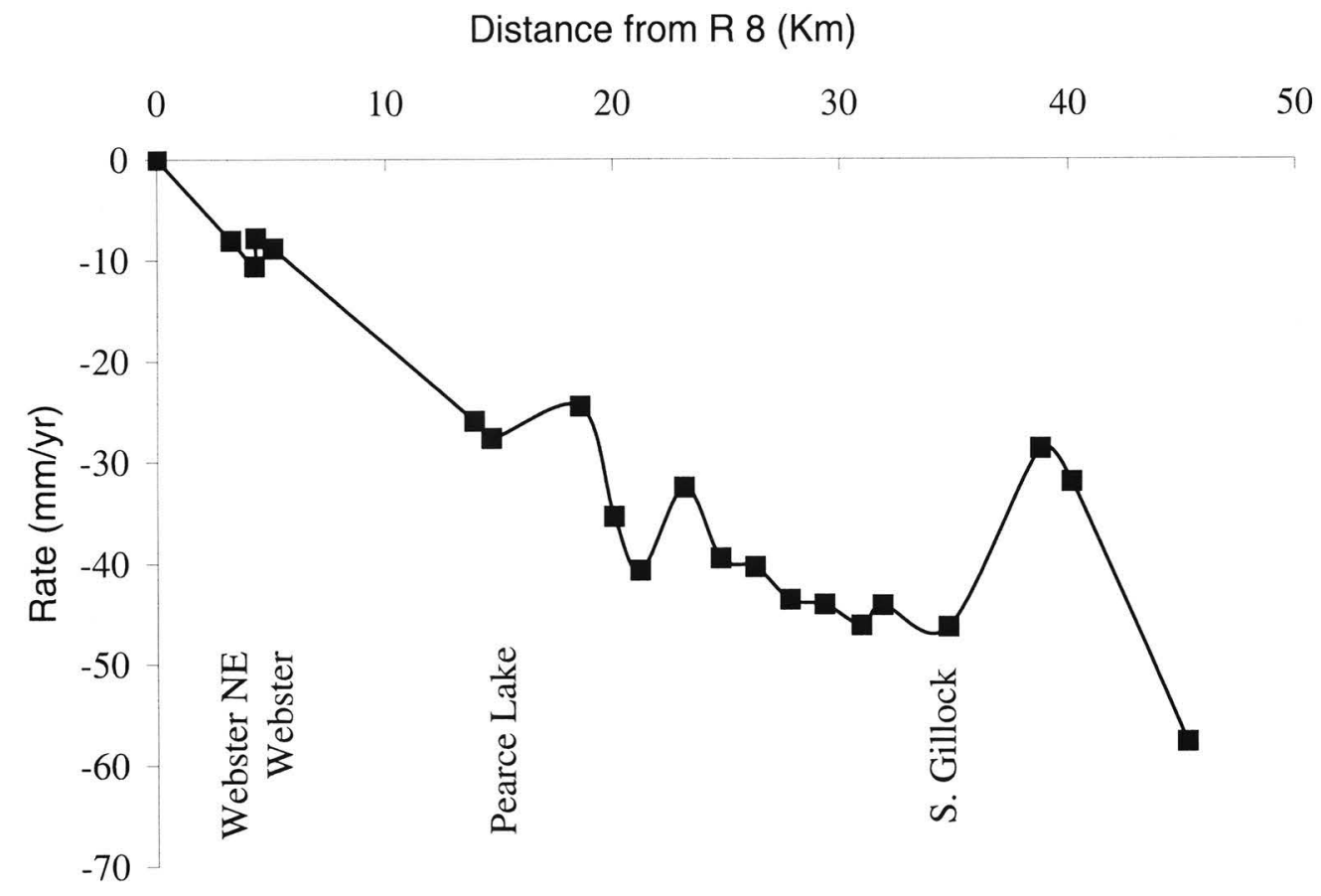

Figure 5.4 Relative rates of vertical movement relative to benchmark R8 

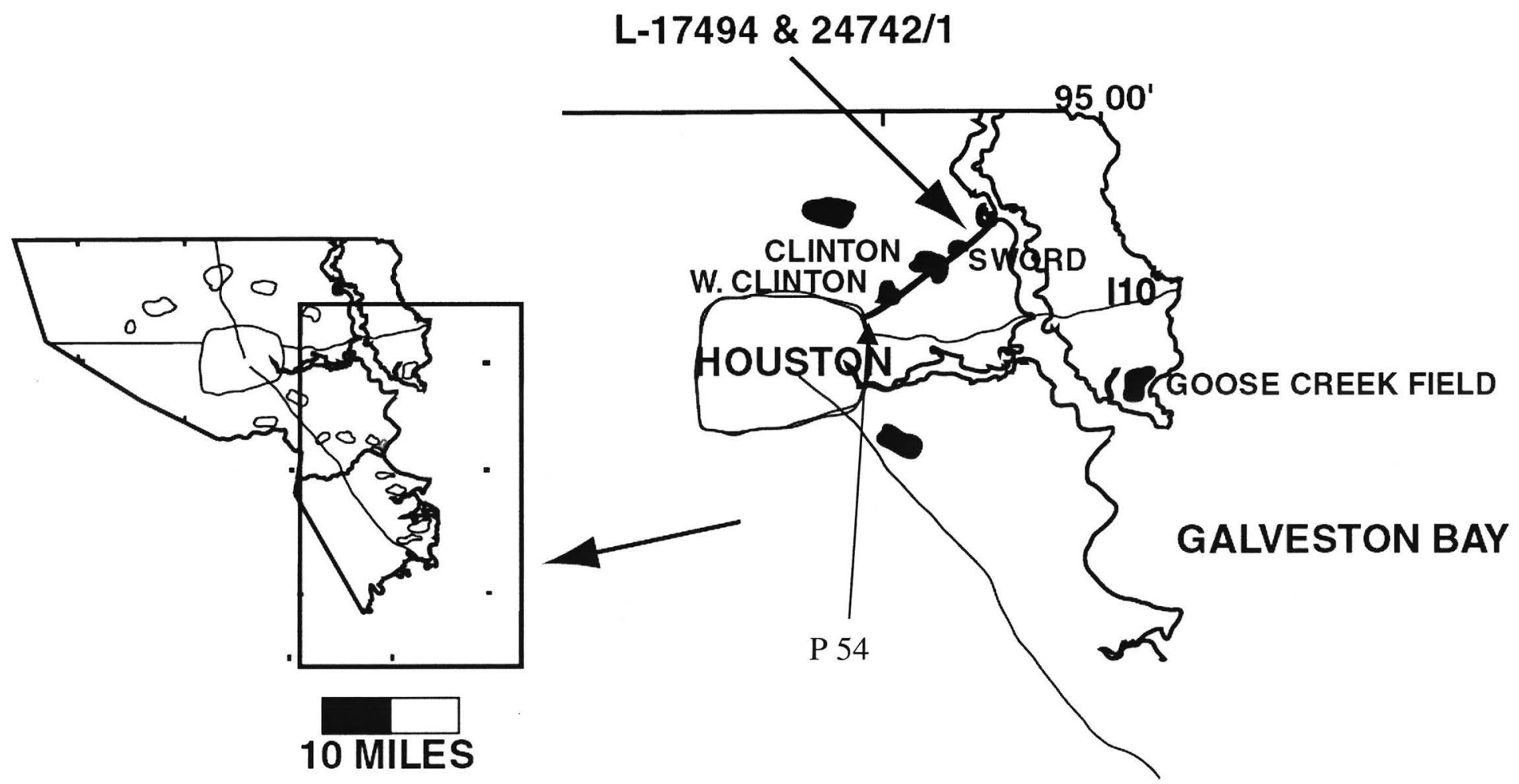

Figure 5.5 Map showing placement of leveling lines L-17494 and L-24742/1 


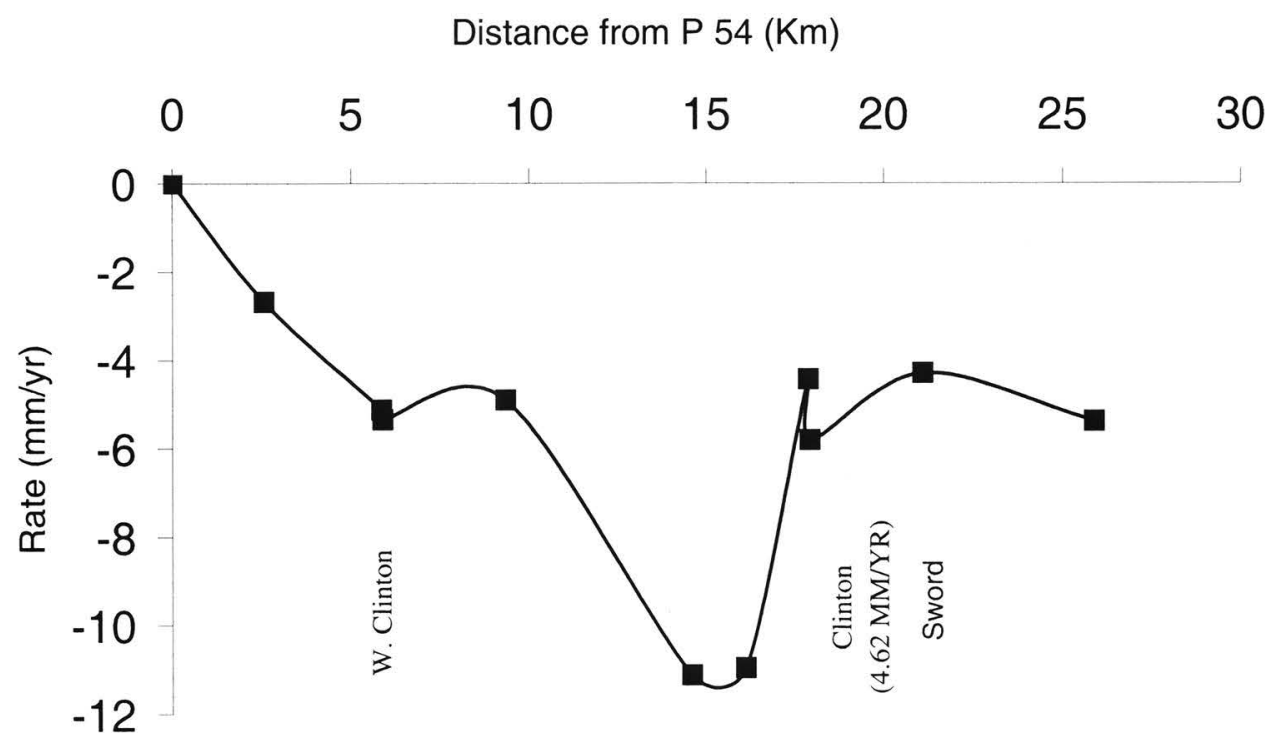

Figure 5.6 Relative rates of vertical movement relative to benchmark P54. Subsidence estimates from the model are shown in parentheses. 
line from 1959 to 1983 . Subsidence bowls are evident on a small scale $(\sim 3.0 \mathrm{~km}$; 1.9 miles) near the West Clinton and Clinton Fields, but no regional trend is apparent in this cross-section. This lack of a regional trend in Figure 5.6 compared to the other leveling lines examined may arise from the amount of subsidence above these fields. The Clinton Field had a calculated subsidence

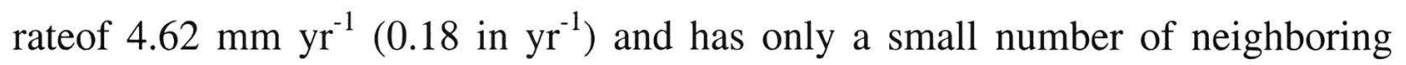
fields. The density of petroleum fields in the previous two cross-sections (Figs. 5.4 and 5.2) is much greater than in Figure 5.6. Hence, the low density of nearby oil and gas fields may account for the lack of a regional trend along this leveling line.

In Figure 5.7 is the line of benchmarks for leveling lines L-17497 and L19672. The cross-section runs through central Harris County east of Loop 610 to Galveston Bay. The cross-section shown in Figure 5.8 is from 1959 to 1964. This cross-section is not taken for the same time period as subsidence estimates were calculated, but was constructed to show the regional trend of subsidence around neighboring oil and gas fields. In Figure 5.8 a regional subsidence bowl can be found above the Goose Creek, Lynchburg, Greens Bayou, and South Houston Fields on the order of $50.0 \mathrm{~km}$ (31.1 miles). During this time period, groundwater was used as the major source of water in the Harris-Galveston region. Subsidence rates shown in Figure 5.8 may contain a groundwater component, although the location of the regional subsidence bowl is centered above these four petroleum fields with a number of neighboring fields located close to the cross-section line. Because of the location of the subsidence bowl, it 


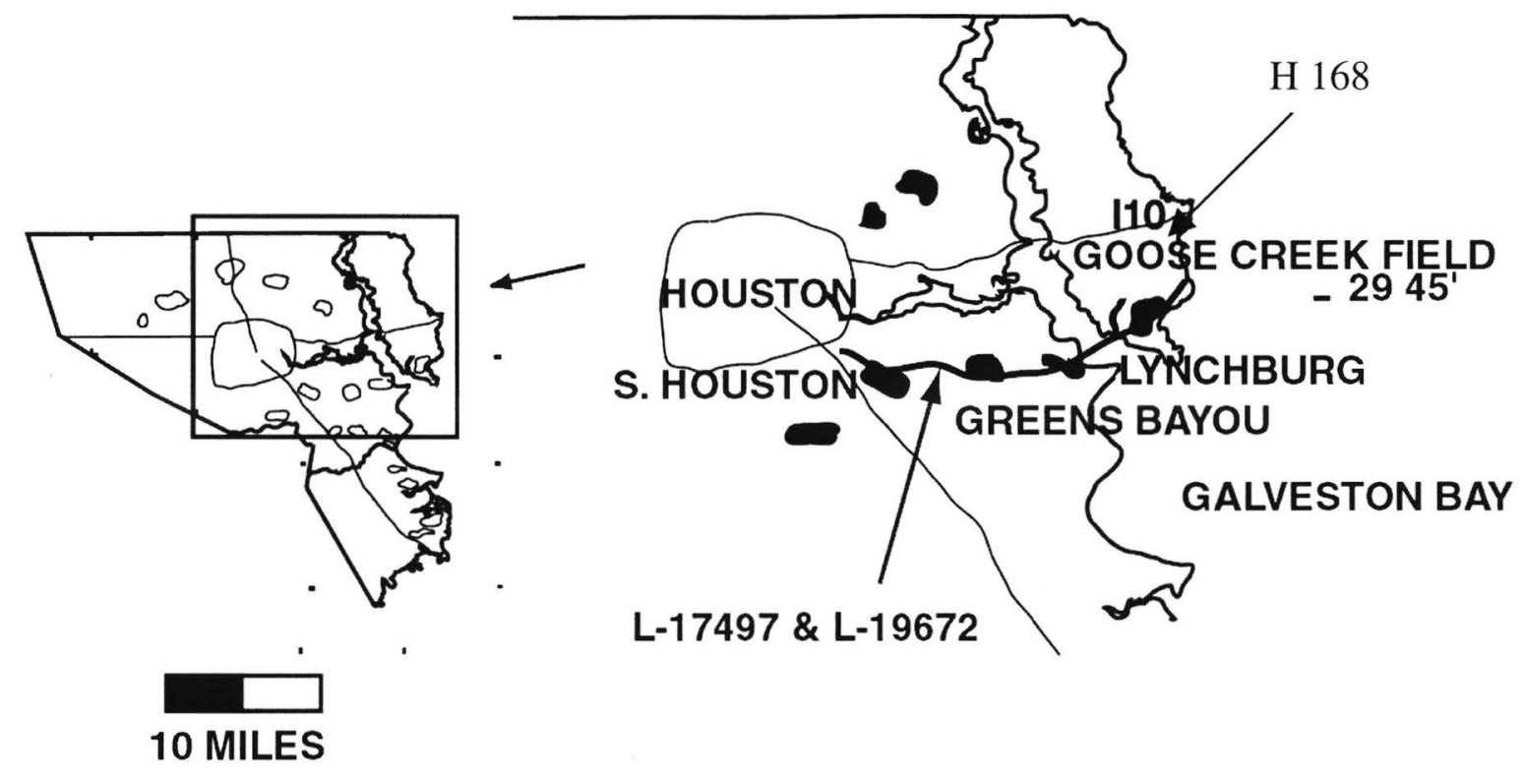

Figure 5.7 Map showing placement of leveling lines L-17497 and L-19672 


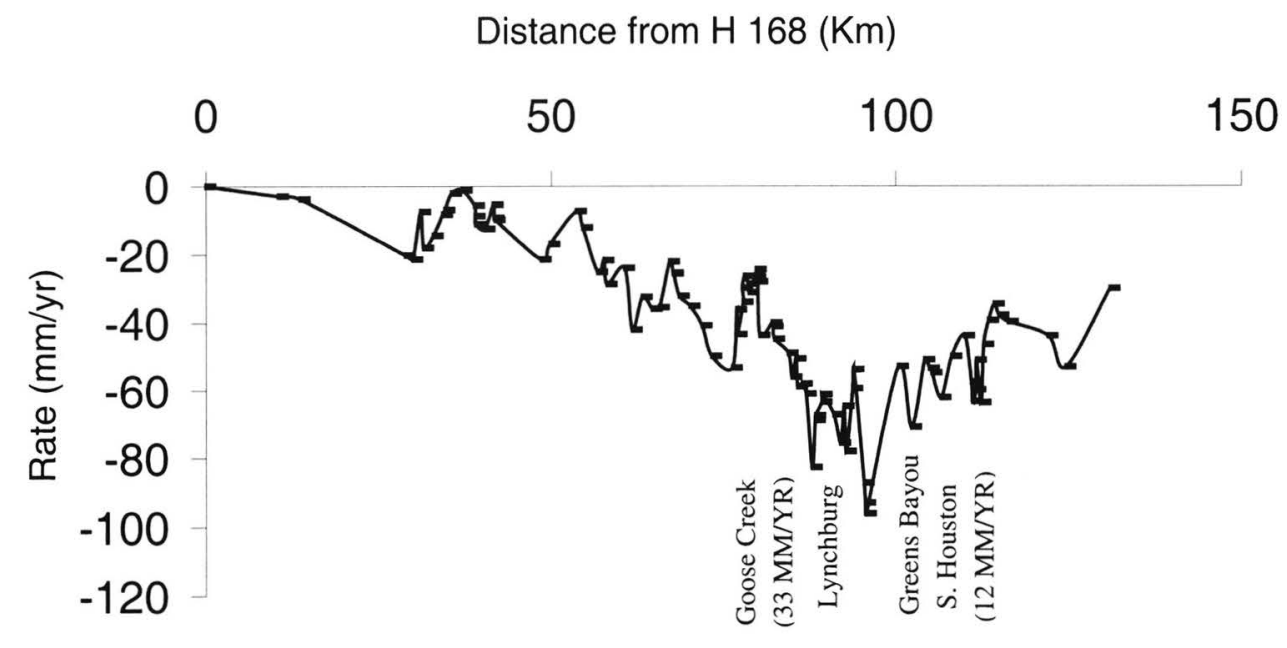

Figure 5.8 Relative rates of vertical movement relative to benchmark H168. Subsidence estimates from the model are shown in parentheses. 
is possible to infer that petroleum production is contributing to this regional trend of subsidence.

In many of the cross-sections, relative rates calculated from benchmarks do not match model estimates of subsidence rates. This difference in elevation rates can be attributed to the way elevation differences are measured with benchmarks. Benchmark elevation is calculated with respect to a common benchmark and not sea level. Therefore, differences in elevation will be skewed somewhat from actual elevation differences. Measuring actual rates of elevation change from benchmarks is not of importance in this chapter. The importance of the benchmark data is to show location of subsidence bowls above oil and gas fields and their relationships to subsidence bowls in neighboring fields. The cross-sections show subsidence bowls occurring above petroleum fields in the Harris-Galveston region on two scales. The local radius of influence around an oil or gas field on a local scale ranges from 2.0 to $5.0 \mathrm{~km}$ (1.2 to $3.1 \mathrm{miles})$. There is also a regional scale of subsidence caused by the combination of neighboring fields both on the cross-section line and adjacent to the cross-section line on the order of 35.0 to $60.0 \mathrm{~km}$ (21.7 to 37.3 miles). The regional trend of subsidence, from the benchmark data, is an increasing trend towards the coast and along the coast going northeast. It should be noted that there is a contribution to these regional trends of subsidence from groundwater withdrawal. Groundwater production was occurring during the time periods that these cross-sections reflect. However, regional scale subsidence bowls link nearby oil and gas fields, implying 
that petroleum production specifically contributes a substantial portion to the regional trend of subsidence.

The benchmark data made it possible for subsidence to be analyzed qualitatively as to the radius of influence around an oil or gas field. Regional versus local scales cannot be quantitatively analyzed because benchmark data is measured in relative elevations with respect to a common benchmark and not in actual differences of elevation. Chapters 3 and 4 showed that during the mid 1970 s to the late 1990 s large amounts of depressurization caused by oil and gas production in the study area have caused measurable amounts of subsidence. In Chapter 5, benchmark data show that there is a regional trend of subsidence caused by the withdrawal of oil and gas in the Harris-Galveston region. The contribution of groundwater withdrawal and petroleum production to the total amount of subsidence should be analyzed further. Chapter 6 estimates the amount subsidence at a point above oil and gas fields in the study area to understand the contribution of groundwater withdrawal and petroleum production to the total amount of subsidence. 


\section{Chapter 6: Point estimation of subsidence from groundwater and petroleum production}

It has been shown in Chapter 3 from BHP data, in Chapter 4 from modeling of subsidence, and in Chapter 5 from benchmark data that depressurization and subsequent subsidence has occurred in the Harris-Galveston region from petroleum production and that there is a regional trend over part of the study area between the mid 1970s to the late 1990s. Groundwater production decreased substantially over a majority of the study area starting in 1972. In this chapter we quantify, at points above oil and gas fields, the separate contribution to the total subsidence by petroleum production and by groundwater withdrawal.

\section{Methodology}

Well data from oil and gas wells obtained from the Texas Railroad Commission, subsidence estimates from model results, and well data from groundwater wells obtained from the USGS (Gandara et al., 1996) were used to quantify at single points the amount of subsidence contributed separately by groundwater and by petroleum production. Within the Harris-Galveston region the Chicot and Evangeline aquifers have provided groundwater to the area. From water well data a change in head and the depth of the well were obtained from the USGS. Water wells in the vicinity of petroleum wells formed a total of 12 sets of points with each point signifying a groundwater and a petroleum component. The depth to the reservoir and a converted decline in head from an oil or gas well within the petroleum field were used to calculate a gradient ( $\mathrm{dh} \mathrm{z}^{-1}$ ) of change in 
head (dh) with depth (z). This head gradient was also calculated for water wells located within both the Chicot and Evangeline aquifers.

A spreadsheet consisting of gradients of decline in head with depth as well as subsidence estimates from model runs for oil and gas fields were the basis of our analysis. Recall that subsidence estimates are from the mid 1970s to the late 1990s, so changes in head were obtained for water wells between the years 1977 to 1997. Total subsidence in the Harris-Galveston region at each of the twelve points was then added to the spreadsheet. The values for total subsidence were obtained from maps developed from benchmark data, GPS data, and extensometer data by the Harris-Galveston Coastal Subsidence District (HGCSD) for the years 1978 to 1995 . The total amount of subsidence caused by groundwater production during this time span is then calculated as the difference between the total subsidence minus the subsidence caused by petroleum production. Certain assumptions were made for the calculation of the contributions to total subsidence caused by groundwater withdrawal and petroleum production, including:

- Time periods for petroleum production, groundwater withdrawal, and total subsidence do not exactly overlap. Changes in head levels and subsidence for less than 3 years are assumed to be small. Therefore, our groundwater and total subsidence time series are assumed to take place over the same time period as our petroleum data.

- Natural compaction from sediment loading is assumed to be negligible. Groundwater withdrawal and petroleum production are the only causes of subsidence in the study area. 
From head gradients and estimated subsidence, we graphed the relationships between head gradients and subsidence to detect any connection between depth of well and subsidence. We created graphs for the Chicot Aquifer, Evangeline Aquifer, and oil and gas fields within the Harris-Galveston region. As shown in the sensitivity analysis in Chapter 4, if all other variables and conditions are roughly equal, a deeper reservoir or aquifer will experience less subsidence than a shallow one. From these graphs and a table showing head declines, depths, and subsidence for our 12 points, we estimated the separate contribution to total subsidence from groundwater and from petroleum production.

\section{Results}

Table 6.1 shows the results obtained for head decline, depth to well, total subsidence, subsidence estimates from oil and gas, and the aquifer in which the well resides or whether it is a petroleum well. Head gradients ( $\left.\mathrm{dh} \mathrm{depth}^{-1}\right)$ and the groundwater component of subsidence were calculated as stated earlier. A decline in head is noted as a negative number; an increase in head is positive. If the petroleum component of subsidence at a point was greater than the total subsidence calculated from the HGCSD, then the groundwater component was assumed to equal zero. A larger estimate of subsidence from petroleum production than total subsidence can be attributed to certain factors, including an overestimate of subsidence by our model simulations or an underestimate of total subsidence by the HGCSD. Of these two reasons, total subsidence estimated by the HGCSD appears to be a greater factor in this discrepancy. Total subsidence maps are constructed by the HGCSD from point values of elevation change from 


\begin{tabular}{|c|c|c|c|c|c|c|c|}
\hline $\begin{array}{l}\text { Point above } \\
\text { petroleum field }\end{array}$ & Aquifer & dh (m) & $\begin{array}{l}\text { Depth } \\
\text { (m) }\end{array}$ & dh/depth & $\begin{array}{l}\text { Total } \\
\text { Sub } \\
\text { (cm) }\end{array}$ & $\begin{array}{l}\text { Oil \& } \\
\text { Gas Sub } \\
\text { (cm) }\end{array}$ & $\begin{array}{l}\text { GW } \\
\text { Sub } \\
(\mathbf{c m})\end{array}$ \\
\hline Clear Lake & Oil/Gas & -94.17 & 1840.08 & -0.05 & 12.19 & 3.02 & \\
\hline Clear Lake & Chicot & 39.62 & 188.98 & 0.21 & 12.19 & & 9.17 \\
\hline Clear Lake & Evangeline & 36.58 & 530.35 & 0.07 & 12.19 & & 9.17 \\
\hline Clinton & Oil/Gas & -587.84 & 2699.92 & -0.22 & 15.24 & 12.00 & \\
\hline Clinton & Chicot & 12.19 & 64.01 & 0.19 & 15.24 & & 3.24 \\
\hline Clinton & Evangeline & 18.29 & 435.56 & 0.04 & 15.24 & & 3.24 \\
\hline Durkee North & Oil/Gas & -501.25 & 2429.26 & -0.21 & 45.72 & 6.30 & \\
\hline Durkee North & Chicot & -3.05 & 138.99 & -0.02 & 45.72 & & 39.42 \\
\hline Durkee North & Evangeline & -18.29 & 406.91 & -0.05 & 45.72 & & 39.42 \\
\hline Dyersdale & Oil/Gas & -109.12 & 1079.30 & -0.10 & 45.72 & 2.00 & \\
\hline Dyersdale & Chicot & -3.05 & 143.26 & -0.02 & 45.72 & & 43.72 \\
\hline Dyersdale & Evangeline & -3.05 & 640.08 & -0.01 & 45.72 & & 43.72 \\
\hline Gillock & Oil/Gas & -156.29 & 2575.56 & -0.06 & 12.19 & 0.65 & \\
\hline Gillock & Chicot & 21.34 & 198.42 & 0.11 & 12.19 & & 11.54 \\
\hline Goose Creek & Oil/Gas & -3743.87 & 4174.54 & -0.90 & 12.19 & 30.00 & \\
\hline Goose Creek & Chicot & 33.53 & 118.87 & 0.28 & 12.19 & & 0 \\
\hline Houston South & Oil/Gas & -566.02 & 1615.44 & -0.35 & 15.24 & 11.01 & \\
\hline Houston South & Chicot & 24.38 & 145.39 & 0.17 & 15.24 & & 4.23 \\
\hline Houston South & Evangeline & 51.82 & 371.86 & 0.14 & 15.24 & & 4.23 \\
\hline Mykawa & Oil/Gas & -1113.02 & 1178.97 & -0.94 & 45.72 & 29.00 & \\
\hline Mykawa & Chicot & 18.29 & 152.40 & 0.12 & 45.72 & & 16.72 \\
\hline Mykawa & Evangeline & 39.62 & 396.24 & 0.10 & 45.72 & & 16.72 \\
\hline New Mykawa & Oil/Gas & -1111.62 & 1483.46 & -0.75 & 45.72 & 20.20 & \\
\hline New Mykawa & Chicot & 18.29 & 137.16 & 0.13 & 45.72 & & 25.52 \\
\hline New Mykawa & Evangeline & 42.67 & 303.28 & 0.14 & 45.72 & & 25.52 \\
\hline Satsuma & Oil/Gas & -694.14 & 2317.70 & -0.30 & 76.20 & 4.20 & \\
\hline Satsuma & Chicot & -24.38 & 76.20 & -0.32 & 76.20 & & 32.20 \\
\hline Satsuma & Evangeline & -0.91 & 487.68 & -0.01 & 76.20 & & 32.20 \\
\hline South Gillock & Oil/Gas & -1326.34 & 2663.95 & -0.50 & 12.19 & 22.00 & \\
\hline South Gillock & Chicot & 30.48 & 259.08 & -0.12 & 12.19 & & 0 \\
\hline $\begin{array}{l}\text { Taylor Lake } \\
\text { East }\end{array}$ & Oil/Gas & -2268.28 & 3096.77 & -0.73 & 12.19 & 14.30 & \\
\hline $\begin{array}{l}\text { Taylor Lake } \\
\text { East }\end{array}$ & Chicot & 36.58 & 188.98 & 0.19 & 12.19 & & 0 \\
\hline $\begin{array}{l}\text { Taylor Lake } \\
\text { East }\end{array}$ & Evangeline & 24.38 & 530.35 & 0.05 & 12.19 & & 0 \\
\hline
\end{tabular}

* Note If Oil \& Gas Sub > Total Sub then GW Sub $=0$

Table 6.1 Point estimation of subsidence for groundwater and petroleum withdrawal. Time frame of petroleum measurements are from the mid 70s to late 90s, groundwater head levels are from 1977 to 1997, and total subsidence measurements are from 1978 to 1995 . Negative values represent drop in head. 
extensometer and benchmark points. These data are point estimates of elevation change throughout the Harris-Galveston region. Many of the points are spread far apart from one another, and maps are generated using a contouring method. The values of total subsidence are taken from contour maps of subsidence in the study area. The value given for total subsidence, therefore, does not reflect an exact measurement of elevation change at that point but rather a contoured estimate of subsidence. Values of total subsidence may in fact be greater than those contoured on the map. Subsidence estimates from petroleum production are calculated at that exact point from oil and gas well data. Hence, we have greater confidence in petroleum estimates of subsidence at an exact point than total subsidence taken from contour maps.

In Table 6.1 values for subsidence attributed to groundwater withdrawal are lower than the petroleum component. Subsidence from groundwater ranges from $0.00 \mathrm{~cm}(0.00 \mathrm{ft})$ to $43.72 \mathrm{~cm}(1.43 \mathrm{ft})$ at the Dyersdale Field in both the Chicot and Evangeline Aquifers. The largest values for subsidence from groundwater withdrawal are found at the Dyersdale Field $(43.72 \mathrm{~cm} ; 1.43 \mathrm{ft})$, Durkee North Field $(39.42 \mathrm{~cm} ; 1.29 \mathrm{ft})$, and the Satsuma Field $(32.20 \mathrm{~cm} ; 1.06 \mathrm{ft})$. All three of these fields are located in northern Harris County where petroleum production and petroleum field density is less than in other areas of the HarrisGalveston region. These higher values of subsidence from groundwater withdrawal can be attributed to small amounts of subsidence from oil and gas fields coupled with a low density of petroleum fields in northern Harris County. 
Subsidence from oil and gas production is highest at the Goose Creek Field $(30.00 \mathrm{~cm})$. Other fields with high values of subsidence from petroleum production include the Mykawa Field $(29.00 \mathrm{~cm})$, the South Gillock Field $(22.00$ $\mathrm{cm})$, and the New Mykawa Field $(20.20 \mathrm{~cm})$. These fields are located along a line from southern Harris County to southeast Galveston County. Oil and gas fields are located in this area of high-density petroleum production. Consequently, a higher amount of subsidence would be the result of the high density and high production of oil and gas for over 70 years.

Figure 6.1 shows a plot of head gradient versus subsidence for oil and gas wells in the study area. From Figure 6.1 we note that as the head gradient becomes more negative (decrease in head), subsidence increases. In Figure 6.1 is an inverse linear correlation between head gradient and subsidence, consistent with Chapter 4 that subsidence is driven by head loss, clay thickness and reservoir depth. As pressure or head decreases, more subsidence would be expected at shallower depths than at deeper depths. Oil and gas production follows the expected trend of increase in subsidence with a decrease in head and depth (head gradient).

Figure 6.2 contains the graph of head gradient versus subsidence for points in the Chicot and Evangeline Aquifers. Although there is some scatter in the data, a trend of decreasing head gradient with increasing subsidence is apparent in the Chicot Aquifer. In the Chicot a few data points show subsidence increasing with increasing head gradient. This same phenomenon is found in points in the Evangeline Aquifer as well. Groundwater usage has decreased substantially in 


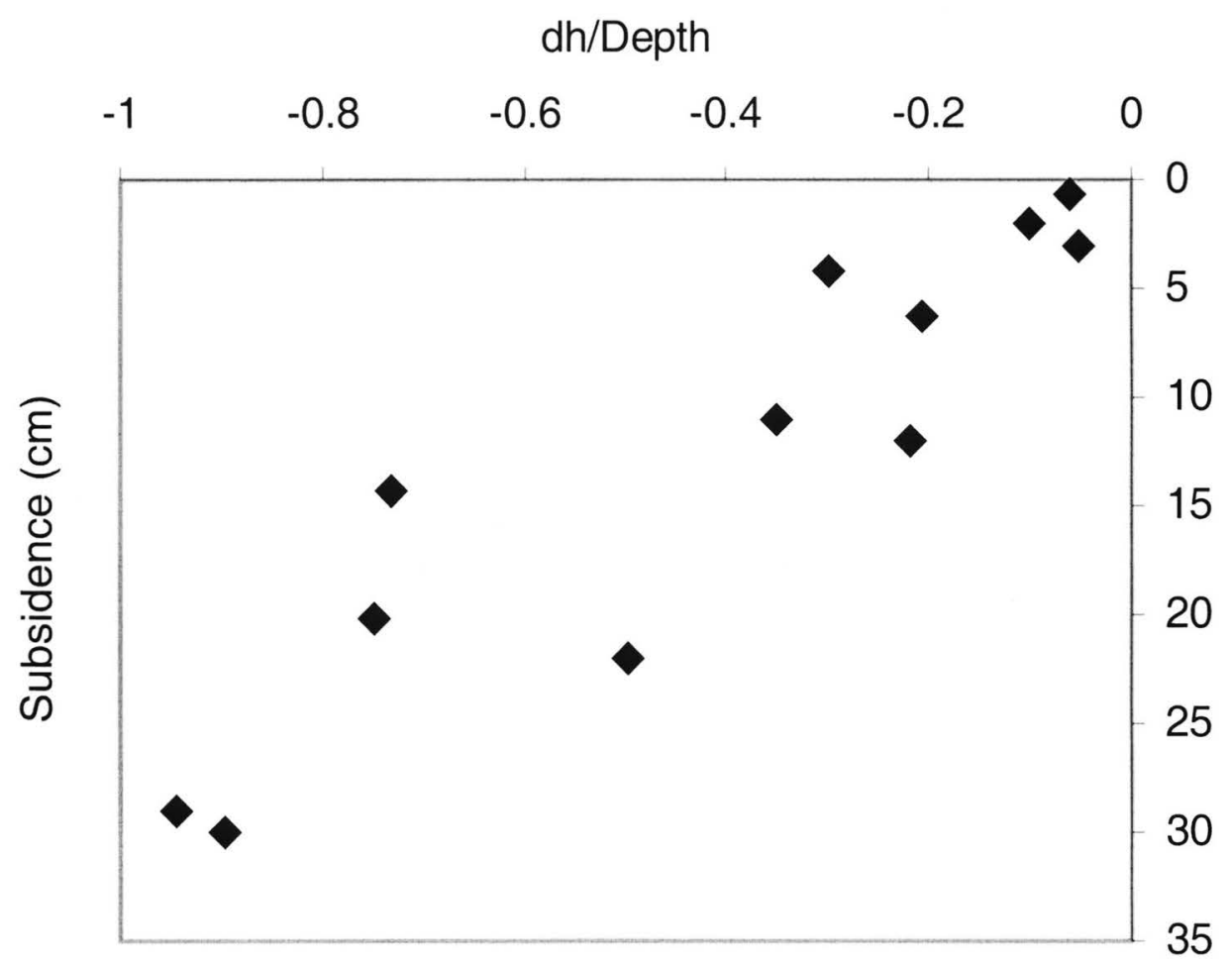

Figure 6.1 Head gradient versus subsidence estimated above petroleum fields 
dh/depth Versus Subsidence for Points Within the Chicot Aquifer

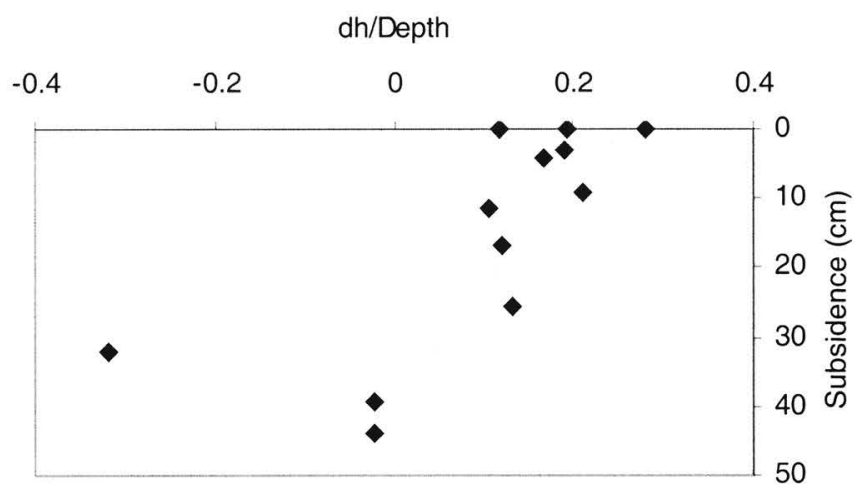

dh/depth Versus Subsidence for Points Within the Evangeline Aquifer

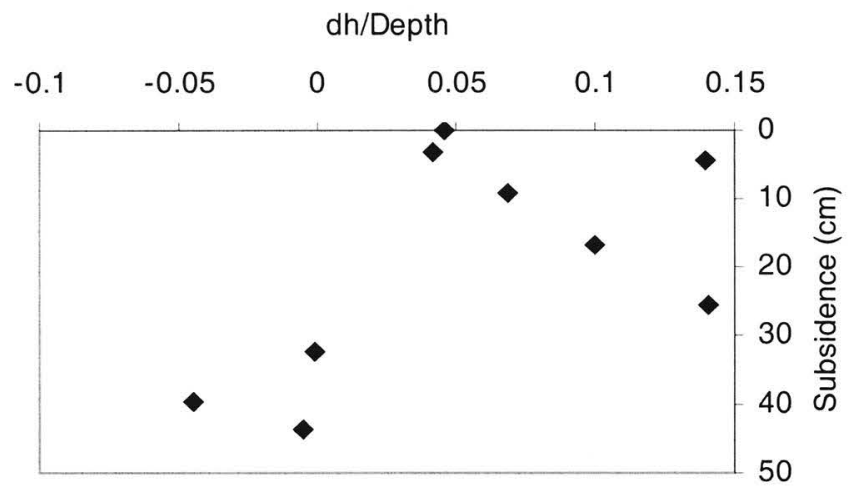

Figure 6.2 Head gradient versus subsidence calculated for points above petroleum fields within the Chicot and Evangeline Aquifers 
the Harris-Galveston region from 1976 (455.8 mgd) to 1997 (289.0 mgd) (HGCSD, 1998). Why would we see outliers with this trend? That is, why is subsidence still occurring from groundwater withdrawal when groundwater is not being pumped and water levels are rising? Recall from Chapter 4, clay compaction for a given decrease in pressure is not instantaneous but rather has a time lag $(\tau)$ associated with it. Values for clay equilibration calculated for oil and gas fields in model simulations were on the order of decades up to 100 years. Similar values for $\tau$ would be expected for groundwater withdrawal. It is plausible then that because of groundwater pumping occurring prior to 1972 , clay equilibration is still taking place, and some subsidence will still occur because of this equilibration. The magnitude of subsidence from clay equilibration must then be determined.

Presently in Harris and Galveston Counties, groundwater withdrawal has ceased in a majority of the study area. Petroleum production continues to occur and has caused measurable amounts of subsidence up to $33.33{\mathrm{~mm} \mathrm{yr}^{-1}}^{-1}$ (1.31 in $\left.\mathrm{yr}^{-1}\right)$. Two dominant causes of subsidence have been found in the region, oil and gas production and clay equilibration caused from previous groundwater withdrawal. The time span of clay equilibration is not known and may be on the same order (decades to a century) as calculated from model simulations for petroleum production. The magnitude of this clay equilibration is difficult to quantify although clays equilibrate exponentially with a majority of clay compaction occurring early in the time period (Domenico and Schwartz, 1990; Helm, 1984; Sharp and Hill, 1995). If $\tau$ for groundwater withdrawal is similar to 
petroleum production (on the order of decades), the majority of clay equilibration 30 years after groundwater pumping has ceased will be minimal. In this case it is plausible that the dominant cause of subsidence in the Harris-Galveston region presently is oil and gas depressurization. When point estimation occurs directly above a petroleum field, it is logical that oil and gas withdrawal and not clay equilibration would cause the majority of subsidence. From the evidence presented in Chapters 3-5, we have shown that where there is petroleum production occurring, which is in most areas of the Harris-Galveston region, the majority of the subsidence is likely to be from oil and gas withdrawal. 


\section{Chapter 7: Conclusions}

In the Harris-Galveston region the main hypothesis tested was that subsidence caused by oil and gas withdrawal is a significant contributing factor to total subsidence. Bottom-hole pressure data reflect the pressure in an oil or gas well and are analogous to a head measurement in a water well. The BHP data used in this study were obtained from Texas Railroad Commission files on petroleum fields within the study area to produce two sets of plots. The first set were plots of pressure versus depth of wells within an oil or gas field in the Harris-Galveston region. The second set of plots showed the relationship between pressure gradient and time. The plots were constructed to quantify the amount of depressurization occurring within these and to show any trends of depressurization with time.

Modeling of subsidence on the fields in the study area was performed by combining two models. The first model was based on Geertsma's nucleus of strain model (1973) modified by Helm (1984), taking into account depressurization and subsequent compaction of clays within the reservoir. The second model was the semi-infinite boundary clay model by Sharp and Hill (1995) taking into account depressurization and compaction of the clays bounding the reservoir. Inputs into the model included BHP measurements taken from the Texas Railroad Commission, and reservoir depth, reservoir radius, reservoir thickness, and cumulative clay thickness taken from electric logs for wells within 
a petroleum field from The University of Texas Bureau of Economic Geology. Model simulations were run for fields that had adequate electric log data and BHP data to estimate the amount of subsidence occurring above the field.

A quantitative analysis compared regional versus local subsidence from oil and gas producing fields using $1^{\text {st }}$ order releveling lines. The releveling lines, consisting of a line of benchmarks, were used to construct 4 cross-sections of a line of oil and gas fields within the study area. Because changes in elevation measured from benchmarks are with respect to a common benchmark and not sea level, elevation measurements were given not as absolute values but rather as relative changes in elevation with respect to the common benchmark. Four releveling lines were thus constructed for the regional versus local comparison.

Estimates of the relative contribution to the total subsidence within the Harris-Galveston region from groundwater withdrawal and oil and gas production were calculated for 12 fields in the study area. Subsidence estimates from model simulations were used as values of subsidence from petroleum production. Contour maps showing total subsidence in the Harris-Galveston region obtained from the HGCSD and well data such as well depth and changes in head obtained from the USGS were used to estimate both total subsidence and the contribution by groundwater withdrawal during the mid 1970s to the late 1990s. The relationship between head gradient $\left(\mathrm{dh} * \mathrm{depth}^{-1}\right)$ and subsidence for points within the Chicot and Evangeline Aquifers as well as petroleum fields could then be plotted. 
From this work, four conclusions can be drawn. The first is that all oil and gas fields in the study area have been depressurized since at least the early 1970s. Pressure declines up to 3073 psi or an equivalent head loss up to $7096 \mathrm{ft}$ (2163 m) have been found at the South Gillock Field in Galveston County for a twenty year time span. This loss in pressure is a direct cause of compaction within petroleum reservoirs in the study area. A temporal variation in depressurization was found from pressure/time plots in oil and gas fields in the Harris-Galveston region. Despite some scatter, the fields exhibited a decreasing trend of pressure decline with time.

From modeling subsidence, our second finding is that subsidence is occurring above a majority of the oil and gas fields in the Harris-Galveston region in measurable amounts from 1 to $33 \mathrm{~mm} \mathrm{yr}^{-1}$ because of the underpressures indicated by BHP data. Up to $30.00 \mathrm{~cm}(\sim 1 \mathrm{ft})$ of subsidence has been calculated in the study area at the Goose Creek Field with a subsidence rate of $33.33 \mathrm{~mm} \mathrm{yr}^{-1}$ (1.30 in $\left.\mathrm{yr}^{-1}\right)$. The average amount of subsidence calculated above oil and gas fields was $12.89 \mathrm{~cm}$ (5.00 in) with an average subsidence rate of $9.70 \mathrm{~mm} \mathrm{yr}^{-1}$ $\left(0.40\right.$ in $\left.\mathrm{yr}^{-1}\right)$.

Cross-sections from $1^{\text {st }}$ order releveling lines reveal two scales of subsidence, local and regional. On a local scale subsidence bowls range from 2 to $5 \mathrm{~km}$. On a regional scale the combination of all neighboring fields in the area form subsidence bowls ranging from 35 to $50 \mathrm{~km}$. We cannot quantify regional trends of subsidence from groundwater withdrawal, although the regional bowls of subsidence we detected are directly above oil and gas fields. In northern Harris 
County, where petroleum field density is low compared to the rest of the HarrisGalveston region, subsidence from oil and gas withdrawal did not have a regional trend. It appears that a high density of oil and gas fields or a large field experiencing enormous amounts of depressurization is required to produce a regional trend of subsidence.

The point analysis of subsidence from groundwater and petroleum production has shown that two causes of subsidence are important in the HarrisGalveston region. They are: 1) oil and gas production and 2) clay equilibration from previous groundwater use. Currently, in most of the study area, values for subsidence from petroleum production are larger than the subsidence from groundwater withdrawal. Groundwater use has decreased substantially since 1976, and the majority of the subsidence experienced from groundwater withdrawal from the years 1976 to present occurred early after groundwater use decreased. The highest rate of clay compaction occurs soon after a given drop in fluid pressure then continues more slowly for some time. The magnitude of subsidence caused by oil and gas production and the time since groundwater withdrawal has ceased suggest that oil and gas production is the principal cause of subsidence in the Harris-Galveston region.

Subsidence will continue in the Harris-Galveston region as long as subsurface fluids are withdrawn at large rates. With the replacement of groundwater by surface water, subsidence rates have been dramatically reduced, and groundwater levels have risen in the past 25 years. Presently, oil and gas production has been generally ignored as a cause of subsidence in the study area, 
even though oil and gas production has been occurring in the region for well over 70 years. From this study it is clear that measurable subsidence is occurring from petroleum production, although not at the same magnitude as groundwater withdrawal. The magnitude of subsidence from petroleum production is smaller than groundwater because the reservoir thickness of most fields in the area is relatively small when compared to groundwater aquifers. Because of this, the total subsidence from oil and gas withdrawal is limited. The subsidence from oil and gas production also appears to be regional in areas with a high density of oil and gas fields. In characterizing an oil or gas reservoir, factors such as depressurization and compaction within the reservoir as well as depressurization and connectivity of neighboring reservoirs should be taken into consideration.

This study considers subsidence from oil and gas production over local and regional scales. Future work should quantify what density of oil and gas fields or amount of depressurization from one large field is needed to produce subsidence on a regional scale. It is evident that petroleum extraction causes subsidence, but we would like to know, on average, how much production would produce measurable amounts of subsidence and also how well we might be able to predict subsidence from oil and gas production. Future work should also include the acquisition of better electric logs to have greater confidence in clay thickness used in estimation of subsidence. With knowledge of the effect of oil and gas production, prediction of subsidence could facilitate better planning of city infrastructure. 


\section{Appendix A (Pressure/Depth Plots)}

A1

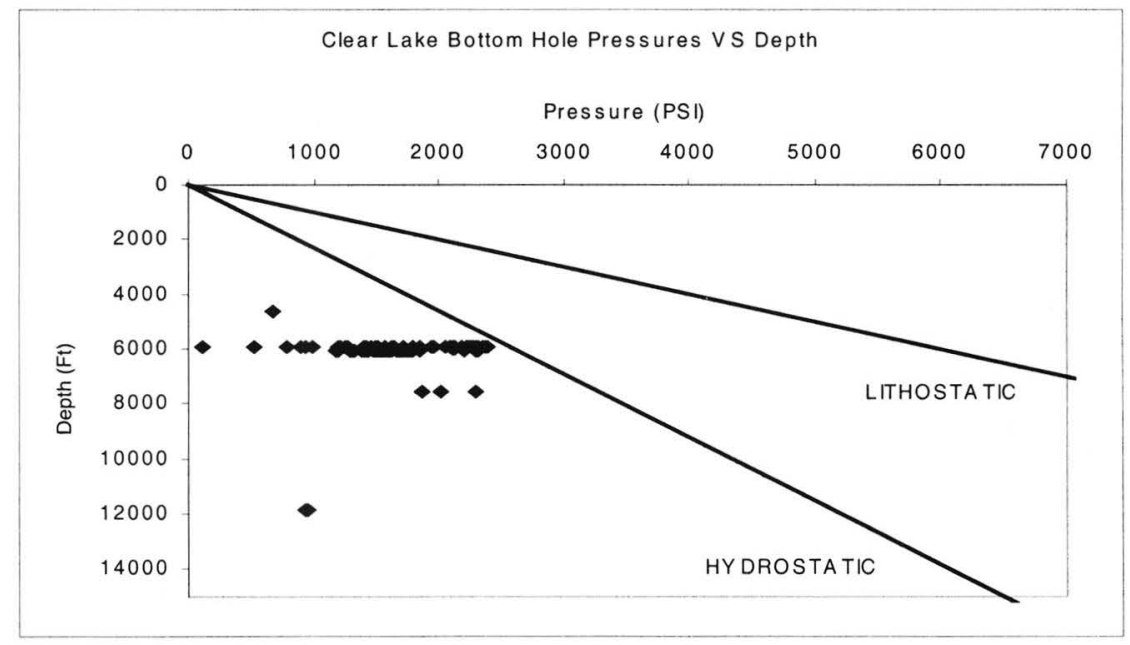

A2

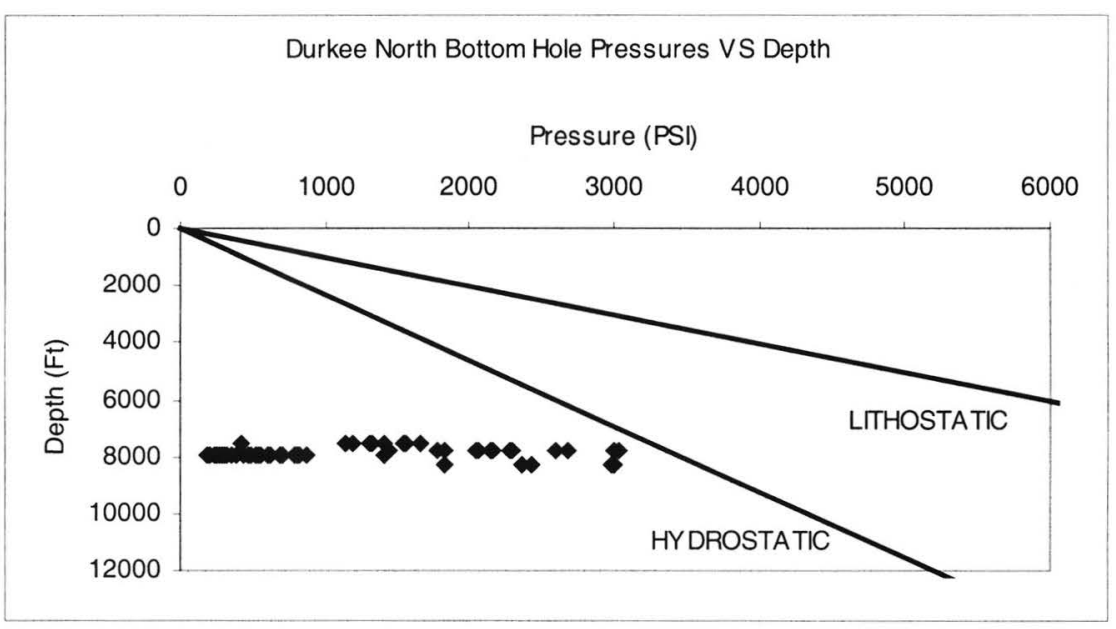


A3

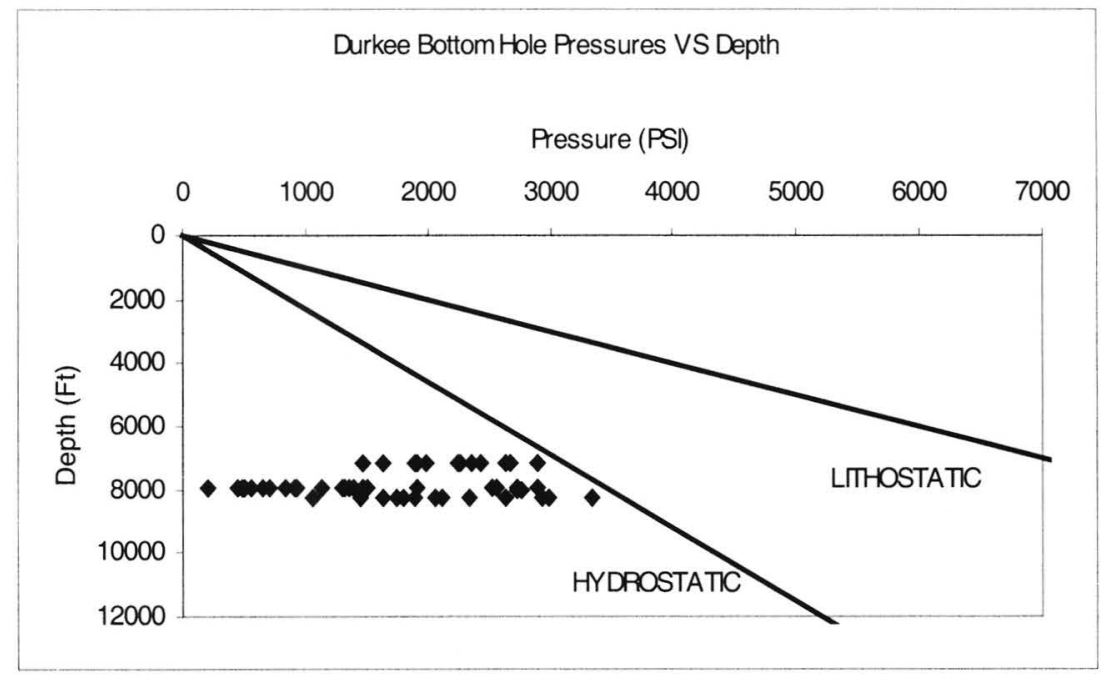

A4

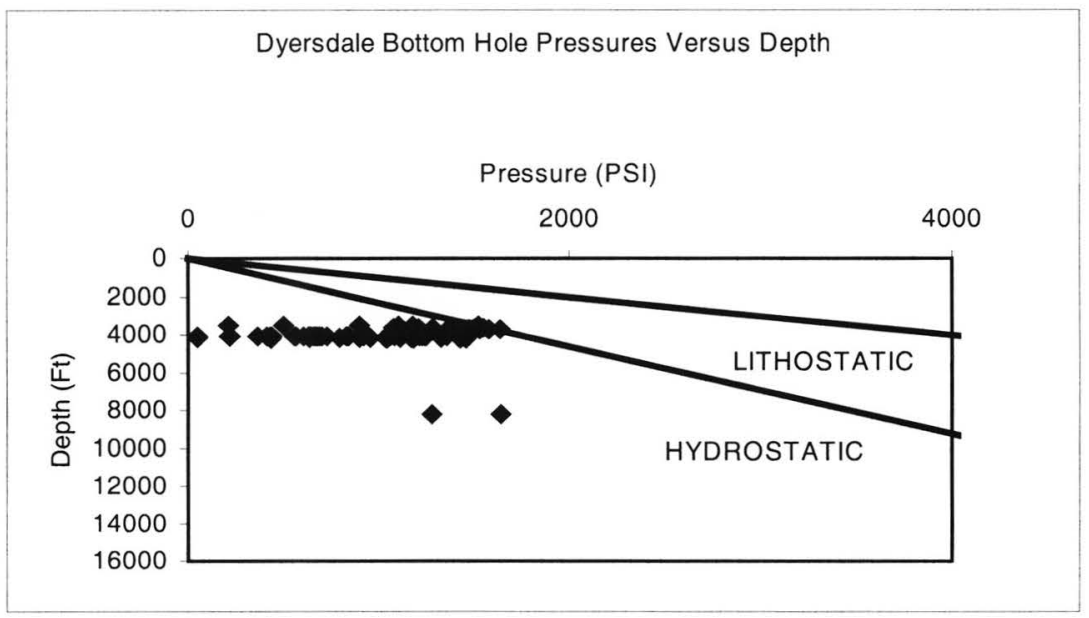




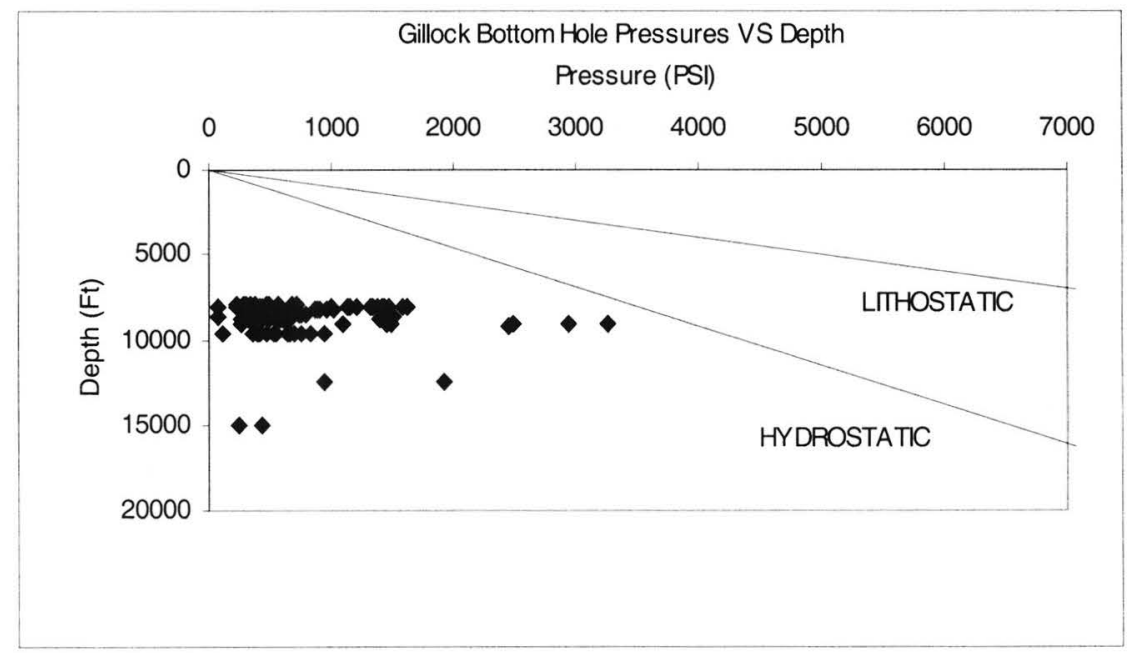

A6

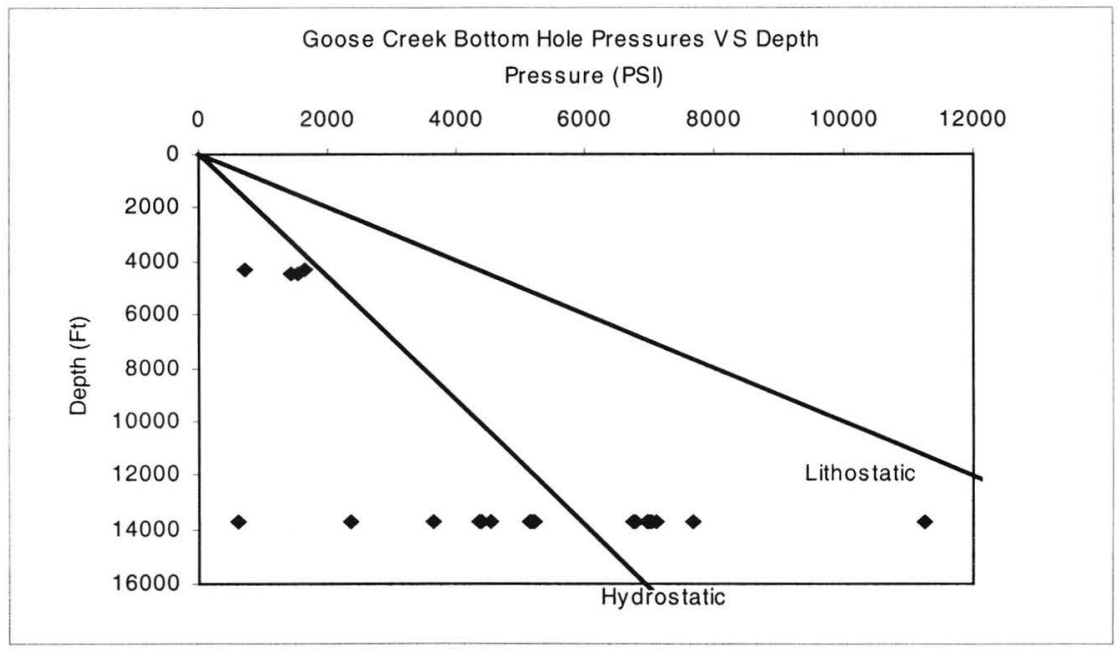


A7

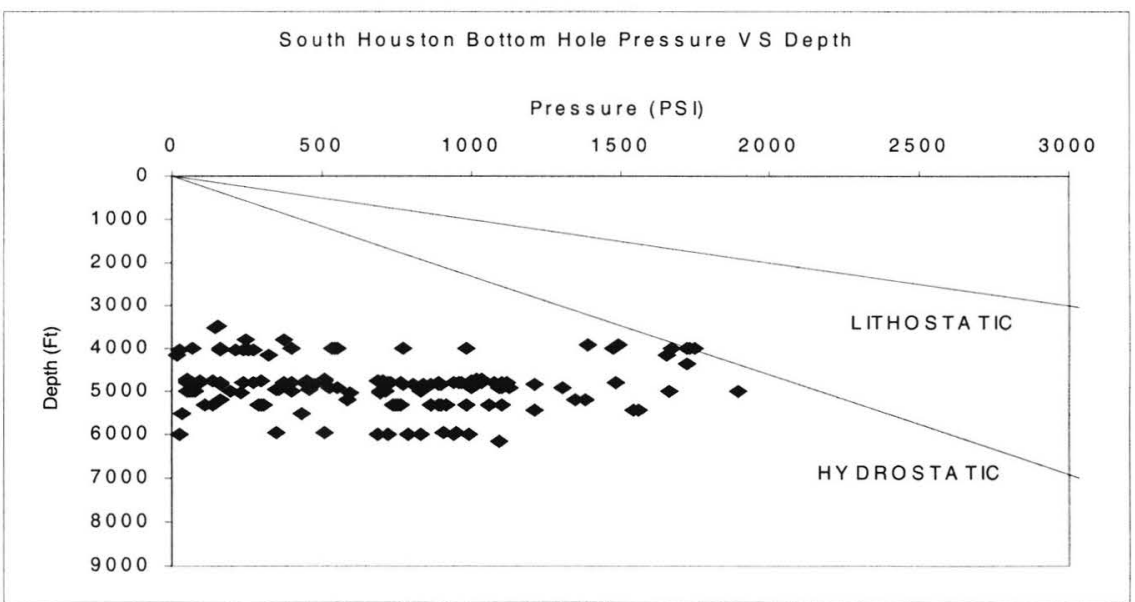

A8

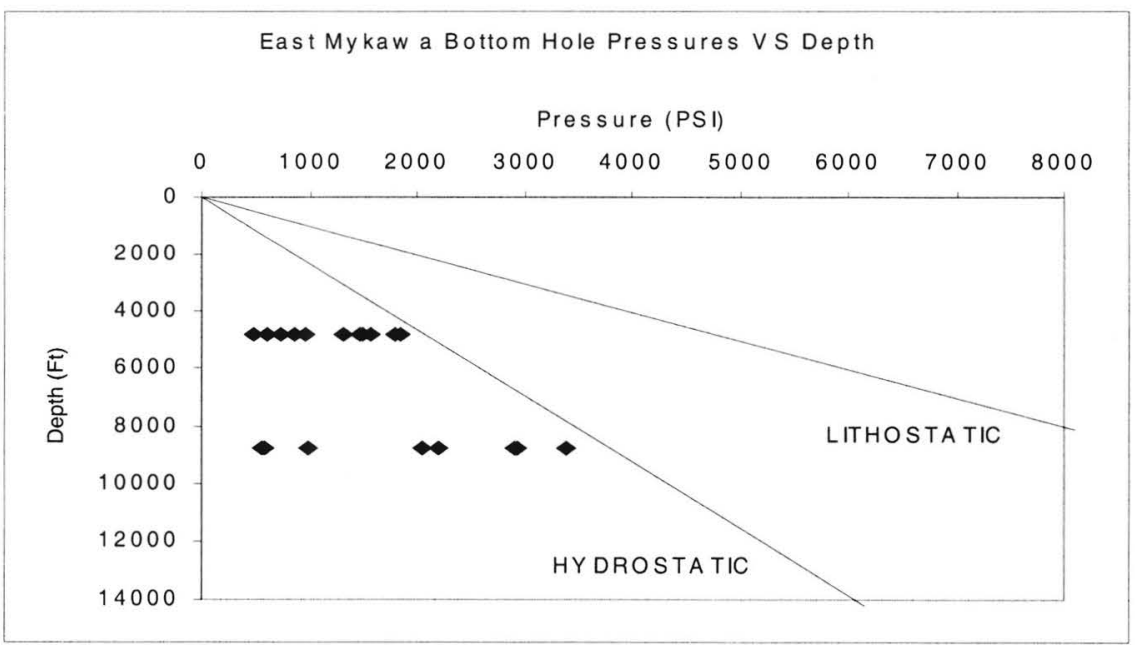


A9

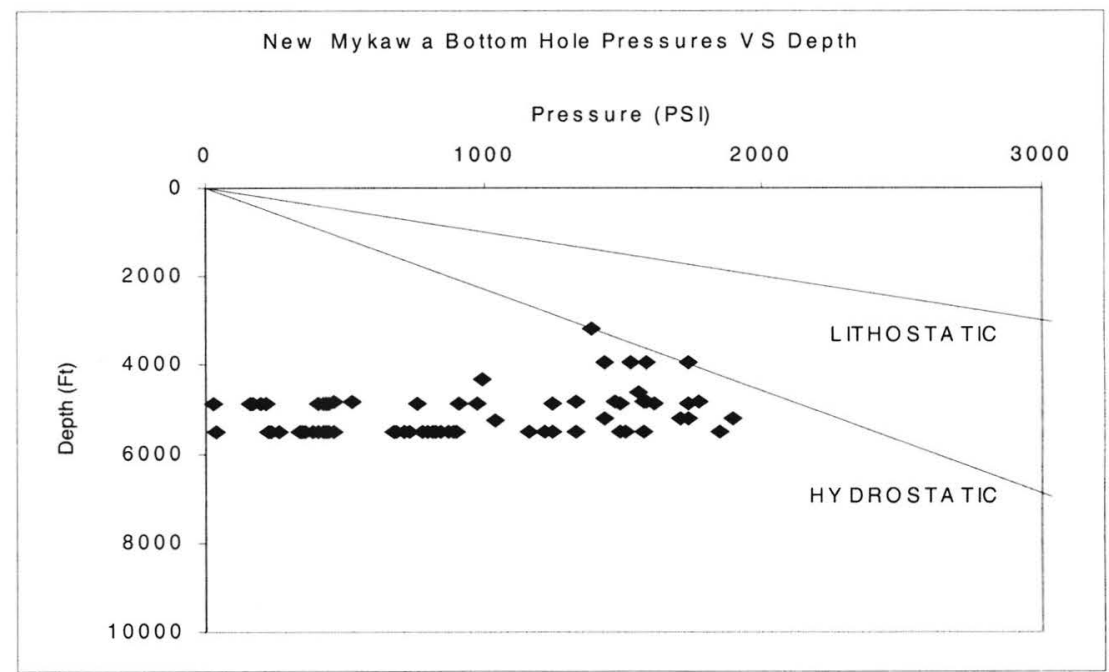

A10

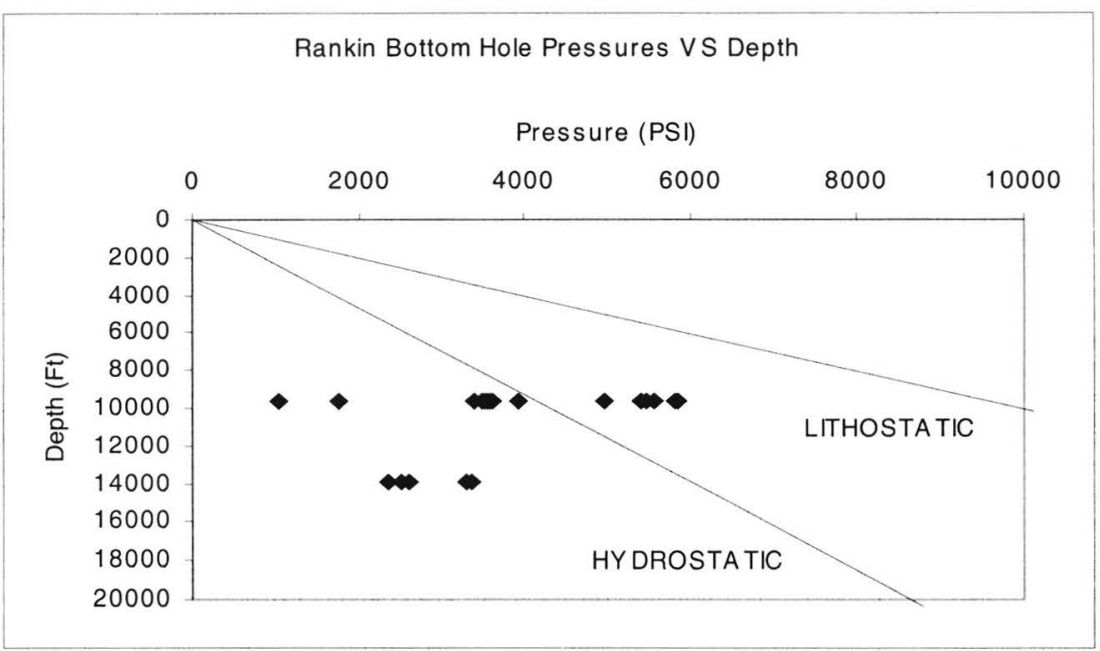


A11

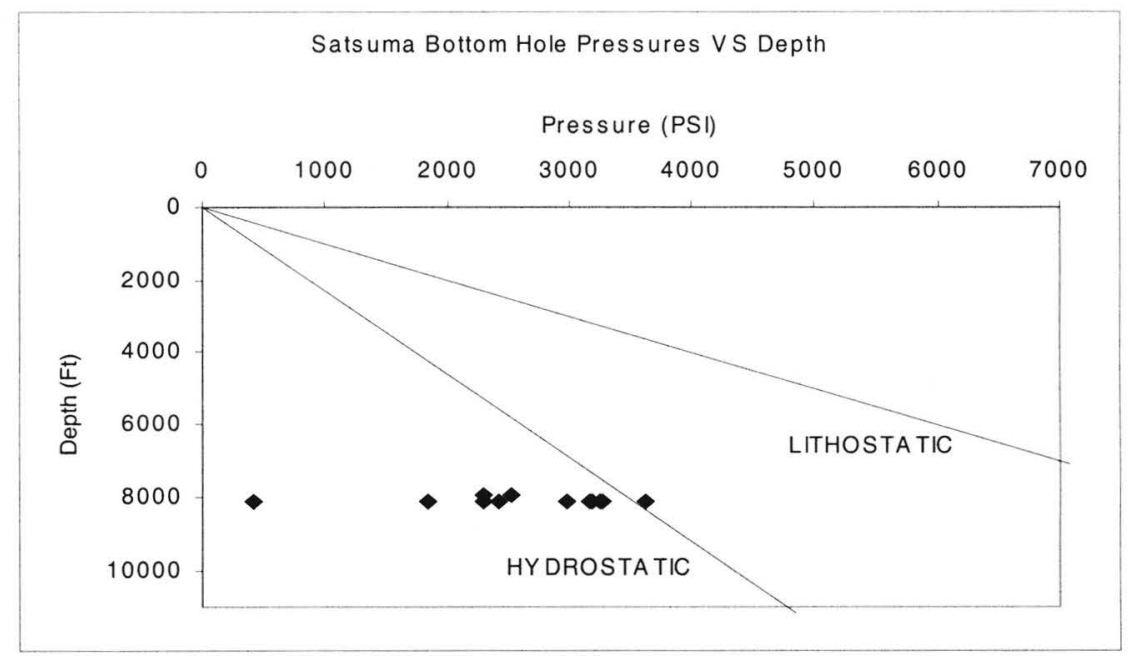

A12

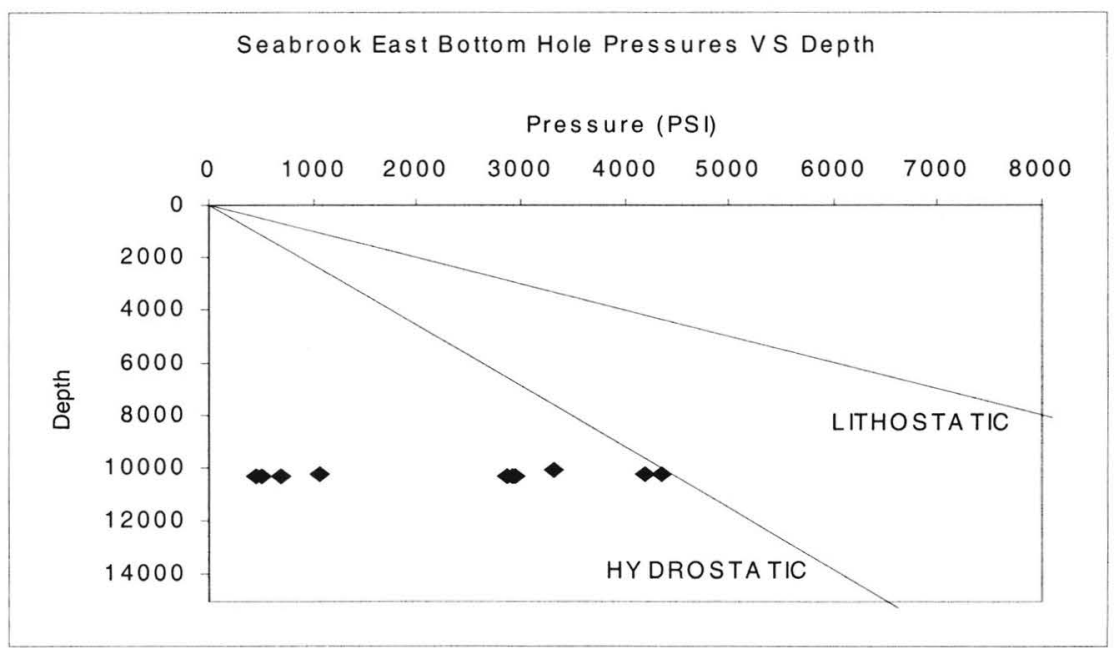


A13

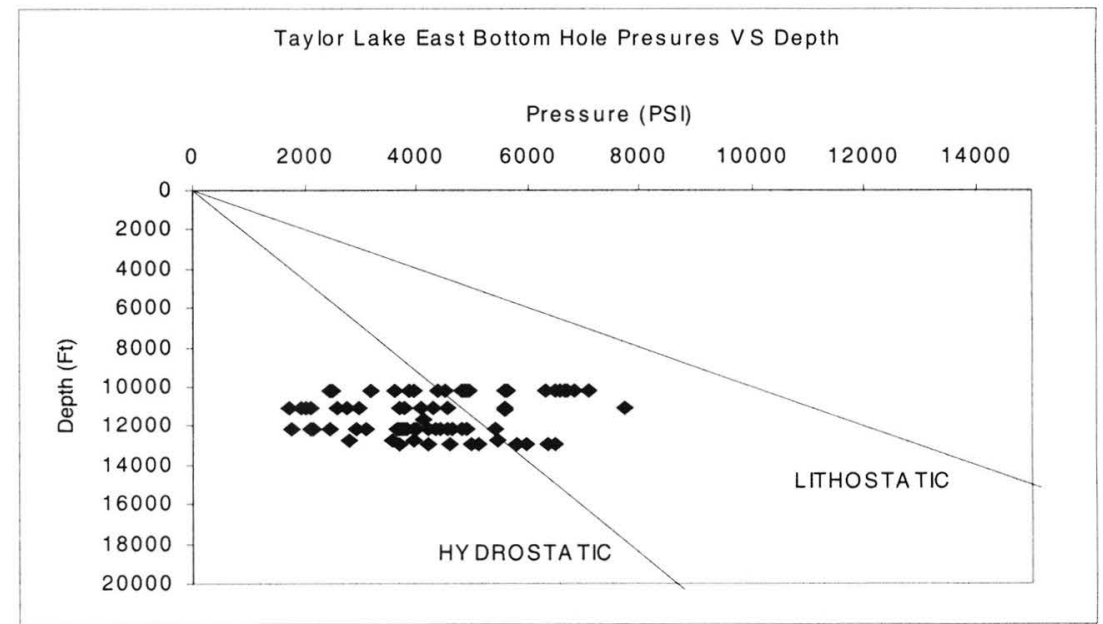

A14

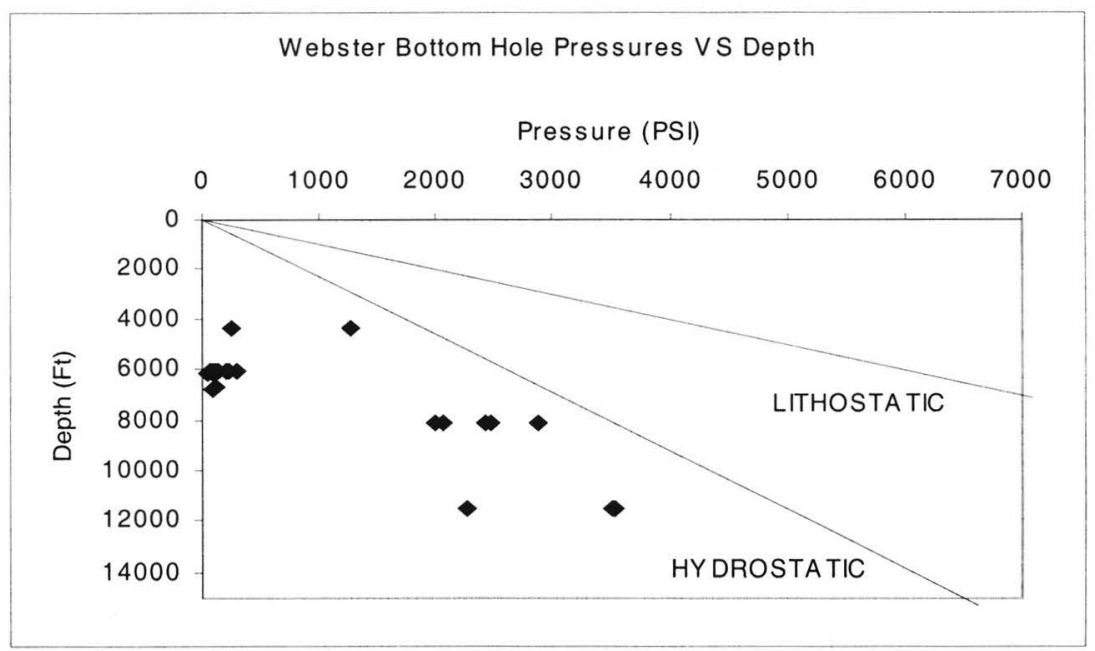




\section{Appendix B (Pressure/Time Plots)}

B1

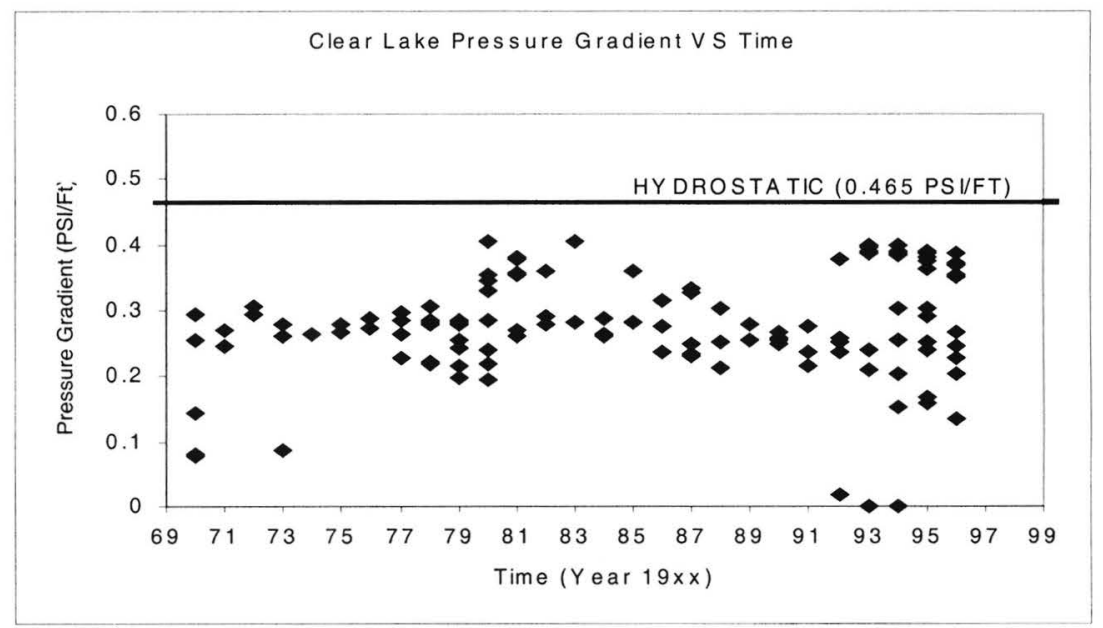

B2

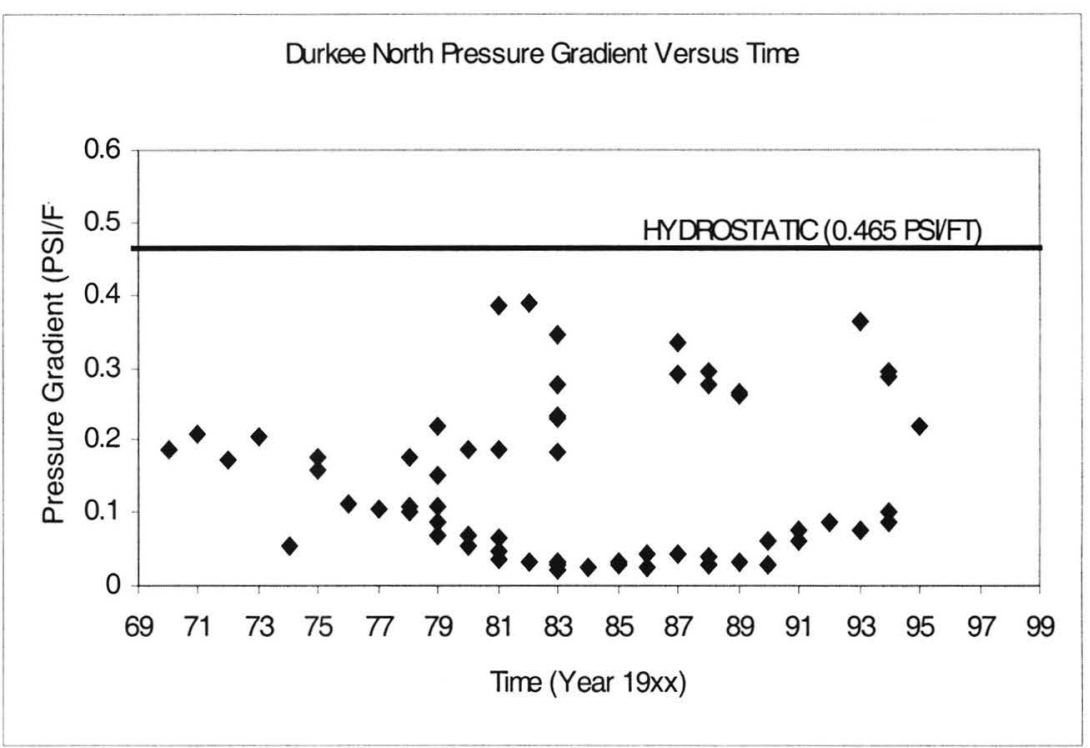




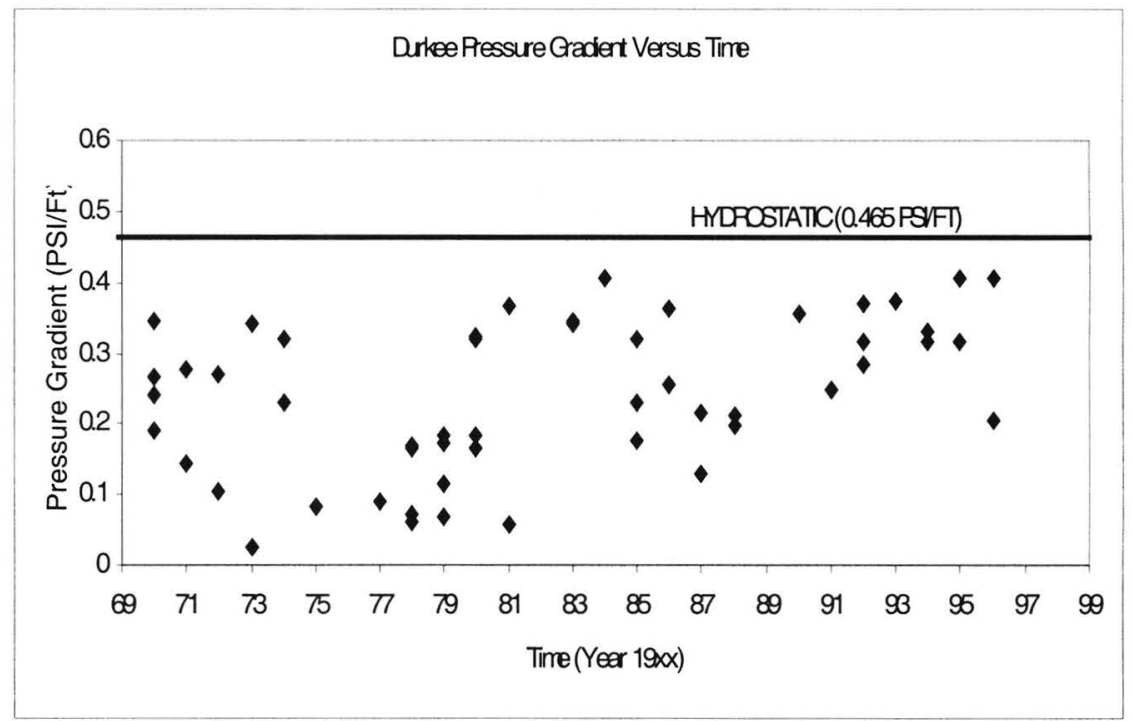

B4

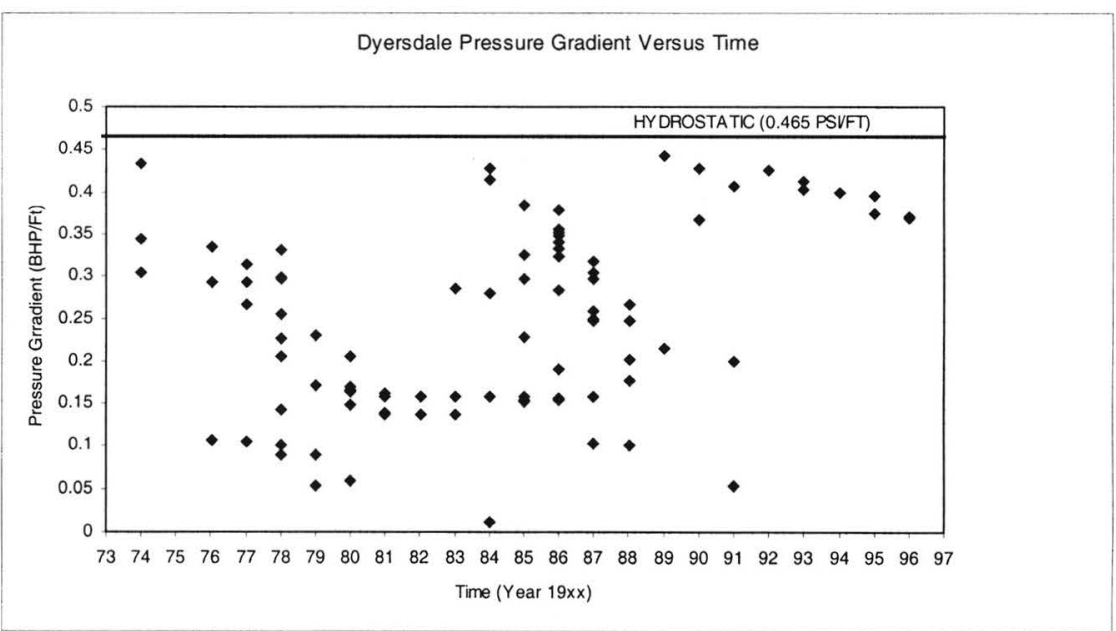

93 
B5

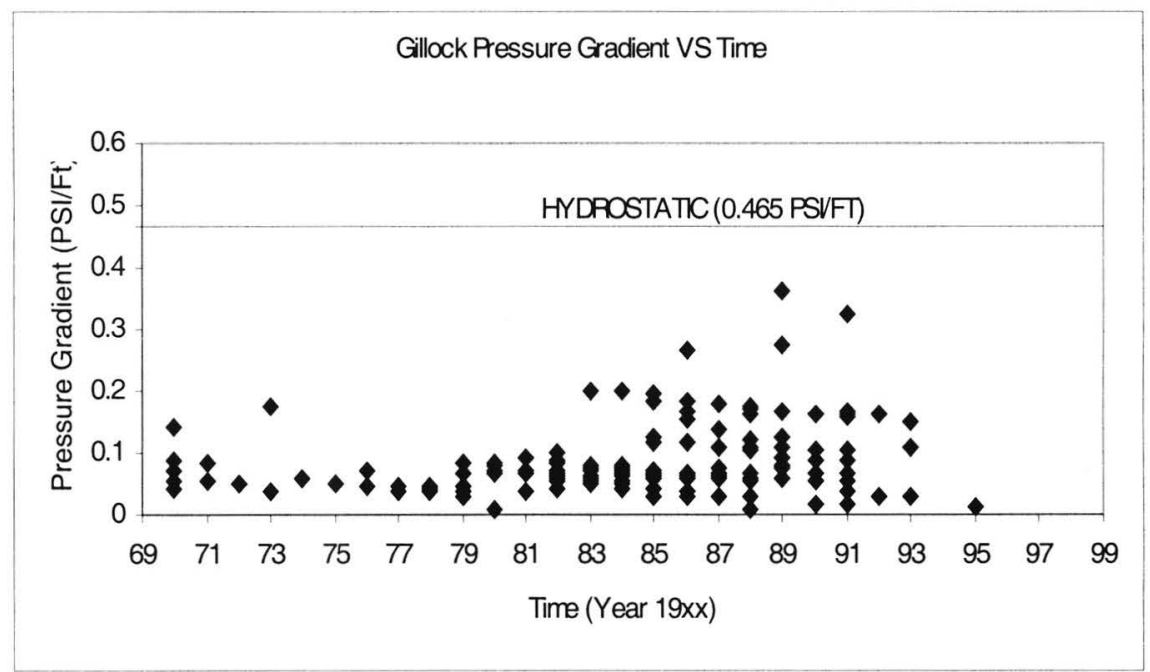

B6

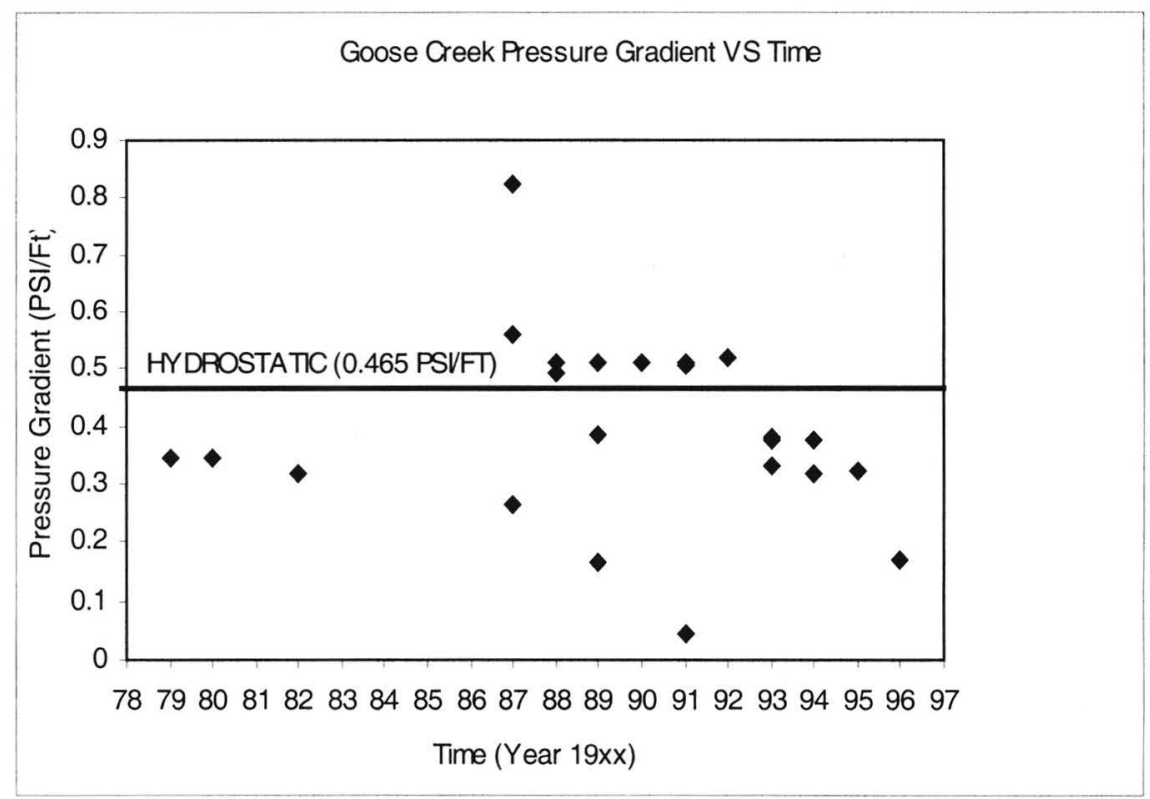


B7

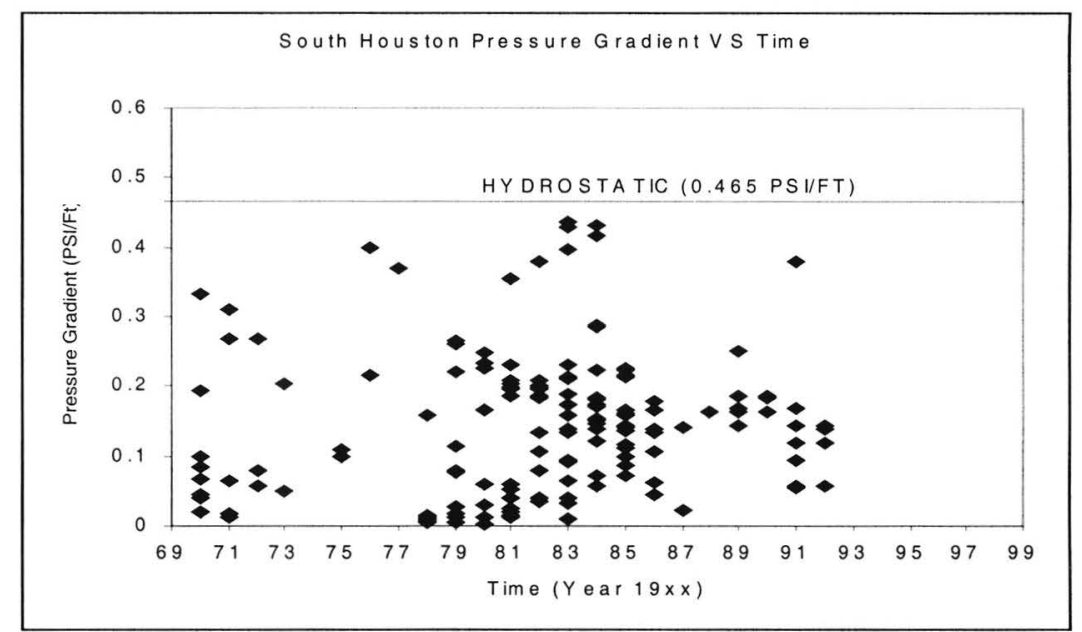

B8

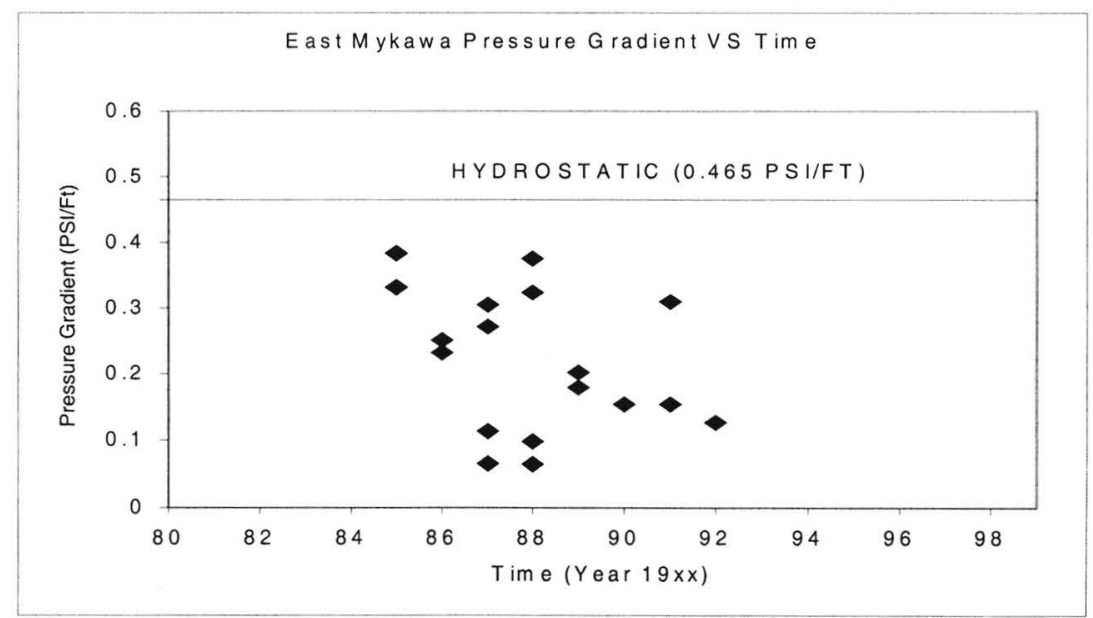


B9

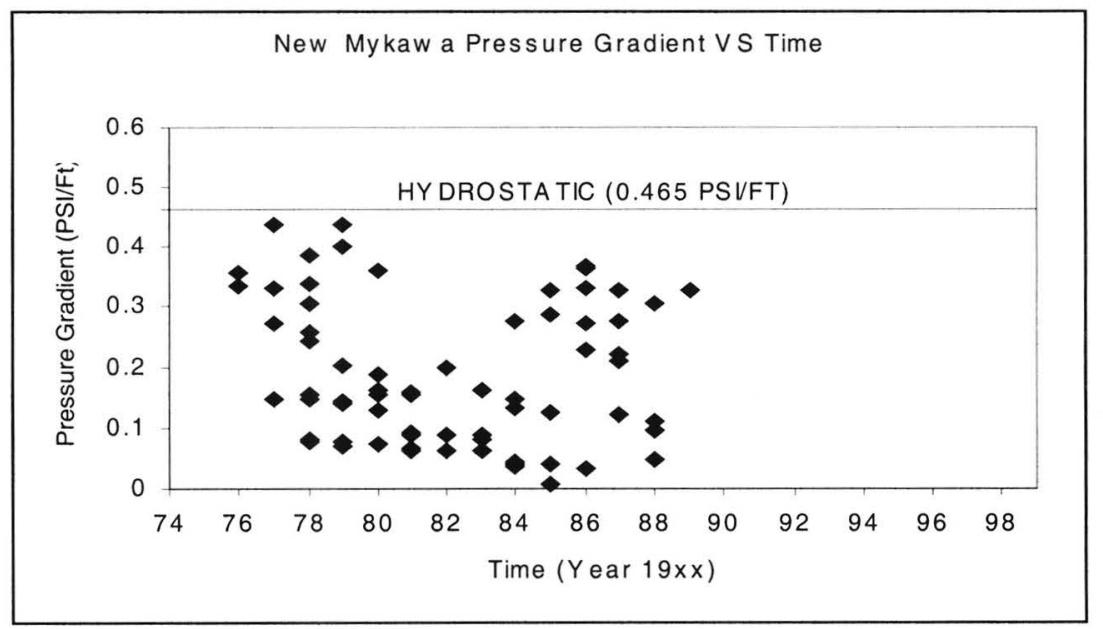

B10

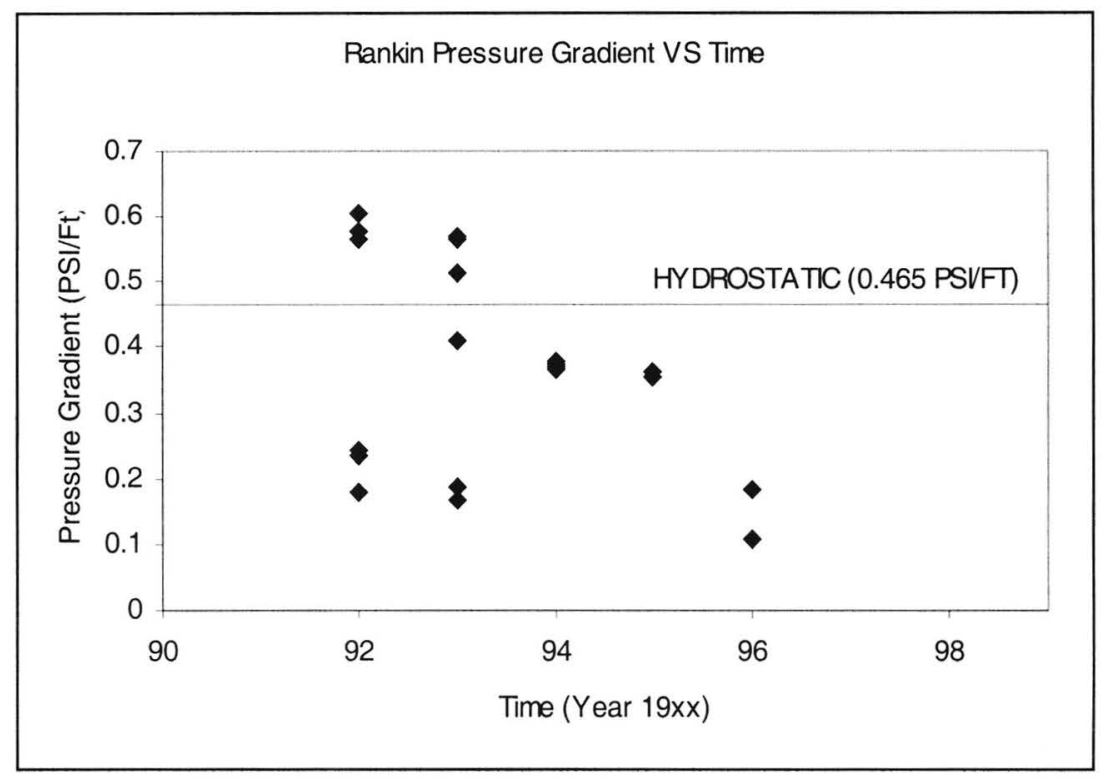




\section{B11}

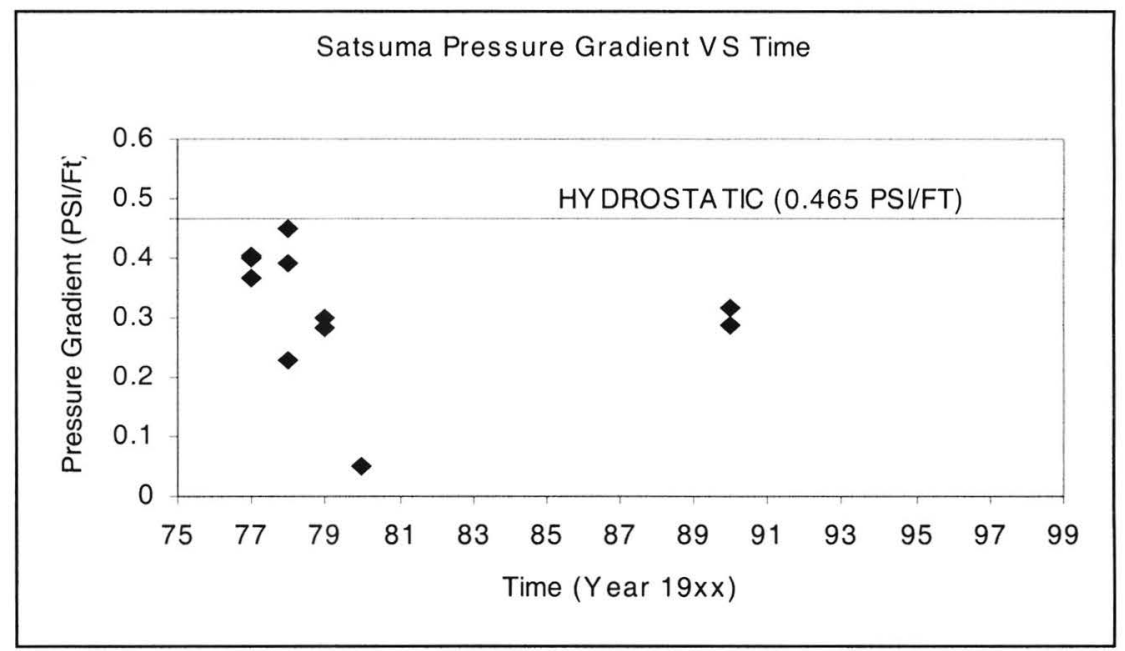

\section{B12}

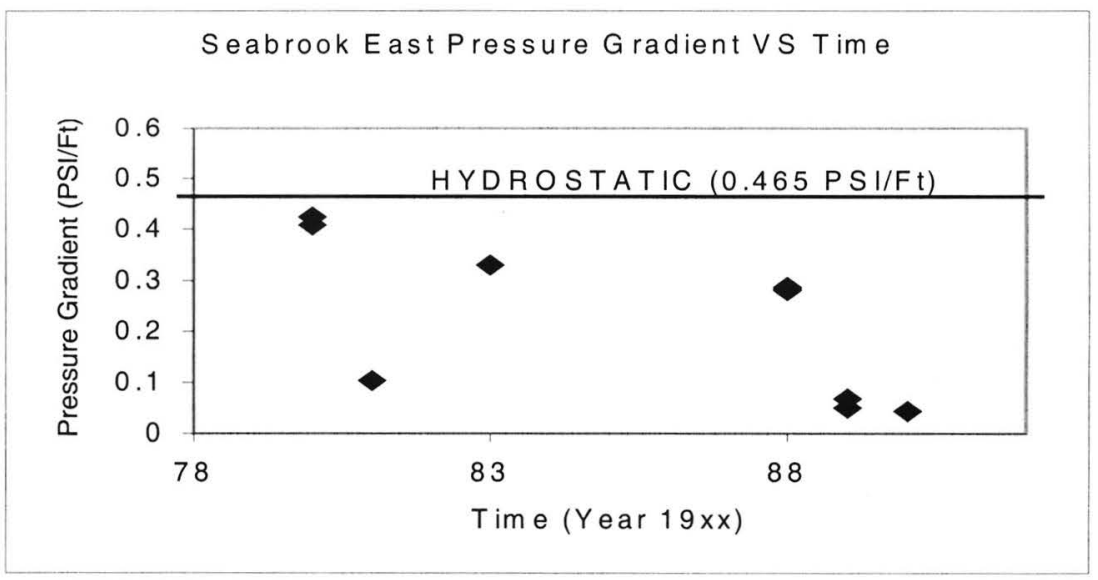


B13

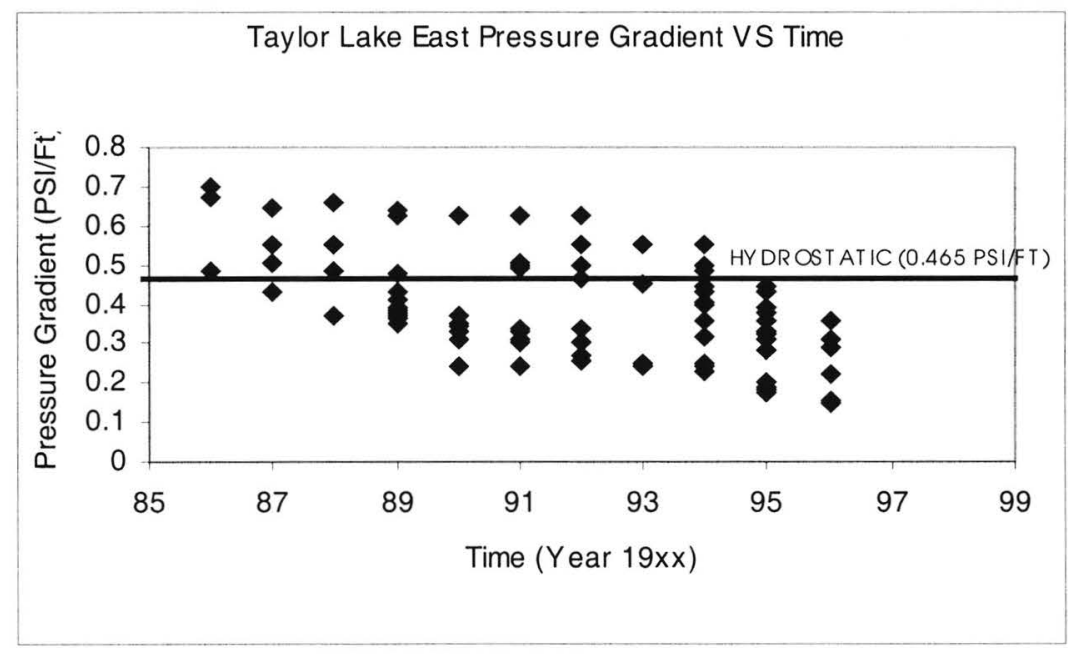

B14

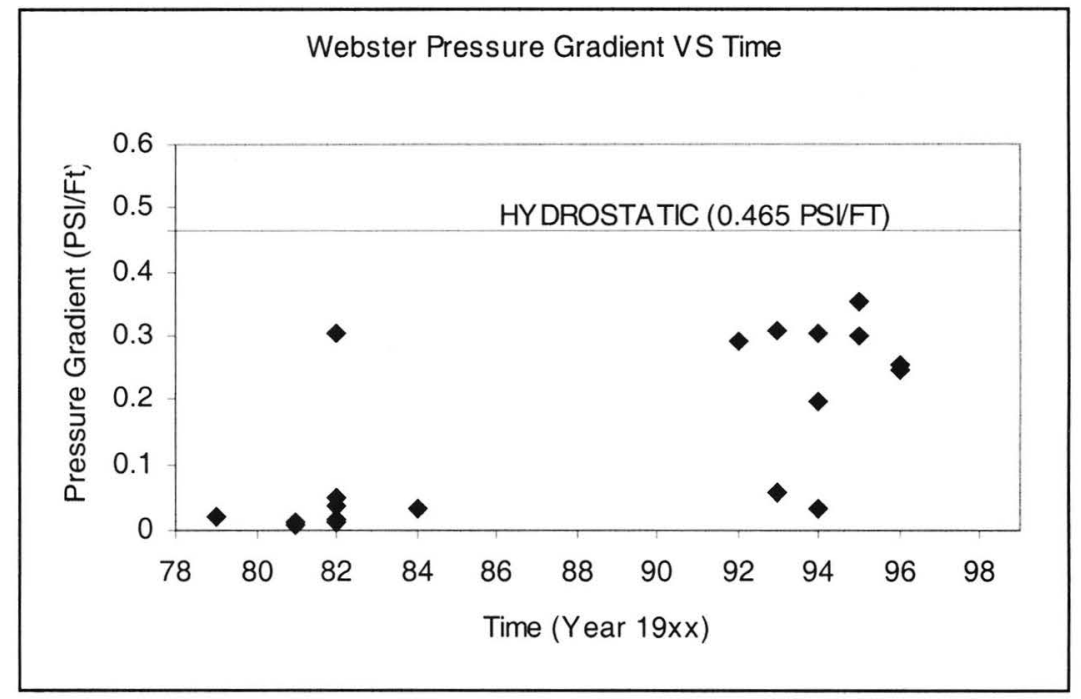




\section{Appendix C (Key to symbols used in FORTRAN code)}

LDeg $=$ Degrees of Latitude

LMin = Minutes of Latitude

LSec $=$ Seconds of Latitude

Latit $=$ Latitude in decimal form

LonDeg $=$ Degrees of Longitude

LonMin $=$ Minutes of Longitude

LonSec $=$ Seconds of Longitude

Lon $=$ Longitude in decimal form

Sub $=$ Subroutine which calculates amount of subsidence within the reservoir

$\mathbf{Z}=$ Depth to reservoir (Meters)

$\mathbf{T}=$ Time interval of subsidence (Years)

$\mathbf{B}=$ Thickness of reservoir (Meters)

CumC $=$ Cumulative clay layer thickness within the reservoir (Meters)

LarC $=$ Thickness of the largest clay bed (Meters)

$\mathbf{G}=$ Sediment specific gravity

Kvert $=$ Vertical Hydraulic conductivity of clays within reservoir $(\mathrm{m} / \mathrm{sec})$

$\mathbf{D p}=$ Change in bottom hole pressure (PSI)

$\mathbf{v}=$ Poisson's ratio

$\mathbf{r}=$ radius of reservoir (Meters)

NStor $=$ Nonrecoverable Specific Storage

$\mathbf{n}=$ porosity

Tau $=$ Timespan of subsidence (Years)

$\mathbf{M}=$ Young's Modulus (Pa)

Dh $=$ Change in head (Meters)

UzMAX = Maximum Subsidence (Meters)

$\mathbf{A t}=$ Attenuation

UznoA = Subsidence not taking attenuation into account (Meters)

$\mathbf{U z A}=$ Subsidence with attenuation (Meters)

$\mathbf{E}=$ Coning factor

$\mathbf{U z E}=$ Subsidence taking coning into affect (Meters)

eprime $=$ Effective stress $(\mathrm{Pa})$

$\mathbf{C M}=$ Vertical compressibility of the aquifer or reservoir $(1 / \mathrm{Pa})$

Zbound = Distance above and below aquifer for calculation of pressure (Meters)

Tsec $=$ Time in seconds

erfarg $=$ Error function argument

deltaPc $=$ Change in pressure at Zbound (PSI)

erf $=$ Error function

SubTotal $=$ Total subsidence from both models (Meters) 
*Note the suffix "bound" applies the same meaning but used in the semi-infinite boundary clay layer model instead of the reservoir model.

\title{
Appendix D \\ (Code to Reservoir and Semi-Infinite Boundary Clay Models)
}

\author{
Section1: Program Subsidence
}

\author{
Program Subsidence \\ Implicit None \\ Integer NX, Cycle1, Datapoints, k \\ Parameter(NX=10000) \\ Real Z,G,B,LarC,Kvert,Dp,v,E,r,a,nref,zref,n,T,erf,Dhbound \\ Real NStor,Z1,Z2,p,gravity,eprime,Dh,Tau,CumC,UzMAX,CM,B2,SubTotal \\ Real At,C,M,Part1,Part2,Part3,Part4,UznoA,UzA,UzE,UzMAXbound \\ Real Lat(NX),Long(NX),Latit,Lon,UzConing(NX),LDeg,LMin,LSec \\ Real LMin1,LSec1,LonDeg,LonMin,LonSec,LonMin1,LonSec1,Zbound \\ Real Atbound,UznoAbound,UzAbound,Ebound,UzEbound,deltaP,deltaPc

\section{Create Output files} \\ Open (10, File='subresout.txt',form='formatted',status='unknown') \\ Open (20, File='subsurfer.txt',form='formatted',status='unknown') \\ Write $(*, *)$ ' Subsidence Calculations' \\ Write $(*, *)$ 'Reservoir and Semi-Infinite Boundary Models' \\ Write $(*, *)$ \\ Write $(*, *)$ 'Enter the number of reservoirs (points) you' \\ Write $(*, *)$ 'want calculations for' \\ Read $(*, *)$ Datapoints \\ Write $(*, *)$ \\ Do Cycle 1=1, Datapoints
}

C Takes Latitude and Longitude and converts it to decimal form to be C used in Surfer

Write $(*, *)$ 'Enter the Degrees of Latitude'

Read $(*, *)$ LDeg

Write $(*, *)$

Write $(*, *)$ 'Enter the minutes of Latitude'

Read $(*, *)$ LMin

Write $(*, *)$

Write $(*, *)$ 'Enter the seconds of Latitude'

Read $(*, *)$ LSec 


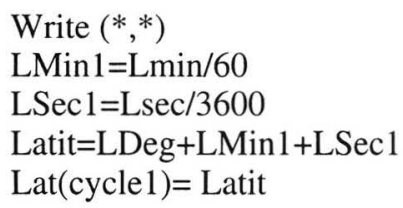

Write $(*, *)$ 'Enter the Degrees of Longitude' Read $(*, *)$ LonDeg

Write $(*, *)$

Write $(*, *)$ 'Enter the minutes of Longitude'

Read $(*, *)$ LonMin

Write $(*, *)$

Write $(*, *)$ 'Enter the seconds of Longitude'

Read $(*, *)$ LonSec

Write $(*, *)$

LonMin $1=($ LonMin $/ 60)$

LonSec $1=(\operatorname{LonSec} / 3600)$

Lon=-(LonDeg+LonMin1+LonSec1)

Long $($ cycle 1$)=$ Lon

C Call Subroutine Sub which calculates subsidence using the reservoir model

Call Sub(T,Z,B,CumC,LarC,G,Kvert,Dp,v,M,r,n,NStor,eprime,UzMAX, -Tau,CM,Dh,At,UznoA,UzA,E,UzE)Uzconing (cycle1)=UzE

C Call Subroutine Bound which calculates subsidence using the semi-infinite C boundary clay layer model

Call Bound(Dp,Kvert,NStor,Zbound,T,erf,deltaP,deltaPc,Z,B,

-CumC,LarC,G,v,M,r,n,eprime,UzMAXbound,Tau,CM,Atbound,UznoAbound, -UzEbound,Dhbound,UzAbound,Ebound)

\section{Output of calulations for reservoir model}

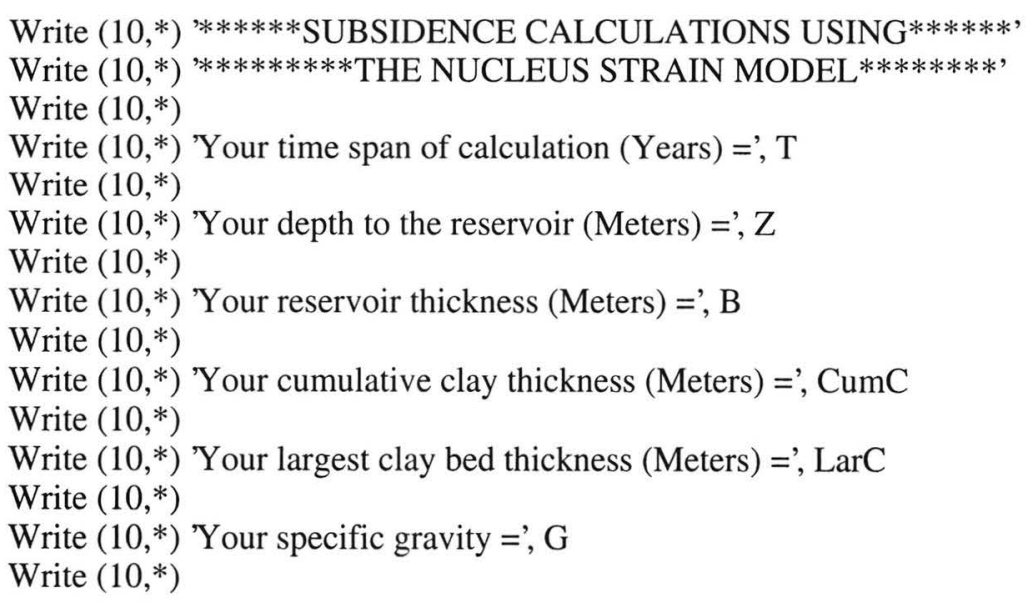


Write $\left(10,{ }^{*}\right)$ 'Your hydraulic conductivity $(\mathrm{M} / \mathrm{sec})=$ ', Kvert

Write $\left(10,{ }^{*}\right)$

Write $\left(10,{ }^{*}\right)$ 'Your decline in bottom hole pressure (PSI) =', Dp

Write $(10, *)$

Write $\left(10,{ }^{*}\right)$ 'Poissons ratio $=$ ', v

Write $(10, *)$

Write $\left(10,{ }^{*}\right)$ 'Youngs Modulus $(\mathrm{Pa})=$ ', $\mathrm{M}$

Write $(10, *)$

Write $\left(10,{ }^{*}\right)$ 'Your reservoir radius (Meters) $=$ ', r

Write $\left(10,{ }^{*}\right)$

Write $\left(10,{ }^{*}\right)$ The porosity $=$ ', $\mathrm{n}$

Write $\left(10,{ }^{*}\right)$

Write $\left(10,{ }^{*}\right)$ The nonrecoverable storativity = ', NStor

Write $(10, *)$

Write $\left(10,{ }^{*}\right)$ 'Your converted head decline (Meters)=', Dh

Write $(10, *)$

Write $\left(10,{ }^{*}\right)$ The effective stress $(\mathrm{Pa})=$, , eprime

Write $\left(10,{ }^{*}\right)$

Write $\left(10,{ }^{*}\right)$ 'The maximum subsidence calculated (Meters)=', UzMAX

Write $(10, *)$

Write $\left(10,{ }^{*}\right)$ The time it takes for subsidence to occur'

Write $\left(10,{ }^{*}\right)$ 'in years (equilibrium of clays) $=$ ', Tau

Write $(10, *)$

Write $(10, *)$ The vertical compressibility of the aquifer'

Write $\left(10,{ }^{*}\right) '(1 / \mathrm{Pa})=$ ', CM

Write $(10, *)$

Write $(10, *)$ 'Attenuation (Meters) $=$ ', At

Write $\left(10,{ }^{*}\right)$

Write $\left(10,{ }^{*}\right)$ 'Subsidence not taking attenuation into'

Write $\left(10,{ }^{*}\right)$ 'account (Meters)=', UznoA

Write $(10, *)$

Write $(10, *)$ ' Subsidence taking attenuation into'

Write $\left(10,{ }^{*}\right)$ 'account (Meters) $=$ ', UzA

Write $(10, *)$

Write $\left(10,{ }^{*}\right)$ 'Coning (Meters) =', E

Write $(10, *)$

Write $\left(10,{ }^{*}\right)$ 'Subsidence taking coning into'

Write $\left(10,{ }^{*}\right)$ 'account (Meters) $=$ ', UzE 
Write $(10, *)$

Write $\left(10,{ }^{*}\right)$ 'Thankyou'

Write $(10, *)$

\section{Output of calulations for semi-infinite boundary clay layer model}

Write $(10, *) * * * * * *$ SUBSIDENCE CALCULATIONS USING $* * * * * *$, Write $(10, *)^{* *}$ THE SEMI-INFINITE BOUNDARY CLAY MODEL $* *$, Write $(10, *)$

Write $\left(10,{ }^{*}\right)$ The vertical distance above and below for which'

Write $\left(10,{ }^{*}\right)$ 'pressure was calculated (Meters) $=$ ',Zbound

Write $\left(10,{ }^{*}\right)$

Write $\left(10,{ }^{*}\right)$ The change in pressure above and below the reservoir'

Write $\left(10,{ }^{*}\right)$ 'at the distance you chose is (PSI) $=$ ', deltaPc

Write $\left(10,{ }^{*}\right)$

Write $\left(10,{ }^{*}\right)$ 'Your converted head decline (Meters)=',Dhbound

Write $\left(10,{ }^{*}\right)$

Write $\left(10,{ }^{*}\right)$ 'Maximum subsidence calculated (Meters)=', UzMAXbound

Write $\left(10,{ }^{*}\right)$

Write $\left(10,{ }^{*}\right)$ 'Attenuation (Meters) $=$ ', Atbound

Write $(10, *)$

Write $\left(10,{ }^{*}\right)$ 'Subsidence not taking attenuation into'

Write $\left(10,{ }^{*}\right)$ 'account (Meters) $=$ ', UznoAbound

Write $(10, *)$

Write $\left(10,{ }^{*}\right)$ 'Subsidence taking attenuation into'

Write $\left(10,{ }^{*}\right)$ 'account (Meters) $=$ ', UzAbound

Write $\left(10,{ }^{*}\right)$

Write $(10, *)$ 'Coning (Meters) =', Ebound

Write $(10, *)$

Write $\left(10,{ }^{*}\right)$ 'Subsidence taking coning into'

Write $(10, *)$ 'account (Meters) $=$ ', UzEbound

Write $(10, *)$

SubTotal=UzEbound + UzE

Write $\left(10,{ }^{*}\right)$ Total Subsidence (Meters)=',SubTotal

Write $(10, *)$

Write $(10, *)$ 'Thankyou'

Write $(10, *)$

Enddo

\section{Output of Latitude/Longitude for Surfer}


Write $\left(20,{ }^{*}\right)$ Lat Long Subsidence(Meters)'

Do $\mathrm{k}=1$, datapoints

Write $\left(20,{ }^{*}\right)$ Lat $(\mathrm{k}), \operatorname{Long}(\mathrm{k})$, Uzconing(k)

Enddo

Stop

End

Section 2: Subroutine Sub

Subroutine Sub(T,Z,B,CumC,LarC,G,Kvert,Dp,v,M,r,n,NStor,eprime, -UzMAX,Tau,CM,Dh,At,UznoA,UzA,E,UzE)

Real T,Z,B,CumC,LarC,G,Kvert,Dp,v,M,r,n,NStor,eprime

Real UzMAX,Tau,C,CM,B2,Dh,Part1,Part2,Part3,Part4,At,UznoA

Real UzA,E,UzE,a,Nref,Zref,Z1,Z2

\section{Asks for various input paramters}

Write $(*, *)$ 'What is the time interval of subsidence'

Write $(*, *)$ 'you want found in Years?'

$\operatorname{Read}(*, *) \mathrm{T}$

Write $(*, *)$ 'Enter the depth to the reservoir in Meters'

$\operatorname{Read}(*, *) \mathrm{Z}$

Write $(*, *)$

Write $(*, *)$ 'Enter the thickness of the reservoir or aquifer'

Write $(*, *)$ 'in Meters'

Read $(*, *)$ B

Write $(*, *)$

Write $(*, *)$ 'Enter the cumulative thickness of the clay beds'

Write $(*, *)$ '(compressible layers) within the reservoir in Meters'

Read $(*, *)$ CumC

Write $(*, *)$

Write $(*, *)$ 'Enter the thickness of the largest clay bed'

Write $(*, *)$ '(compressible layer) within the reservoir in Meters'

Read $(*, *)$ LarC

Write $(*, *)$

Write $(*, *)$ 'Enter the Sediments Specific Gravity'

Read $(*, *) \mathrm{G}$

Write $(*, *)$

Write $(*, *)$ 'Enter the Vertical Hydraulic Conductivity of the'

Write $(*, *)$ 'clays (compressible layers) within'

Write $(*, *)$ 'the reservoir in $\mathrm{m} / \mathrm{sec}^{\prime}$

Read (*,*) Kvert

Write $(*, *)$

Write $(*, *)$ 'Enter the decline in bottom hole pressure between'

Write $(*, *)$ 'the time interval wanted in PSI' 
$\operatorname{Read}(*, *) \mathrm{Dp}$

Write $(*, *)$

Write $(*, *)$ 'Enter Poissons Ratio you want used (from 0.1 - 0.5)'

$\operatorname{Read}(*, *)$ v

Write $(*, *)$

Write $(*, *)$ 'Enter Youngs Modulus in Pa'

$\operatorname{Read}(*, *) \mathrm{M}$

Write $(*, *)$

Write $(*, *)$ 'Assuming a disk shaped reservoir, enter the radius'

Write $(*, *)$ 'of the reservoir in Meters'

Read $(*, *) \mathrm{r}$

Write $(*, *)$

$\mathrm{a}=0.103$

nref $=0.05$

$\mathrm{zref}=10000$

$\mathrm{Z} 1=\mathrm{Z} / \mathrm{Zref}$

$\mathrm{Z} 2=\log (\mathrm{Z} 1)$

$\mathrm{n}=$ nref $-(\mathrm{a} * \mathrm{Z} 2)$

C Calulation of nonrecoverable specific storage

NStor $=0.103 /((\mathrm{G}-1) *((1-n) * * 2) * \mathrm{Z})$

C Conversion of BHP in PSI to a change in head

$\mathrm{Dh}=\mathrm{Dp} *(0.704)$

C Calculation of effective stress

eprime $=1000 * 9.8 * \mathrm{Dh}$

C Maximum subsidence

UzMAX=NStor $* \mathrm{Dh} * \mathrm{CumC}$

C Timespan for subsidence to occurr

Tau $=$ NStor $*(($ LarC $/ 2.0) * * 2) /($ Kvert*3600*24*365))

$C$ Vertical compressibility of the aquifer

$\mathrm{CM}=\mathrm{NStor} /(1000 * 9.8)$

$\mathrm{B} 2=\mathrm{CumC} /(2 * \mathrm{r})$

$\mathrm{C}=\mathrm{Z} / \mathrm{r}$

C Calculation of Attenuation

Part $1=(2 * \mathrm{C} *(1-\mathrm{v})) /(\mathrm{SQRT}(1+(\mathrm{C} * \mathrm{C})))$

Part2 $=\mathrm{B} 2 /(2 *(\mathrm{SQRT}(1+(\mathrm{B} 2 * \mathrm{~B} 2))))$

Part3 $=(((2 * \mathrm{C})-\mathrm{B} 2) *(3-(4 * \mathrm{v}))) /(2 *(\mathrm{SQRT}(1+(((2 * \mathrm{C})-\mathrm{B} 2) *((2 * \mathrm{C})-\mathrm{B} 2)))))$

Part4 $=((\mathrm{C}-\mathrm{B} 2) /((1+(((2 * \mathrm{C})-\mathrm{B} 2) *((2 * \mathrm{C})-\mathrm{B} 2))) * * 1.5))$

$\mathrm{At}=(\mathrm{Cm} *$ CumC*eprime $) *($ Part1-Part2-Part3+Part4)

C Subsidence without attenuation

UznoA $=(\mathrm{Cm} *$ CumC $*$ eprime $) *(2 *(1-v)) *(1-(\mathrm{C} /(\operatorname{SQRT}(1+(\mathrm{C} * \mathrm{C})))))$ 
C Subsidence with attenuation

$\mathrm{UzA}=\mathrm{UzMAX}-\mathrm{At}$

C Coning factor

$\mathrm{E}=1-$ Part $1+$ Part2+Part3-Part4

C Subsidence taking coning into account

$\mathrm{UzE}=\mathrm{E} * \mathrm{NStor} * \mathrm{CumC} * \mathrm{Dh}$

Return

End

\section{Section 3: Subroutine bound}

Subroutine bound(Dp,Kvert,NStor,Zbound,T,erf,deltaP,deltaPc,Z,B,

-CumC,LarC,G,v,M,r,n,eprime,UzMAXbound,Tau,CM,Atbound,UznoAbound, -UzEbound,Dhbound,UzAbound,Ebound)

Real Dp,Kvert,Zbound,NStor,T,Tsec,erf,erfarg,deltaP,deltaPc

Real Pi,UznoAbound

Real Z,B,CumC,LarC,G,v,M,r,n,eprime,Dhbound

Real UzMAXbound,Tau,C,CM,B2,Dh,Part1,Part2,Part3,Part4,Atbound

Real UzAbound,Ebound,UzEbound,a,Nref,Zref,Z1,Z2

Write $(*, *)$ 'Enter the vertical distance above and below the'

Write $(*, *)$ 'reservoir for which you want pressure calculated'

Write $(*, *)$ in Meters'

Read $(*, *)$ Zbound

Write $(*, *)$

Tsec $=\mathrm{T} * 365 * 24 * 60 * 60$

$\mathrm{Pi}=3.141592654$

erfarg $=$ Zbound $/(2 * \operatorname{SQRT}(($ Kvert*Tsec $) /$ Nstor $))$

erf $=$ SQRT $(1-\exp ((-4 * \operatorname{erfarg} * * 2) / \mathrm{Pi}))$

deltaP=Dp*erf

deltaPc $=\mathrm{Dp}$-deltaP

$\mathrm{a}=0.103$

nref $=0.05$

$\mathrm{zref}=10000$

$\mathrm{Z} 1=\mathrm{Z} / \mathrm{Zref}$

$\mathrm{Z} 2=\log (\mathrm{Z} 1)$

$\mathrm{n}=$ nref $-(\mathrm{a} * \mathrm{Z} 2)$

NStor $=0.103 /((\mathrm{G}-1) *((1-n) * * 2) * \mathrm{Z})$

Dhbound $=\operatorname{deltaPc} *(0.704)$ 


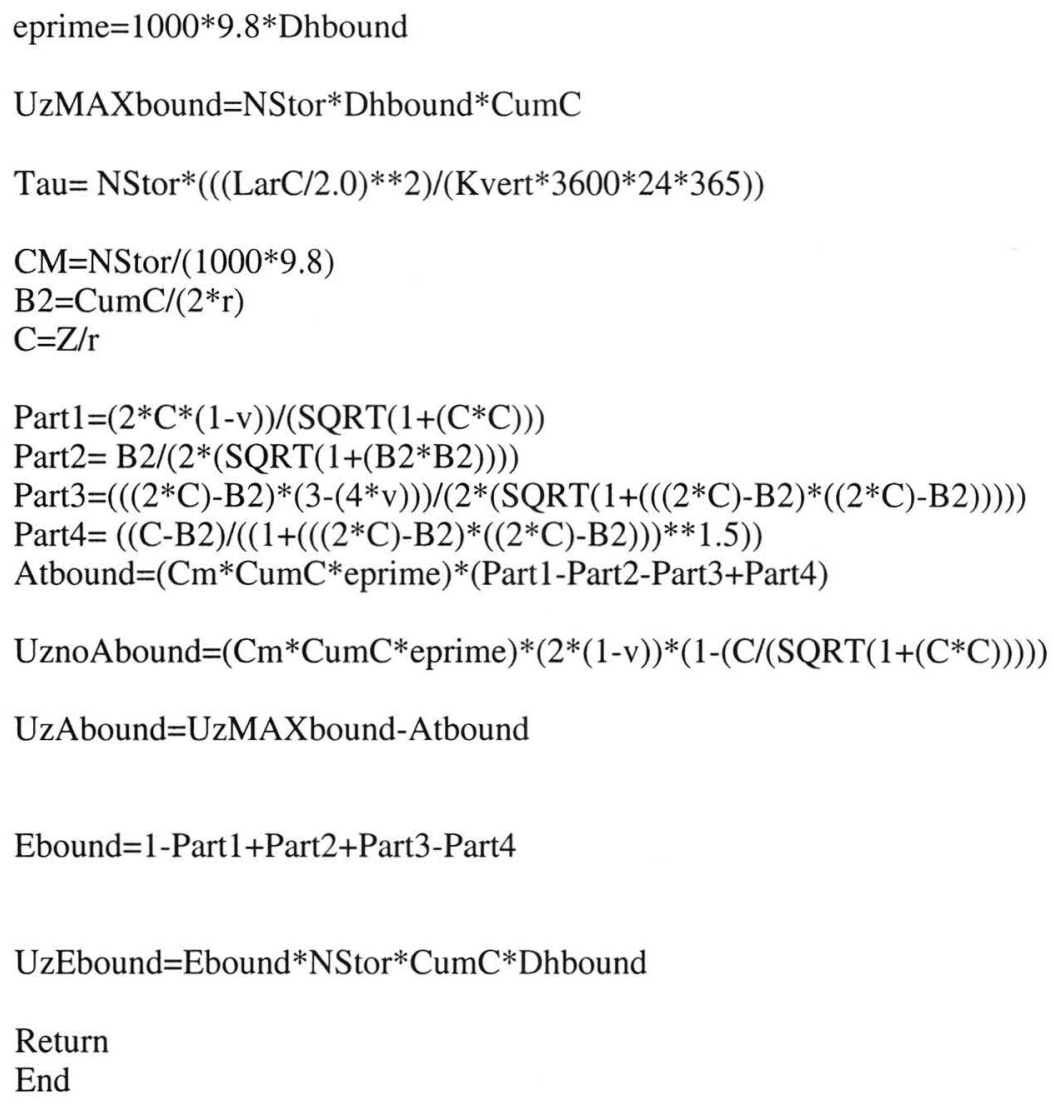




\section{Bibliography/References}

Bau, D., Gambolati, G. and Teatini, P., 1999. Residual Land Subsidence Over Depleted Gas Fields in the Northern Adriatic Basin. Environmental and Engineering Geoscience, V. 5 No. 4: 389-405.

Borchers, J.W., 1998. Using Down-Well Television Surveys to Evaluate Land Subsidence Damage to Water Wells in the Sacremento Valley, California. In: J.W. Borchers (Editor), Proceeding of the Dr. Joseph F. Poland Symposium on Land Subsidence. Star Publishing, Sacremento, California, pp. 89-95.

Carslaw, H.S. and Jaeger, J.C., 1959. Conduction of Heat in Solids. 2nd ed., Oxford University Press, Ely House, London W. I., N.Y.

Dickinson, G., 1953. Geological Aspects of Abnormal Reservoir Pressures in Gulf Coast Louisiana. AAPG Bulletin, V. 37(No. 2): 410-432.

Domenico, P.A. and Schwartz, F.W., 1990. Physical and Chemical Hydrogeology. John Wiley and Sons, New York, 824 pp.

Erickson, R.C., 1976. Subsidence Control and Urban Oil Production- A Case History Bevery Hills (East) Oil Field, California. Proceedings of the Anaheim Symposium. IAHS Publication No. 121: 285-297.

Freeze, R.A. and Cherry, J.A., 1979. Groundwater. Prentice Hall INC., Englewood Cliffs, N.J., 604 pp.

Gabrysch, R.K. and Coplin, L.S., 1990. Land-Surface Subsidence Resulting from Ground-Water Withdrawals in the Houston-Galveston Region, Texas, Through 1987. Report of Investigations No. 90-01, U.S. Geological Survey in cooperation with the Harris-Galveston Coastal Subsidence District. 
Galloway, W.E., Hobday, D.K. and Magara, K., 1982. Frio Formation of the Texas Gulf Coast Basin-Depositional Systems, Structural Framework, and Hydrocarbon Origin, Migration, Distribution, and Exploration Potential, The University of Texas Bureau of Economic Geology Report Investigations $122.78 \mathrm{pp}$.

Galloway, W.E., Jirik, L.A., Morton, R.A. and DuBar, J.R., 1986. Lower Miocene (Fleming) Depositional Episode of the Texas Coastal Plain and Continental Shelf: Structural Framework, Facies, and Hydrocarbon Resources, The University of Texas Bureau of Economic Geology Report Investigations 150, Austin, TX.

Gandara, S.C., Jones, R.E. and Barbie, D.L., 1996. Water Resources Data Texas, Water Year 1996. U.S. Geological Survey Water Data Report TX-96-4, V. 4: 337 .

Geertsma, J., 1973. A Basic Theory of Subsidence Due to Reservoir Compaction: The Homogeneous Case. Verhandelingen der Koninkljke Nederlands Geologisch Mijhbouw, V. 28: 43-62.

Germiat, S.J. and Sharp, J.M.Jr., 1990. Assessment of Future Coastal Land Loss Along the Upper Texas Gulf Coast. Bull. Assoc. Engineering Geologists, V. 27: 263-280.

Hejmanowski, R., 1995. Prediction of Surface Subsidence Due to Oil or Gas Development. Land Subsidence: Natural Causes, Measuring Techniques, the Groningen Gasfields. Proceedings of the Fifth International Symposium on Land Subsidence. Balkema Publishers: 291-300.

Helm, D.C., 1984. Field-Based Computational Techniques for Predicting Subsidence Due to Fluid Withdrawal. GSA Reviews in Engineering Geology, V. 6: 1-22.

HGCSD, 1998. Harris-Galveston Coastal Subsidence District Groundwater Management Plan, Friendswood, Texas.

Holzer, T.L. and Bluntzer, R.L., 1984. Land Subsidence Near Oil and Gas Fields, Houston, Texas. Ground Water, V.22(No. 4): 450-459.

Holzer, T.L. and Gabrysch, R.K., 1987. Effect of Water-Level Recoveries on Fault Creep, Houston, Texas. Ground Water, V. 25(No. 4): 392-397. 
Jorgensen, D.G., 1975. Analog-Model Studies of Ground-Water Hydrology in the Houston District, Texas: Texas Water Development Board Report 190: 84.

Kasmarek, M.C., Coplin, L.S. and Santos, H.X., 1997. Water-Level Altitudes 1997, Water-Level Changes 1977-97 and 1996-97, and Compaction 197396 in the Chicot and Evangeline Aquifers, Houston-Galveston Region, Texas, U.S. Geological Survey Open-File Report 97-181, Austin, Texas.

Kreitler, C.W., 1976. Faulting and Land Subsidence From Ground-Water and Hydrocarbon Production, Houston-Galveston, Texas. Land Subsidence Symposium, Proceedings of the Anaheim Symposium. IAHS publication No. 121, pp. 435-446.

Meckel, L.D., 1993. Stratigraphy and Sedimentology of the Eocene Yegua Formation, Texas Gulf Coast, The University of Texas Masters Thesis, Austin, TX.

Murria, J., 1991. Subsidence Due to Oil Production in Western Venezuela: Engineering Problems and Solutions. Land Subsidence Symposium. Proceedings of the Fourth International Symposium on Land Subsidence. IAHS Publication No. 200: 129-139.

Neuzil, C.E., 1986. Groundwater Flow in Low Permeability Environments. Water Resources Res., V. 22: 1163-1196.

Paine, J.G., 1991. Late Quaternary Depositional Units, Sea Level, and Vertical Movement Along the Central Texas Coast. Unpublished PhD dissertation Thesis, The University of Texas at Austin, Austin, Texas, 256 pp.

Poland, J.F. and Davis, G.H., 1969. Land Subsidence Due to Withdrawal of Fluids. Reviews in Engineering Geology. Geological Society of America, V.2: $187-269$.

Pratt, W.E. and Johnson, D.W., 1926. Local Subsidence of the Goose Creek Oil Field. Journal of Geology. University of Chicago Press, V. 34: 577-590.

Railroad-Commission, 1995. Railroad Commission Oil and Gas Division Annual Report, Railroad Commission of Texas, Texas. 
Schoonbeek, J.B., 1977. Land Subsidence as a Result of Gas Extraction in Groningen, the Netherlands, 2nd International Land Subsidence Symposium Proceedings. International Association of Hydrological Sciences Publication 121, Anaheim, California, pp. 267-284.

Sharp, J.M.Jr. and Germiat, S.J., 1990. Risk Assessment and Causes of Subsidence and Inundation Along The Texas Gulf Coast, Greenhouse Effect, Seal, and Drought. Kluwer Academic Publishers, Netherlands, pp. 395-414.

Sharp, J.M.Jr. and Hill, D.W., 1995. Land Subsidence Along the Northeastern Texas Gulf Coast: Effects of Deep Hydrocarbon Production. Environmental Geology, V. 25: 181-191.

Sheets, M.M., 1979. Oil Fields and Their Relation to Subsidence and Active Faulting in the Houston Area. Houston Geological Society Publication, 1$20 \mathrm{pp}$.

Tuma, J.J., 1983. Handbook of Physical Calculations. McGraw Hill, New York.

Verbeek, E.R. and Clanton, U.S., 1981. Historically Active Faults in the Houston Metropolitan Area, Texas, In Etter, E.M., ed., Houston Area Environmental Geology-Surface Faulting, Ground Subsidence, Hazard Liability. Houston Geological Society Special Publication, pp. 28-68.

Warren, J.P., Jones, L.L., Griffin, W.L. and Lacewell, R.D., 1974. Costs of Land Subsidence, Texas Water Resources Institute, Texas A\&M University.

Williams, J.F. and Ranzau, C.E., 1987. Ground-water Withdrawals and Changes in Ground-water levels, Ground-water Quality, and Land-surface Subsidence in the Houston District, Texas, 1980-84. U.S. Geological Survey Water-Resources Investigations Report 87-4153: 56.

Winker, C.D. and Edwards, M.B., 1983. Unstable Progradational Clastic Shelf Margins. In: D.J. Stanley and G.T. Moore, eds., The Shelfbreak: Critical Interface on the Continental Margin. Society of Economic Paleontologists and Minerologists, Special Publication No. 33: 139-157.

Yerkes, R.F. and Castle, R.O., 1969. Surface Deformation Associated With Oil and Gas Field Operations in the United States, 1st International Land Subsidence Symposium Proceedings. International Association of Hydrological Sciences Publication 88, Tokyo, Japan, pp. 55-66. 
The vita has been removed from the digitized version of this document. 